\title{
Discovery of novel antituberculosis compounds using an intra-macrophage
} assay

\author{
A thesis \\ Submitted in fulfilment \\ Of the requirements \\ For the degree of \\ Master of Science in Molecular Microbiology \\ At \\ Victoria University of Wellington \\ By

\section{Rekha Veliyayi Murikoli}

\author{
School of Biological Sciences \\ Victoria University of Wellington \\ New Zealand \\ 2010
}




\section{ABSTRACT}

The causative agent of tuberculosis (TB) is Mycobacterium tuberculosis, which affects 2 billion of the world population and kills 1.8 million people annually. It is among the top three infectious killers in the world human immuno deficiency virus, TB and Malaria. Every year among 300-400 new cases of TB are reported in New Zealand according to a recent WHO 2008 report. The current treatment regimen for TB is very long and results in significant toxicity, development of resistant strains and is unable to

eliminate the latent bacilli. The above reasons demonstrate the growing need of research for novel antimycobacterial compounds and novel targets for the treatment of TB. Many in vitro and biochemical screens are available for testing against different mycobacterium strains but none of these screens can be considered comprehensive. The reason for this can be the lack of resemblance of the in vitro screen model with the biological systems. Hence we chose the intra-macrophage infection screening model to look for novel antimycobacterial prodrugs which are not active in an in vitro screen but selectively active inside macrophage cell lines. We were successful in establishing and validating such an intra-macrophage infection model using the non-pathogenic $M$. smegmatis. The model was validated using common anti-tuberculosis drugs. A preliminary high throughput screen was then set up using a mini-library demo model, followed by screening with an actual Lopac synthetic library. 


\section{ACKNOWLEDGEMENTS}

I would like to thank my primary supervisor Dr. Ronan O' Toole and secondary supervisor Prof. John $\mathrm{H}$ Miller for all their valuable suggestions and support throughout my research project. I would also like to acknowledge Dr. An Tann, Dr. Bronwyn Kivell, Dr. David Maass, Dr. Darren Day, Dr. Geoff Chambers and Prof. Paul Atkinson who generously opened their lab doors and gave me permission to work with their instruments, without which I would have not able to complete my project successfully. My hearty thanks to Cameron Jack and Peter Bircham who helped me to solve the Opera high throughput microscope related technical troubles. I would also like to thank Sushila Pillai so as to spend many hours time to help me while working with the confocal microscope. I would also like to thank all the lab members of KK817, KK816, KK812, KK801, KK613 and KK602 who supported me by providing all minor to major helps along with good mental support so as to finish my work. Last but not least I would like to specially thank Christopher H Miller, Emma Earl, Anja Wilmes, Mischa Walton, Mannivannan Yagambaram, Miles Benton, Mudassar Altaf and Shahista Nisa who had a significant contribution in one way or another throughout my lab work and thesis writing completion. Finally, I would also like to thank my mum, dad, elder brother and fiancée so as to support me in all ways without which I would have not completed my studies. 


\section{TABLE OF CONTENTS}

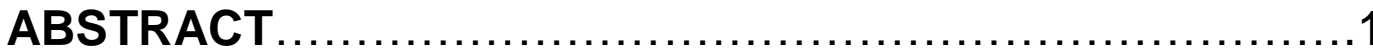

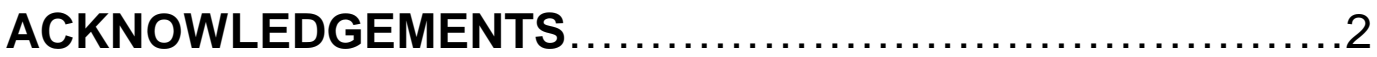

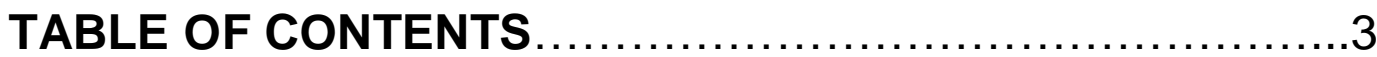

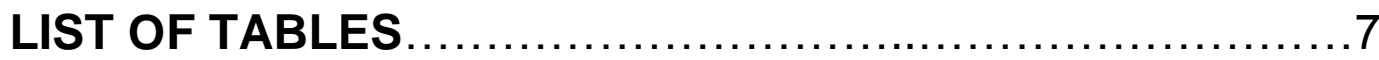

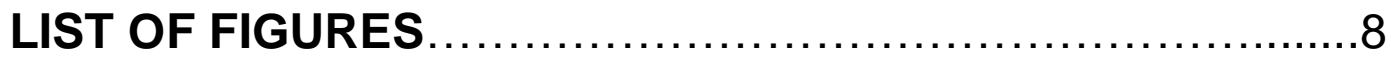

ABBREVIATIONS ...........................................

1. Chapter One: General Introduction................................................15

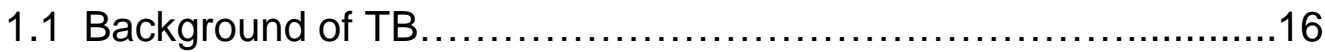

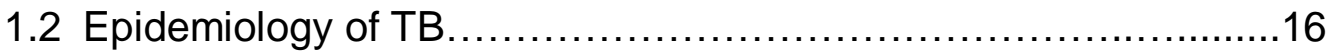

1.3 Pathogenesis of TB....................................................

1.3.1 Latent TB and reactivation of TB infection......................22

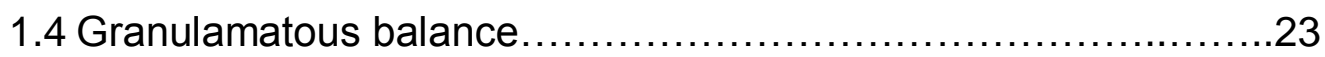

1.4.1 Mycobacterial interference with phospatidylinositol -3phosphate (PI3P) mediated signalling pathways in host macrophage.

1.4.2 Mycobacterial interference with calcineurin signalling

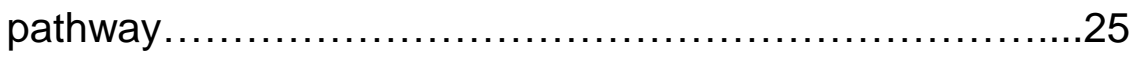

1.4.3 Protein kinase-G mediated mycobacterium virulence........26

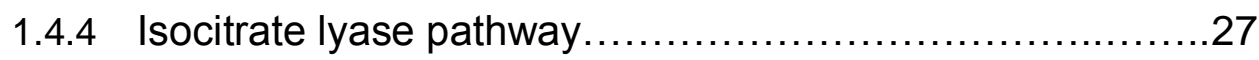

1.4.5 Vitamin D mediated host defence mechanism against

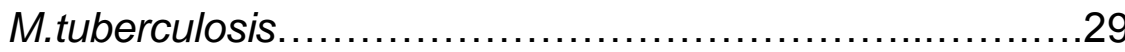

1.4.6 Reactive oxygen and nitrogen intermediates mediated stress

1.4.7 Defensive mechanisms adapted by the mycobacterium against various stresses.........................................

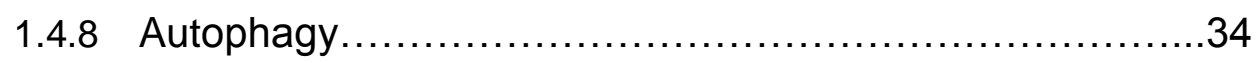

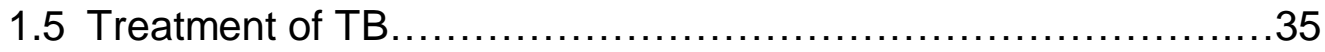


1.5.1 Need of intra- macrophage assay in TB drug discovery research.

$1.6 \mathrm{~J} 774$ macrophage infected with GFP labelled M.smegmatis as a intra-macrophage screening model of study. 43

1.7 Project Aims. 46

2. Chapter two: Materials and Methods. .47

2.1 Development of intra-macrophage infection assay. 48

2.1.1 J774 macrophage cell culture ..............................48

2.1.2 Bacterial strains, plasmid and cell culture conditions.........49

2.1.3 Dispersion of M.smegmatis clumps.........................50

2.1.4 Visualization of the single cell suspension...................50

2.1.5 Colony forming units........................................ 50

2.1.6 Low throughput macrophage infection assay................51

2.1.7 Development of a mini high throughput demo library infection

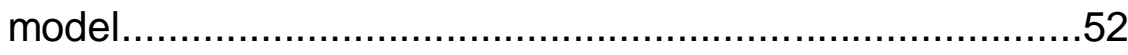

2.1.8 Implementation of the intra- macrophage infection assay set up for synthetic library screening............................54

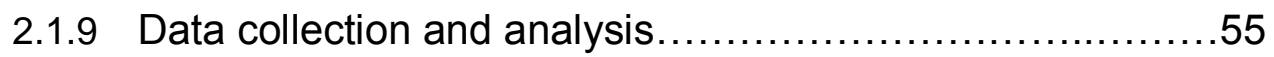

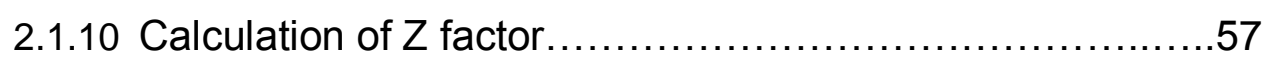

2.1.11 Validation of the intra-macrophage infection assay..........57

2.1.12 Image acquisition by confocal microscope....................59

2.1.13 Image J software analysis..................................60

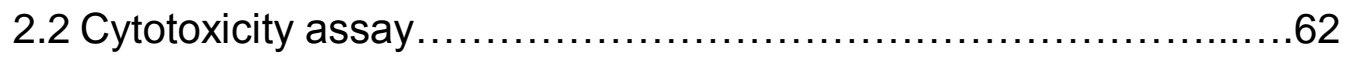

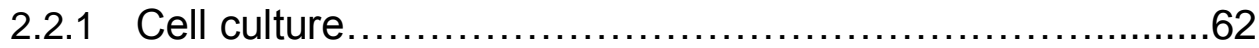

2.2.2 Cell counting using haemocytometer........................62

2.2.3 Cytotoxicity or viability testing ..............................64

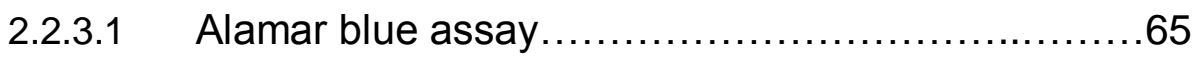

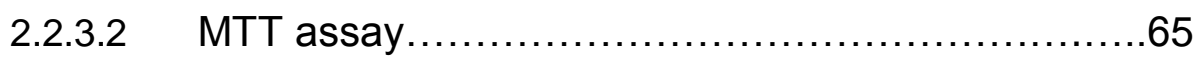

2.2.3.3 Comparison of alamar blue and MTT assay..........66

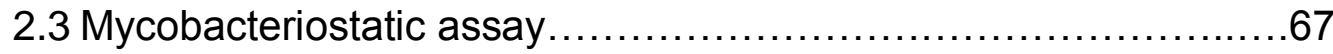

2.3.1 Data collection and analysis...............................66 
2.4 Mycobactericidal assay. 69

3. Chapter three: Development and validation of the intramacrophage assay. .72

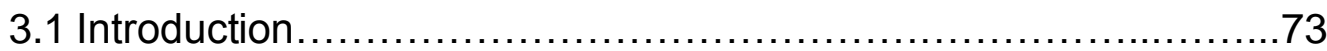

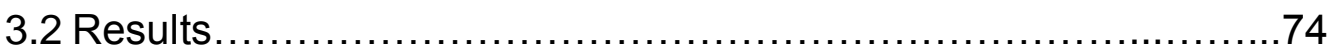

3.2.1 Infection of the J774 macrophage cell line with mycobacterium cell suspension.............................. 74

3.2.2 Development of the low throughput macrophage infection assay against standard antituberculosis drugs. 76

3.2.3 Image acquisition using Olympus FV1000 confocal microscope. .79

3.2.4 Development of the mini high throughput demo library model as a preliminary step for synthetic library screening 81

3.2.5 Validation of the mini high throughput demo library model using opera high throughput confocal microscope .88

3.3 Troubleshooting .96

3.4 Discussion 99

4. Chapter four: Implementation of Cytotoxicity Assays in Intamacrophage Assay Development...........................................106

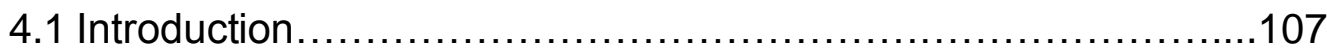

4.2 Different types of the cytotoxicity assays...........................108

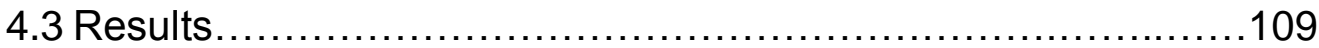

4.3.1 Comparison of MTT/ Alamar blue assay in different cell line.

4.3.2 Cytotoxicity assay against antituberculosis drugs...........110

4.3.3 Cytotoxicity assays against LOPAC compounds............111

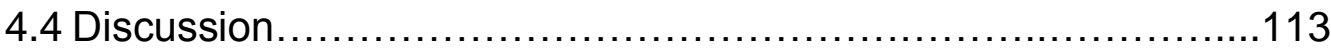


5. Chapter five: Application of intra-macrophage assay in synthetic

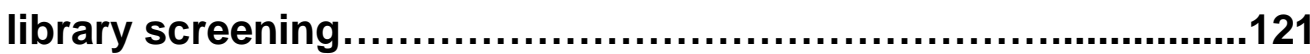

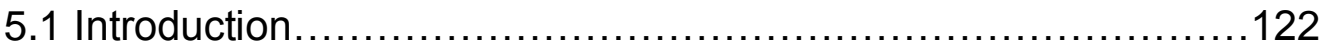

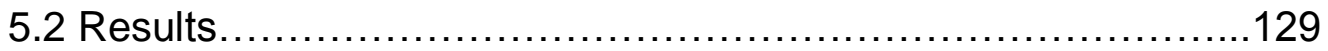

5.2.1 Validation using opera high-throughput confocal images...132

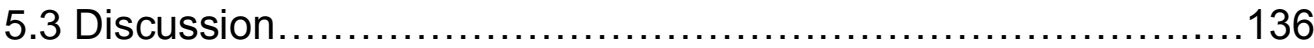

6. Chapter six:General discussion................................................141

6.1 General discussion................................................

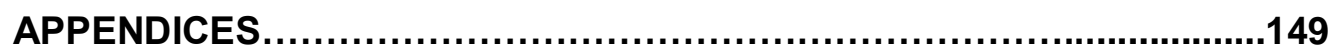

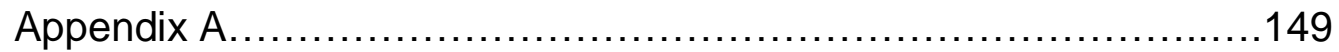

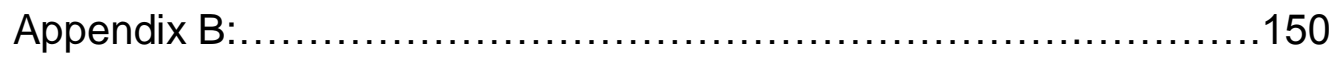

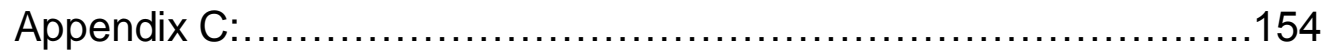

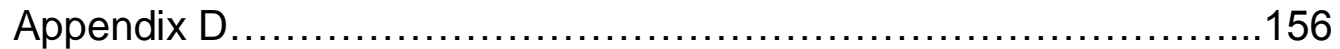

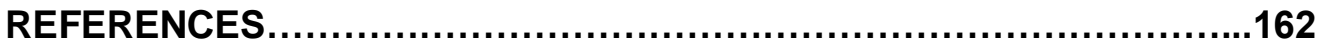




\section{ㄴIST OF TABLES}

Table 1.1: Mechanism of oxidative and nitrosative stress

Table 1.2: List of currently used common antituberculosis drugs and their mode of action.

Table 2.1: Details of the list of the compounds on which cytotoxicity assays were performed.

Table 3.1: Colony forming units using sub inoculated overnight M.smegmatis culture of OD 1

Table 3.2: Comparison of in-vivo and in-vitro $I C_{50}$ s against standard antituberculosis drugs. 77

Table 3.3: Mini library high throughput demo model screening results

Table 3.4: Comparison of in-vivo and in-vitro IC $C_{50}$ s of intramacrophage LOPAC hits. 86

Table 3.5: Opera high throughput confocal microscope results for minilibrary.

Table 4.1: Comparison between MTT and alamar blue assay.. 110

Table 4.2: IC $C_{50}$ for known antituberculosis drugs. .111

Table 4.3: IC ${ }_{50}$ s for LOPAC compounds. 112

Table 5.1: Results for synthetic library (LOPAC) screening. 123

Table 5.2: Back validation of intra-macrophage assays against different mycobacterium sp. and cytotoxicity testing against $\mathbf{J 7 7 4}$ macrophages cell lines.

Table 5.3: Opera high throughput confocal microscope results for synthetic library (LOPAC) screening. 


\section{LIST OF FIGURES}

Figure 1.1: Pathogenesis of TB

Figure 1.2: Various pathways involved in host pathogen

interactions.

Figure 1.3: Schematic representation of isocitrate lyase pathway.

Figure 1.4: Schematic representation of the reactive oxygen and nitrosative stress.

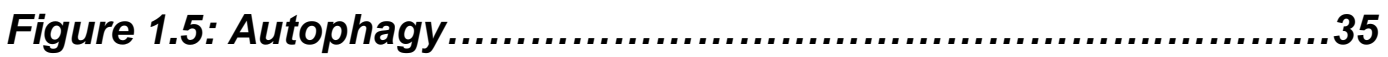

Figure 2.1: Plate design of low throughput in-vivo macrophage assay

Figure 2.2: Plate design of high throughput in-vivo macrophage assay. 55

Figure 2.3: Haemocytometer.............................................63

Figure 2.4: Plate design of the cytotoxicity assay......................65

Figure 3.1: Visualisation by fluorescent microscope.....................74

Figure 3.2: Graphs of known antituberculosis drugs....................78

Figure 3.3: Image-iT stained images acquired from confocal microscope.

Figure 3.4: Schematic representation of the mini library high throughput infection model.

Figure 3.5: Graphs for intramacrophage hits from minilibrary demo model.

Figure 3.6: Validation using opera images..............................89

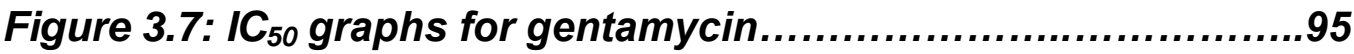

Figure 3.8: $I C_{50}$ graphs for rifampicin and capreopmycin...............97

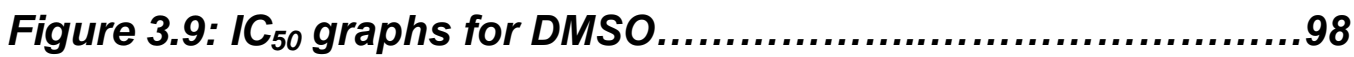

Figure 3.10: Structure of common antituberculosis compounds....106

Figure 4.1: Conversion of resazurin to resorfin (Alamar blue assay). 106

Figure 4.2: Conversion of MTT to formazon (MTT assay). 107 
Figure 4.3: Graphs showing comparisons of MTT and alamar blue assays against different cell lines........................................117

Figure 5.1: IC 50 graphs for the intramacrophage specific hits........129

Figure 5.2: Validation of the intramacrophage hits using opera

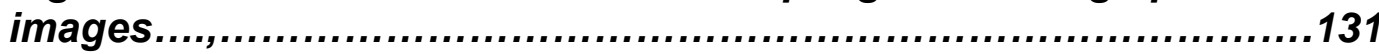

Figure 5.3: Structures of the intramacrophage specific hits...........137

Figure 7.1: Montage of image-iT stained images acquired from confocal microscope. 


\section{ABBREVIATIONS}

TB Tuberculosis

BCG Bacilli calmette Guerin

PAS Para amino salicylic acid

HIV Human immuno deficiency virus

MDR Multidrug resistant strain

XDR Extensive drug resistant strain

DOTS Direct observed therapy

CR Complement receptor

FcR Fragment crystallizable region

ITAM Immunoglobulin gene family tyrosine activator motif

PI3K Phosphoinositide-3-kinase

MHC Major Histocompatibilty Complex

CD Cluster of differentiation

LAM Lipoarabinomannan

CaMK Calcium calmodulin protein kinase

MAP Mitogen activated protein kinase

GDP Guanosine 5' diphosphate

GDI Guanosine nucleotide dissociation inhibitor

EEA-1 Endosomal membrane tethering molecule

SNARE Soluble NSF Attachment Protein

TACO Tryptophan aspartate containing coat protein

PRR Pattern recognition receptor

PAMP Pathogen associated molecular pattern

TLR Toll like receptor

NF-kB Nuclear factor

VDR Vitamin D receptor

ICL Isocitrate lyase 
NOS Nitric oxide synthase

Phox Phagocyte oxidase

SOD Superoxide dismutase

ROI Reactive oxygen intermediates

RNI Reactive nitrogen intermediates

Msr Methionine sulphoxide reductase

Mpa Mycobacterium proteasome ATPase

Paf A Proteasome associated factor

prcBA Proteasome encoding gene

MACE Mycolic acid cyclopropanating enzyme

alrA D-alanine racemase

NAT Arylamine-N-acyltransferases

ALS Acetolactate synthase

KARI Ketol acid reducto isomerase

CT Cholera toxin

PPD Purified protein derivatives

LPS Lipopolysaccharides

LOPAC Library of pharmacologically active compounds

GFP Green fluorescent protein

RFP Red flourescent protein

ATCC American type culture collection

RPMI Roswell park memorial institute

MTT 3-[4, 5 - dimethylthiazol -2-yl] -2, 5 - diphenyl tetrazolium bromide

XTT 2, 3-bis (2-methoxy-4-nitro-5-sulfophenyl)-5-[(phenylamino) carbonyl]$2 \mathrm{H}$-tetrazolium hydroxide

WST-1 4-[3-(4-iodophenyl)-2-(4-nitrophenyl)-2H-5-tetrazolio]-1, 3-benzene disulfonate

EpoA Epothilone A

OADC Oleic acid albumin dextrose complex 
MOI Multiplicity of infection

IC50 Inhibitory concentration

MIC Minimum inhibitory concentration

HTS High throughput screening

7-OH-DPAT 7-hydroxy-3-methyl-2-9-(dipropylamino) tetralin

ATM Ataxia telangiectasia mutated

PARP-1 Poly (ADP ribose) polymerase-1

PDMS Poly (dimethylsiloxane)

LDH Lactate dehydrogenases

DIP Diphenyleneiodonium chloride

DMSO Dimethyl sulphoxide

CS Citrate synthase

ACN Aconitase

IDH Isocitrate dehydrogenase

ODH 2-oxyglutarate dehydrogense

SCS succinyl-CoA synthetase

FUM Fumarase

MDH Malate dehydrogenase

MS Malate synthase

ICL Isocitrtae lyase

96 wp 96 well plate

HEPES (4-(2-hydroxyethyl)-1-piperazineethanesulfonic acid) 
Chapter 1

General Introduction

15 | P a g e 


\section{Chapter 1}

\section{General Introduction}

\subsection{Background of TB}

Mycobacterium tuberculosis is the causative agent of tuberculosis (TB) (Smith, 2003). Other names given to TB since ancient times are Pott's disease or phthisis or scrofula (Daniel, 2006). M. tuberculosis belongs to the genus Actinobacteria and family Mycobacteriaceae. It is aerobic, nonmotile and is neither gram positive nor gram negative, as it does not retain any gram stains due to the high lipid content in its cell wall. Therefore, Ziehl-Neelsen staining (involving carbolfuchsin, acid alcohol and methylene blue) is used which allows it to be categorized as an acid fast gram-positive bacterium. The multiplication time of $M$. tuberculosis is 1520 hrs (Kaufmann, 2001). The mycobacterium cell wall comprises mainly outer lipids, mycolic acids, polysaccharides, peptidoglycan, plasma membrane, lipoarabinomannan and phosphatidylinositol mannoside (Brennan, 2003).

\subsection{Epidemiology of tuberculosis}

TB is a deadly infectious disease caused by $M$. tuberculosis that affects one third (approximately 2 billion) of the world population (WHO, 2006). There were 9.4 million new cases of TB in the year 2008, of which 3.6 million were 
women and 1.4 million patients were co infected with HIV. The annual casualties due to TB infection in the year 2008 were 1.8 million (WHO, 2009). Among all the cases reported $3.6 \%$ of TB infection is of a multidrug resistant (MDR) strain type. The top 5 countries with the highest number of MDR-TB are India, China, Russia, South Africa and Bangladesh. Strains of TB that show extensive resistance to front line drugs (XDR-TB) have been reported from 58 countries worldwide. It has been estimated that around 440000 and 40000 cases of MDR-TB and XDR-TB emerge globally each year respectively. MDR-TB refers to the mycobacterial strains that are resistant to most common front line drugs such as rifampicin and isoniazid. XDR-TB refers to the mycobacterial strains resistant to mainly fluoroquinolones (ofloxacin, ciprofloxacin, levofloxacin, sparofloxacin etc.), at least one of the three second line drugs such as (capreomycin, kanamycin and amikacin) and most common first line drugs such as (isoniazid and rifampicin) (Prabhudesai and Singh, 2009) and (WHO, 2010). TB was declared a global threat by the World Health Organization (WHO) in the year 1993 (WHO, 2006). The StopTB partnership has the target of halting a 50\% rise in new TB incidences by the year 2015 and complete TB case eradication by the year 2050 . This can be achieved by improved and effective diagnostic techniques. One of the treatment methods followed is Directly Observed Therapy (DOTS) in which the patients are observed while vaccinations are given, and by provision of support for further TB research that may lead to improved diagnostics, antibiotics and vaccines (WHO, 
2006). Every year 300-450 new cases and in the year 2008, 297 new TB cases were reported in New Zealand (Das et al., 2006).

\subsection{Pathogenesis of tuberculosis}

TB infection is established by the inhalation of aerosol droplets containing M. tuberculosis bacilli. The primary site of infection for tuberculosis is the lung, where the bacilli are phagocytosed by the alveolar macrophages. Phagocytosis into the macrophages occurs through multiple receptor molecules, which is likely to be due to the complexity of the M. tuberculosis cell wall surface (Kaufmann, 2001). The multiple receptors can be listed as follows

Complement receptor (CR) Phagocytosis is mediated by binding of these receptors including CR1, CR3 \& CR4 with serum complement proteins of the opsonized bacterium. CR1 is a single chain transmemebrane protein, that is responsible for bacilli binding and CR3, CR4 are heterodimeric integrin family members mainly responsible for bacilli internalization (Ernst, 1998).

Fc (fragment crystallisable region) receptor $\mathrm{FcR}$ is a single-chain protein consisting of an extracellular Fc binding domain, a transmembrane domain and a cytoplasmic tail containing ITAM motifs (immunoglobulin gene family tyrosine activation motifs). The binding of mycobacterium to $\mathrm{FcR}$ results in its cross-linking followed by ITAM motifs phosphorylation via activation of the src family of kinases and recruitment of syk tyrosine kinase resulting, in 
activation of the kinase enzyme. It further triggers several downstream effectors including phosphatidyl kinases (PI3 K), phospholipase C (PLC-2) and protein kinase $\mathrm{C}$. This process leads to phagocytosis of the mycobacterium followed by activation of transcription and release of inflammatory mediators by the alveolar macrophages (Aderem and Underhill, 1999).

Mannose receptor: Phagocytosis is mediated through the binding of mannose receptors with the branched mannose and fucose oligosaccharides present on the cell wall of the mycobacterium (Ernst, 1998).

Phagocytosis of the mycobacterium by alveolar macrophages results in the formation of phagosomes. In the phagosomes the mycobacterium is exposed to both MHC class I and class II antigen processing and presentation mechanisms resulting in the stimulation of CD8+ (cytotoxic) and CD4+ (helper) T cells. The stimulated CD4+ helper T cells results in the production of IFN- $\gamma$, which synergizes with TNF- $y$ to activate the macrophages to kill the phagocytosed mycobacterium by phagolysosomal fusion. The phospholigands and glycolipids produced by the mycobacterium can also be presented to $\gamma \delta \mathrm{T}$ cells and CD1 restricted T cells, respectively, resulting in their activation. The stimulated CD8+ cells, $y \delta$ and CD1 T cells secrete perforin and granulysin that can directly kill the mycobacterium inside the macrophages (Kaufmann, 2001) Fig 1.1. 
Inside the macrophages $M$. tuberculosis bacterium is kept in check within structures called granulomas (Cosma et al., 2003). The granuloma comprises infected macrophages, foamy macrophages and giant multinucleate cells in the centre surrounded by different types of T cells and activated and non-activated macrophages (Gordon et al., 1994). The cytoplasm of the foamy macrophages is loaded with fatty vacuoles. These cells do not have the capacity to phagocytose mycobacteria, as they are devoid of phagocytic receptors (Lay et al., 2007). However, they can still present antigens to the MHC antigen processing machinery on the cell surface and activate $T$ cell machinery. The macrophages residing inside a granuloma comprise both actively dividing and dormant bacilli. The infected macrophages in the centre present antigens to different types of $T$ cells (CD4+ and CD8+) via MHC II and I antigen-processing machinery leading to their stimulation. The stimulated T cells produce chemokines and cytokines that keep the macrophages in an activated state and allow the continuous recruitment of other immune cells to the site of the granulomatous lesion (Apt and Kondratieva, 2008). The main function of a granuloma is to segregate the infection and immune system effector functions to one focal point, which further prevents the dissemination of disease to other major organs of the body via the blood stream (Flynn and Chan, 2001). 
Inhalation of aerosols containing

mycobacterium bacilli

$\downarrow$

Phagocytosis by alveolar macrophages.

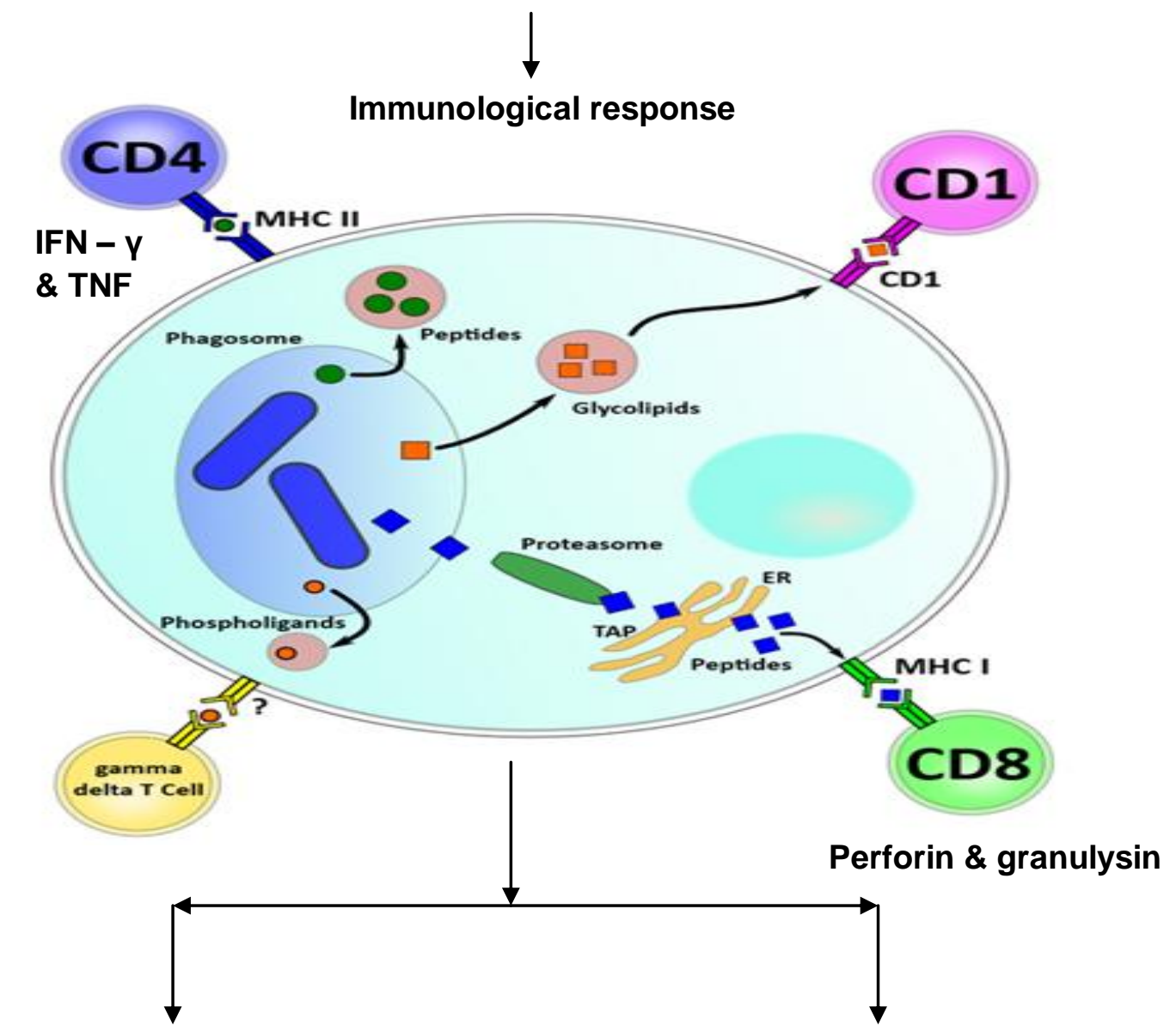

Granuloma formation

Spontaneous healing

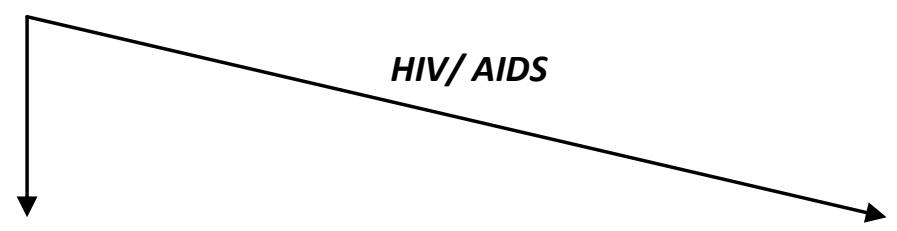

Latent $\mathrm{Tb}$ -

Containment (>90\%) Reactivation $<10 \%$
Active Tb - Infective and progressive disease

Figure 1.1: Pathogenesis of TB. This figure is adapted from (Kaufmann, 2001). 
1.3.1 Latent TB and reactivation of TB infections The formation of a granuloma provides an effective structure allowing the host's immune system to isolate and control a life threatening bacterial pathogen. This is the main reason why $90 \%$ of the individuals who are infected with mycobacterium bacilli do not develop the disease (Cardona, 2006). This condition, called latent TB, may or may not end up with complete healing via various immune mechanisms.

In patients with a compromised immune system (for example, patients infected with HIV) the disease will develop immediately after infection with the mycobacterium bacilli (Long, 2000). Thus, there is a great need for research in the field of latent TB as $10 \%$ of these infected cases shows reactivation at some stage of the patient's life by sudden mycobacterial growth (Scanga et al., 1999). M. tuberculosis survive in an aerobic environment but have a genetic and biochemical ability to persist in anaerobic (absence of oxygen) conditions as well. This property is referred to as latency (Long, 2000). The reasons for activation of latent TB bacilli are mainly environmental conditions such as migration from TB endemic regions, malnutrition, severe alcoholism and smoking habits. Other factors like HIV and the emergence of drug resistant strains can also contribute to the activation of latent bacilli (Apt and Kondratieva, 2008). 


\subsection{Granulomatous balance}

In the following sections, the mechanisms utilized by the mycobacterium to block the phagolysosomal fusion which is responsible for its enhanced survival and by the infected macrophages to clear the bacterial load will be discussed. These mechanisms may be the basis of the balance established inside a granuloma and therefore represent novel in vivo drug targets in TB drug discovery.

\subsubsection{Mycobacterial interference with phosphatidylinositol-3-} phosphate (PI3P) mediated signalling pathways in host macrophages

A compound from M. tuberculosis, lipoarabinomannan (LAM), can inhibit the phagolysosome fusion by inactivating Rab5 that therefore interferes with signalling networks for recognition of $M$. tuberculosis in the phagosomes (Fratti et al., 2003). LAM down regulates the amount of phosphatidylinositol-3-phosphate on the early phagosomal membrane by two converging pathways. Firstly, LAM interferes with calmodulin (a calcium binding protein) protein kinase CaMK11 pathway that leads to the inhibition of the sphingosine-1-phosphate regulated cytosolic calcium rise (Malik et al., 2003). This reduced cytosolic calcium level further prevents the recruitment of PI3K hVPS34 and its modulatory subunit p150 to the phagosomal membrane. This leads to down-regulation of the amount of PI3P accumulation on the phagosomes. PI3P is produced on the phagosomal membranes by hVPS34, a type III phosphatidylinositol-3- 
kinase (PI3K) (Vergne et al., 2003). Secondly, LAM is responsible for the p38 mitogen-activated protein kinase (MAP kinase)-mediated phosphorylation of GDP dissociation inhibitor (GDI) (Fratti et al., 2003). This phosphorylated GDI binds with Rab5 and inactivates it (Cavalli et al., 2001). Rabs are small GTP binding proteins that are responsible for the organization of the intracellular organelles, protein sorting and membrane trafficking pathways. Their activation and inactivation status depends on GTP or GDP bound states (Roberts et al., 2006). Rab5 is considered an effector molecule for both PI3K hVPS34 and early endosomal membrane tethering molecule EEA-1. The inactivation of Rab5 blocks the recruitment of EEA-1 to the phagosomal membranes (Fratti et al., 2003). EEA-1 in cooperation with Rab5 and the trans - Golgi network (TGN) SNARE Syntaxin 6 is required for the delivery of $\mathrm{VoH}+$ ATPase and lysosomal hydrolases (cathepsins) to the phagosomes. VoH+ ATPase and lysosomal hydrolases are required for the acidification of phagosomes and later in phagolysosomal fusion (Vergne et al., 2003). Vacuolar type H+ATPases are comprised of two domains namely a V1 complex on the cytoplasmic side responsible for ATP hydrolysis and a V0 complex across the membrane responsible for proton $(\mathrm{H}+)$ transport. Vacuolar type H+ATPases are present in all eukaryotic cells (Voss et al., 2010). 


\subsubsection{Mycobacterial interference with the calcineurin signaling} pathway

Coronin I, also known as tryptophan aspartate containing coat protein (TACO) or p57, of mammalian cells shows approximately $30 \%$ homology to coronin from the amoeba Dictyostelium discoideum. In D. discoideum the function of coronin $\mathrm{I}$ is to control F-actin related processes. In mammalian cells, coronin I prevents the phagolysosome fusion by regulating the calcineurin signaling pathway (de Hostos et al., 1991). Calcineurin $2 \mathrm{~B}$ is a heterodimeric protein phosphatase $2 \mathrm{~B}$ containing regulatory and catalytic domains. It controls various cellular processes and is regulated by calcium levels (Deghmane et al., 2007). Phagocytosis of the mycobacterium leads to the recruitment of coronin I into the phagosomal membrane (Ferrari et al., 1999). Coronin I is further responsible for calcium release from the intracellular stores (endoplasmic reticulum) and its influx from the extracellular matrix. The rise in cytosolic calcium is responsible for the (Tueberiberger et al., 2001) calcineurin activation that prevents phagolysosome fusion (Nguyen and Pieters). Calcineurin activity is inhibited by cyclosporine A or FK-506 (Voss et al., 2010) (Fig 1.2). 


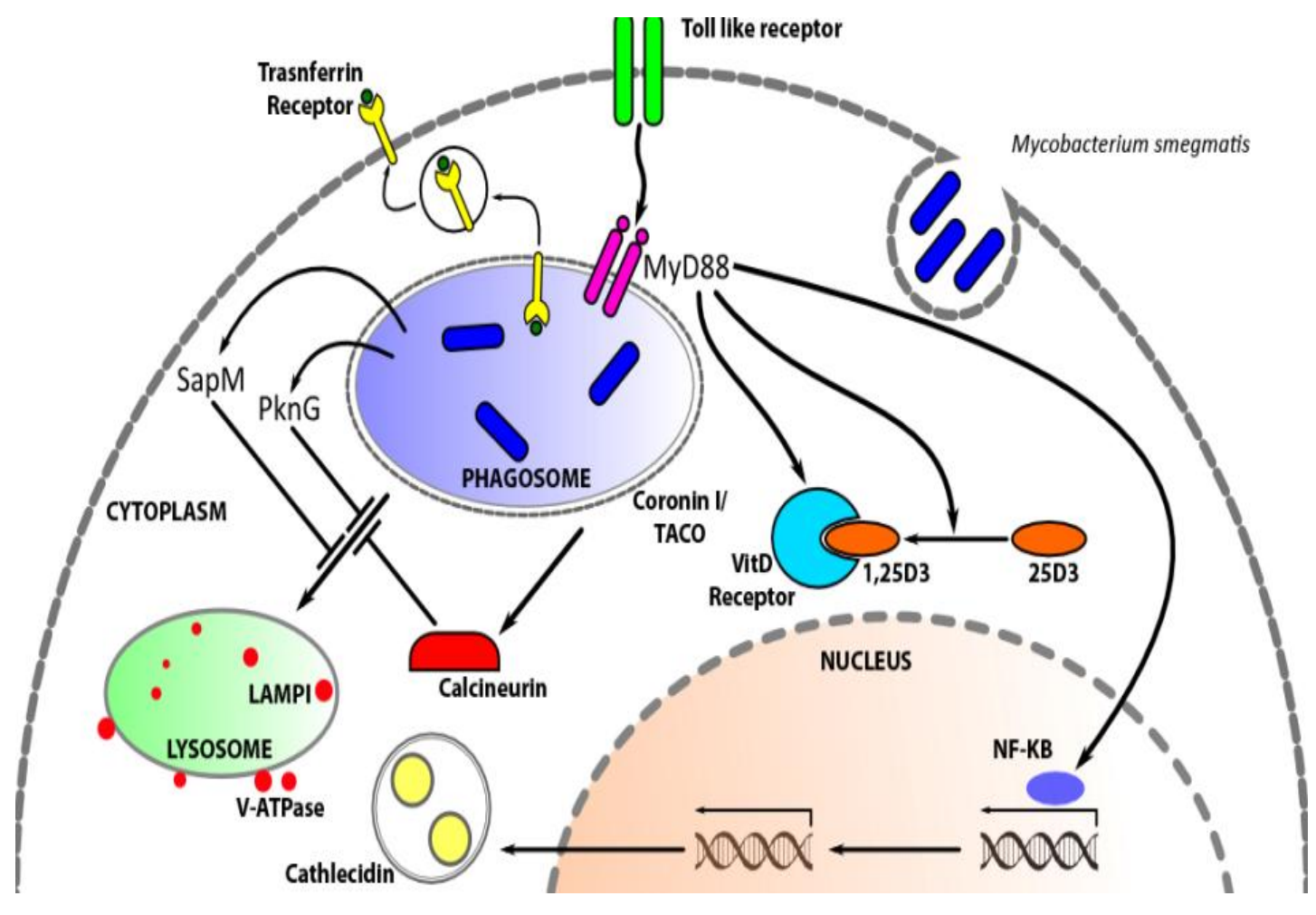

Figure 1.2: Various pathways involved in the host-pathogen interaction. This figure is adapted from (Pieters, 2008) and (Liu and Modlin, 2008).

\subsubsection{Protein kinase G-mediated mycobacterium virulence}

M. tuberculosis has developed many mechanisms to survive inside the macrophages. The mycobacterium has to continuously sense the external environment and rapidly adjust to the new conditions. These adjustments occur via activation of the signal transduction pathways. The signal transduction pathways are organised into a two component system that is made up of two domains, namely a sensor and a receiver. There are 13 
histidine kinase sensor proteins and 11 eukaryotic type serine/ threonine histidine kinases sensor proteins and 11 eukaryotic type serine/ threonine kinases (specifically PknA, B, D, E, F, G, H, I, J, K, and L) in mycobacteria that probably formed as a result of horizontal gene transfer. When the sensor protein, histidine kinase, binds with its ligand (or responds to an external stimulus) it binds to and hydrolyses ATP. This ATP hydrolysis results in the autophosphorylation of the histidine residues, resulting in the formation of a high-energy phosphoryl group. This phosphate is transferred to the aspartic residues of the regulator domain leading to its activation. In the majority of the cases this activated regulator domain upregulates or down-regulates the transcription by the production of transcriptional activators or repressors, respectively (Fontan et al., 2004). Amongst all the 11 serine/threonine kinases reported, PknG is the only soluble cytosolic kinase. Hence, it can be translocated from the mycobacterium inside the phagosome to the macrophage cytoplasm. PknG inhibits the phagolysosome formation by phosphorylating the host molecule that is likely to be responsible for the phagolysosomal fusion (Tiwari et al., 2009). el drugs that mediate phosphorylation of PknG can interfere with this phagosome maturation block (Vohra et al., 2006).

\subsubsection{Isocitrate lyase pathway}

Smith and Gunsalus were the first to report the presence of isocitrate lyase (ICL) in mycobacteria in 1954. Isocitrate lyase is responsible for the cleavage of isocitrate to glyoxylate and succinate. The significance of the 
isocitrate lyase pathway lies in the fact that it contributes to the pathogenic effects of mycobacterial infection. The ICL pathway skips the $\mathrm{CO} 2$ production step of the Krebs cycle and assimilates the carbon for the production of intermediates for various biosynthetic pathways like gluconeogenesis. M. tuberculosis has more than 250 genes that are responsible for fatty acid metabolism or degradation of fatty acids. The resulting fatty acid products, ethanol etc are the precursors for acetyl CoA. Therefore, the pathway involved in the production of the two dicarboxylic acids malate and succinate ( $\mathrm{C} 4$ compounds) from acetate ( $\mathrm{C} 2$ comound) is called the isocitrate lyase or gloxylate pathway. The chief enzyme in the glyoxylate or ICL pathway is isocitrate lyase instead of isocitrate dehydrogenase. Isocitrate dehydrogenases have more affinity towards isocitrate than ICL. In the M. tuberculosis pathogenesis process isocitrate dehydrogenase (IDH) enzymes are inactivated by the phosphorylation effect of an enzyme called IDH kinase-phosphatase. Hence, isocitrate lyase acts on the substrate isocitrate and directs the pathway towards the glyoxylate route. The ICL pathway is known to be inhibited by non toxic natural extracts from Illicium verum and Zingiber officinale that may act as a novel intra-macrophage infection assay inhibitor (Dunn et al., 2009). 


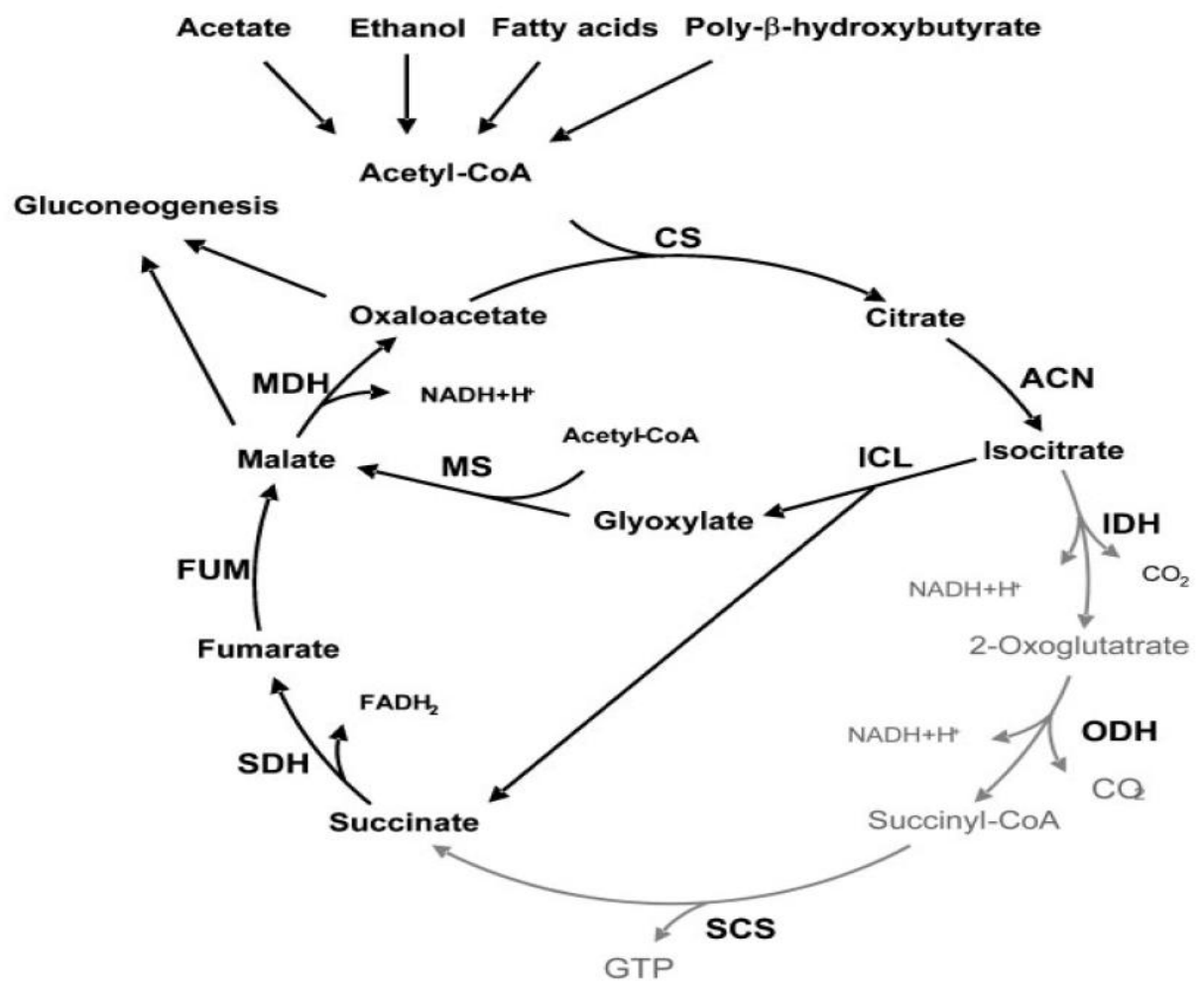

Figure 1.3: Isocitrate lyase (ICL) pathway Acetyl CoA is produced from different pathways. The carbon of which is preserved by ICL pathway avoiding the $\mathrm{CO} 2$ generation steps of the TCA cycle. This figure is replica from (Dunn et al., 2009). [For abbreviations see page 13].

\subsubsection{Vitamin D mediated host defense mechanism against $M$. tuberculosis}

Vitamin D deficiency causes activation of TB (Talat et al., 2010). Phagocytosis of mycobacterium by macrophages occurs via Toll like receptors (TLRs). TLR-mediated phagocytosis involves the binding of pattern recognition receptors (PRRs) responsible for host cell gene 
expression with pathogen associated molecular patterns (PAMPs), which include mannans, formylated peptides, lipopolysaccharides and lipoteichoic acids of M. Tuberculosis (Armstrong and Hart, 1975). The TLRs are present in abundance on macrophages and act as alarm systems for the innate and adaptive immune system. The binding of $M$. tuberculosis with the TLRs (heterodimer complex of TLR1 and TLR2) is associated with the activation of the transcription factor NF-kB. The activation of TLRs also results in the enhanced expression of 25hydroxyvitaminD3-1a-hydroxylase (CYP27b1) and vitamin D receptor (VDR). Induction of CYP27b1 by synthetic analogues may result in the conversion of vitamin $D$ prohormone (25D) into the active $1,25 \mathrm{D} 3$ state. This activated 1,25D3 state binds with the vitamin $\mathrm{D}$ receptor for the induction of bactericidal peptides called cathelicidins (Liu and Modlin, 2008) (Fig 1.2).

\subsubsection{Reactive oxygen and nitrogen intermediate - mediated stress}

Phagocytosis of the mycobacterium by macrophages is responsible for the assembly of phagocyte oxidase and nitric oxide synthase involved in a host-mediated stress response into an enzymatically active complex. These two enzymes are responsible for the production of the reactive oxygen (ROI) and nitrogen (RNI) intermediates respectively. ROls can be defined as the intermediate products in the reduction pathway of oxygen to water by the transfer of electrons from cytosolic NADPH to molecular oxygen for the production of superoxide anions $\left(\mathrm{O}^{2-}\right)$, hydrogen peroxide 30 | P a g e 
$\left(\mathrm{H}_{2} \mathrm{O}_{2}\right)$ and hydroxyl radical $(\mathrm{OH})$ etc. RNIs can be defined as different nitrogenous oxidation and adduct forms resulting from the activity of nitric oxide synthases (iNOS). Furthermore, dismutation of the superoxide anions by superoxide dismutases (SOD) leads to the production of hydrogen peroxide $\left(\mathrm{H}_{2} \mathrm{O}_{2}\right)$ and toxic hydroxyl radicals (Bedard and Krause, 2007). Activated iNOS when synergised with interferon gamma produces the toxic radicals' nitrite $\left(\mathrm{NO}^{2-}\right)$ and nitrate $\left(\mathrm{NO}^{3-}\right)$ from nitric oxide (NO). Under acidic conditions the nitrite forms nitrous acid $\left(\mathrm{HNO}_{2}\right)$ that can dismutate to form nitric oxide and another poisonous radical named nitrogen dioxide $\left(\mathrm{NO}_{2}\right)$ (Nathan and Shiloh, 2000). In some cases the nitric oxide can combine with superoxide anions to form toxic peroxynitrite, which, under acidic conditions, gets converted to peroxynitrous acid (Beckman et al., 1990). These oxidative and nitrosative intermediates are bactericidal for the mycobacterium because they damage nucleic acids, lipids, proteins and carbohydrates (Fig 1.4). 


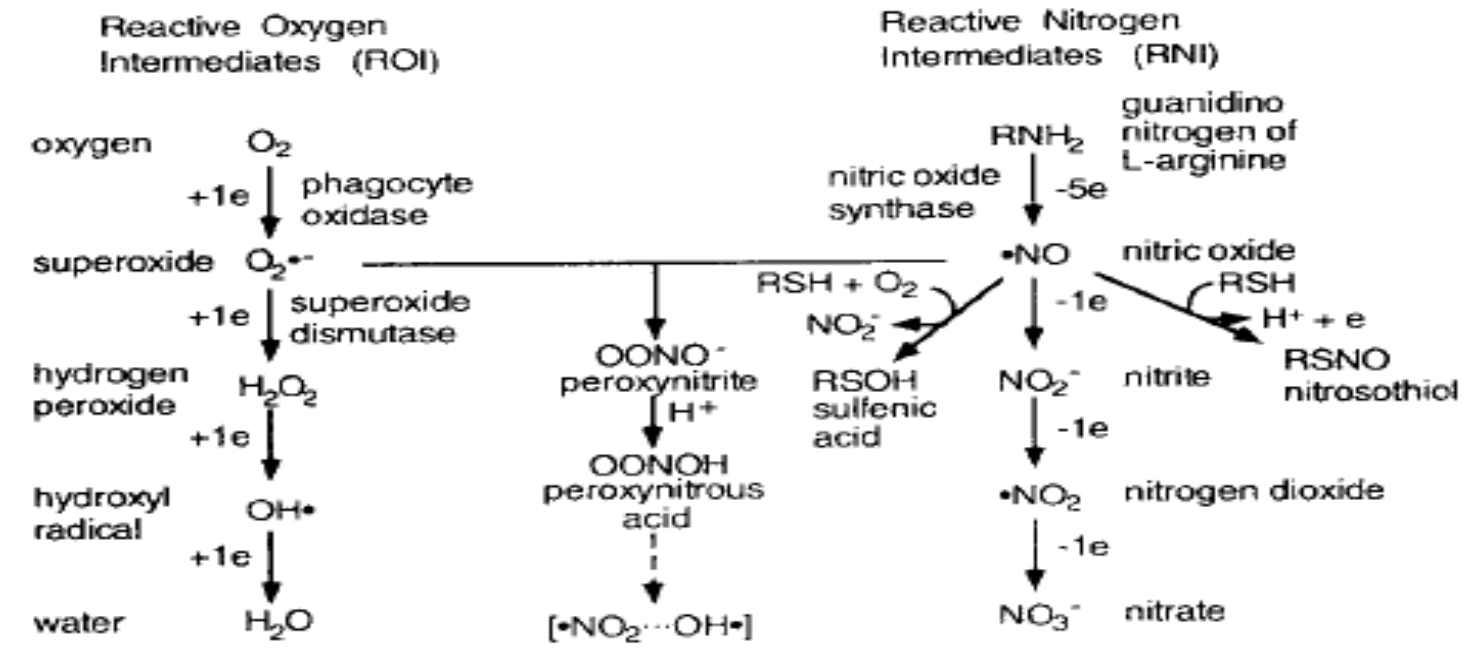

Figure 1.4: Schematic representation of the reactive oxygen and nitrosative stress. This figure is replica from (Nathan and Shiloh, 2000).

\subsubsection{Defensive mechanisms adapted by the mycobacterium against various stresses}

Mycobacteria have evolved many mechanisms to defend against the toxic effects of oxidative and nitrosative stress due to ROls and RNIs. Mycobacteria have evolved many mechanisms to protect themselves from such adverse effects. For example, mycolic acid cyclopropanating (MACE) and cyclopropane mycolic acid synthase (CMA) enzyme are responsible for the cyclopropropanation of the mycolic acid in the mycobacterium cell wall. This renders the bacilli resistant to the adverse oxidative and nitrosative effects posed by the macrophages (Vohra et al., 2006). Hence 
novel drugs targeting these components can help in the in vivo bactericidal activity of the bacilli. Table 1.1 below shows the various genes and proteins and their defensive functions for preventing damage under oxidative and nitrosative stress conditions.

\begin{tabular}{|c|c|}
\hline $\begin{array}{l}\text { Essential genes for defense } \\
\text { against ROIs and RNls stress }\end{array}$ & Functions \\
\hline (a) Superoxide dismutase (SOD) & $\begin{array}{l}\text { Conversion of superoxide anions to } \\
\text { hydrogen peroxide (Seyler et al., 2001). }\end{array}$ \\
\hline $\begin{array}{l}\text { (b) Low molecular weight thiols like } \\
\text { glutathione and mycothiol. }\end{array}$ & Antioxidants (Masip et al., 2006). \\
\hline $\begin{array}{l}\text { (c) Methionine sulfoxide reductase } \\
\text { (Msr A and B) }\end{array}$ & $\begin{array}{l}\text { Involved in protein repair. Msr helps in the } \\
\text { conversion of methionine sulfoxide } \\
\text { (generated in the presense of ROI or RNI) } \\
\text { back to methionine (Weissbach et al., } \\
\text { 2002). }\end{array}$ \\
\hline $\begin{array}{l}\text { (d) Mycobacterium proteasome } \\
\text { ATPase (mpa), proteasome } \\
\text { associated factor (pafA) and core } \\
\text { proteasome encoding gene } \\
\text { (prcBA) }\end{array}$ & $\begin{array}{l}\text { Proteasome helps in the turn over of the } \\
\text { irreversibly damaged proteins. It is also } \\
\text { responsible for the stability of the various } \\
\text { regulatory factors needed for oxidative } \\
\text { and nitrosative stress (Maira and Darwin, } \\
2009 \text { ). }\end{array}$ \\
\hline (e) UvrB and DnaE2 & $\begin{array}{l}\text { Involved in repair of DNA damage caused } \\
\text { by ROls and RNIs (Boshoff et al., 2003). }\end{array}$ \\
\hline (f) NOXR1, NOXR3 & $\begin{array}{l}\text { Provides resistance against RNIs. } \\
\text { Mechanism unknown (Shiloh et al., 1997). }\end{array}$ \\
\hline
\end{tabular}

Table 1.1: Defensive mechanisms adapted by mycobacterium against various oxidative and nitrosative stress. 


\subsubsection{Autophagy}

Autophagy can be defined as a biological process in which long-lived cytosolic components and damaged or excess organelles are enclosed by a double membrane sac called an autophagosome. It is a cell survival mechanism engaged during starvation to use non-functional or surplus organelles for energy production. In certain conditions, however, excessive autophagy may result in programmed cell death. Autophagy involves the activation of PI3K hVPS34 leading to the accumulation of inositol triphosphate (PI3P) on the phagosomal membranes. PI3P plays an important role during the initiation, elongation and maturation steps of autophagosome production. During the initiation step the double membrane isolation membrane, called a phagophore, is activated by serine/threonine kinases of Tor (target of rapamycin) and beclin I. Beclin I is a component of PI3K hVPS34. The phagophore engulfs the cytoplasmic organelles (damaged and long-lived) with the help of Atg (autophagy related homologue) factors by forming two complexes that are Atg5 combined with Atg12 - Atg16L and Atg8, also called LC3 that binds to phosphatidylethanolamine. This results in the formation of the autophagosome. This autophagosome delivers its contents to the lysosomes for the final degradation (Deretic et al., 2006) (Fig 1.5). 
AUTOPHAGY STAGES

\section{Initiation 2. Elongation 3. Maturation/Flux}

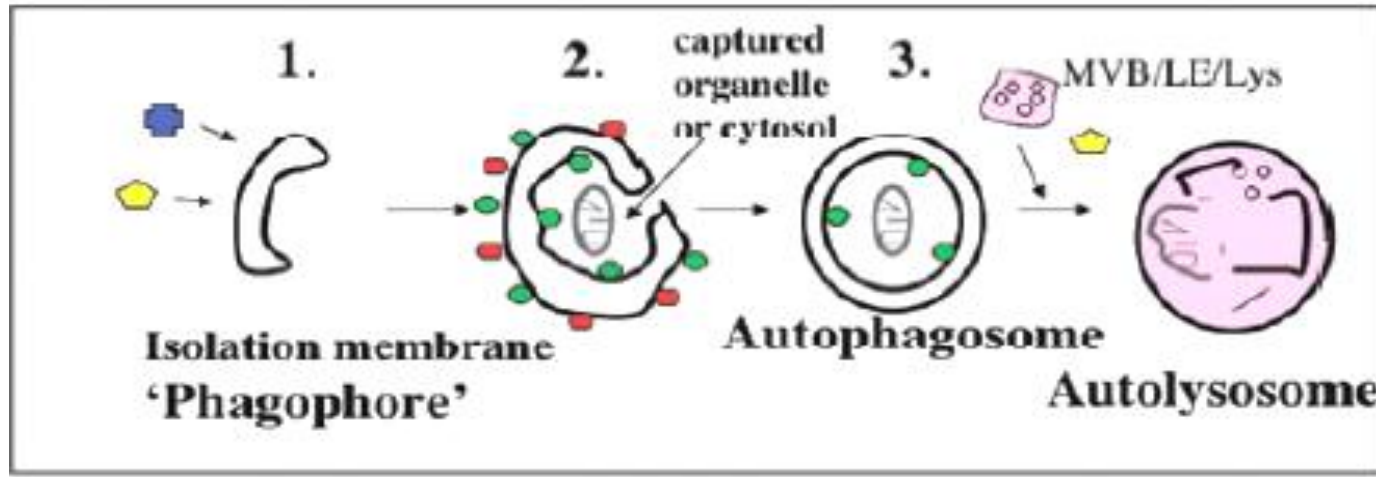

Tor

hVPS34 + Atg6 (Beclin 1)
- Atg5-Atg12-Atg16L

- Atg8 (LC3 II PE)

Figure 1.5: Process of Autophagy. This figure is replica from (Deretic et al., 2006)

\subsection{Treatment of tuberculosis}

TB dates back to antiquity for the past 125 years. Ancient traces of TB have been found in fossil bones and Egyptian mummies. In the year 1834 Johann Lukas Schonleen of Wurzberg coined the term TB (Basel, 1998). Jean Antonie Villemin postulated for the first time that inhalation of aerosol droplets containing bacilli was the main cause of TB disease transmission (Schluger, 2005). Robert Koch discovered M. tuberculosis to be the causative organism of TB in 1882 and was awarded a Nobel Prize in the year 1905 for his discovery of tuberculin extracts from the bacterium 
(Smith, 2003). In the early 1900s Frenchmen Calmette and Guerin developed bacilli calmette guerin vaccine (BCG vaccine). This vaccine was produced from 231 continuous passages of virulent $M$. bovis strain through medium containing glycerol and ox bile that resulted in the complete loss of virulence of $M$. bovis. The BCG immunization was first carried out in Paris in 1921. In 1908, pasteurization of milk was introduced in order to prevent bovine TB from infecting humans (Smith, 2003). Despite some initial reluctance due to an unfortunate incident where a virulent strain was mistakenly substituted for the vaccine, BCG has become accepted as the gold standard against which all experimental vaccines are compared. The ability of BCG to prevent childhood forms of the disease is well known, but the protection provided by BCG against the vast majority of disease is often less than $50 \%$ and in the most recent trial it provided no protection at all. There are other attenuated mycobacterial strains including Mycobacterium bovis BCG. Mycobacterium microti, which causes tuberculosis in rodents but is naturally avirulent for humans, has also been used to a very limited extent. It provides protection against tuberculosis similar to that provided by BCG. An attenuated strain of Mycobacterium tuberculosis, known as H37Ra, is almost as old as BCG and was commonly used for studies in laboratory animals. It did not provide better protection than BCG in the animal models used at the time and is now used infrequently (Collins, 2000).

Albert Schatz and Selman Waksman discovered streptomycin from Steptomyces griseus in the year 1944 (Waksman, 1946). This was 
followed by demonstration of the suppressive effects of the drug in both guinea pigs and humans by Feldman and Hinshaw. Previous studies results have showed that streptomycin is considered to be the most effective antibacterial agent with low toxicity against tuberculosis. Streptomycin is not distributed equally throughout different parts of the tissues. This results in variation of its response towards different types of tuberculosis. It is helpful in the treatment of uncomplicated meningitis, military tuberculosis, pulmonary tuberculosis tuberculous sinuses, adenitis and gastro-intestinal tuberculosis. The detailed mechanism of action for streptomycin is given in Table 1.2.

In the year 1940, Bernheim first noticed that certain chemical substance like benzoic acid and salicylic acid can stimulate the oxygen consumption by the tubercle bacillus and hence increasing its carbon dioxide production, hence, changing the metabolism and affecting mycobacterium growth and virulence. This led Lehmann and Sweden for the discovery of a bacteriostatic agent known as para-aminosalicylic acid (PAS) in 1946 (Singh and Mitchinson, 1995). The detailed mechanism of action for PAS is given in Table 1.2. The action of PAS in tuberculosis patients is known to be complex and involves marked reduction of number of bacilli in sputum, rapid clinical improvement, lowering of temperature and weight gain. It was also seen that PAS was often effective in cases such as endobronchial disease where streptomycin failed to show any effect. PAS in combination with streptomycin is used for the treatment of TB meningitis. 
The 1950-1960s represented the golden era of TB drug discovery with the introduction of other first and second line antituberculosis drugs such as isoniazid (1952) (Ramaswamy et al., 2003), pyrazinamide (Zhang et al., 2003), ethionamide, ethambutal (Sreevatsan et al., 1997) cycloserine, kanamycin, amikacin, viomycin, capreomycin, rifampicin and broadspectrum quinolones (Janin, 2007).

Since that time a huge global investment has been made into TB research worldwide. But the complete eradication of TB is still not possible to achieve because of the long TB treatment period associated with the disease, failure to eliminate latent tuberculosis bacilli and the emergence of drug (MDR-TB and XDR-TB) resistant strains (Andreu et al., 2010).

The most recommended treatment for TB is directly observed treatment, short course (DOTS). DOTS involve a supervised medication to the tuberculosis patient by a health care worker. It has a cure rate of $95 \%$ (Burman, 2010). The current DOTS treatment regimen is 6 months long and involves an initial 2-month treatment with 4 drugs - isoniazid, rifampicin, pyrazinamide, and ethambutol, followed by a final 4-month treatment with just isoniazid and rifampicin (Teresa et al., 2006). Although this 6-month long DOTS therapy is very effective in completely eradicating TB bacilli from the lesions, it has many side effects associated with it as well (Burman, 2010). The side effects include significant toxicity during such a long medication course, development of drug resistant strains and failure to kill latent or dormant bacilli. 
According to the Mitchinson model, the tubercle bacilli in the lung lesions can be divided into 4 categories comprising actively growing bacteria, bacilli having different rates of metabolic activity, bacilli residing in an acidic $\mathrm{pH}$ and having a low metabolic rate, latent and dormant bacilli (Mitchinson, 1979). General broad spectrum antibacterial drugs like streptomycin can also be ineffective against TB due to the intracellular location of the mycobacterium inside the macrophages. Because of the all above mentioned reasons there is a growing need of research that can lead to the discovery of novel antituberculosis drugs that can shorten the current 6-month TB therapy, kill latent and intracellular bacilli effectively and a need for discovery of novel drug targets that can be knocked out or activated and result in effective and fast treatment of TB (Chopra et al., 2003). Table 1.2 summarises the known antituberculosis drugs with their mechanisims of action, type of drug and genes involved in resistance. 


\section{Table 1.2 List of currently used common antituberculosis drugs and their mode of action}

\section{Antituberculosis drug (MIC values in $\mu \mathrm{g} / \mathrm{ml}$ )}

1. isoniazid

$(0.02-0.2)$

2. rifampicin

$(0.05-1)$

3. pyrazinamide

$(16-50)$

\section{Type}

Mode of action

Bactericidal

KatG (catalase peroxidase) - INH is a prodrug, which is activated by KatG to produce reactive oxygen and nitrogen species.

InhA (enoyl ACP reductase) is a component of InhA and ndh: Cell mycolic acid synthesis pathway that is inhibited by wall INH-NAD adduct. Active species responsible for inhibition is isonicotinic acyl radical.

ndh: catalyses $\mathrm{NADH}+(\mathrm{H}+)+\mathrm{X} \rightarrow(\mathrm{NAD}+)+$ reduced $\mathrm{X}$

Bactericidal Inhibition of RNA synthesis.

Bactericidal/

Bacteriostatic
Bacterial DNA dependent RNA

polymerase

Membrane proton motive force
Pyrazinamide (prodrug) is converted to pyrazinoic acid in acidic $\mathrm{pH}$ that lowers the membrane potential followed by influx of protons into the cell causing its cytoplasmic acidification. It completely disrupts the membrane's proton motive force.

\section{Genes involved in the action}

rpoB (Williams et al., 1998)

pncA (Zhang et al., 2003)

40 I P a g e 


\section{Antituberculosis \\ drug}

4. ethionamide

$(2.5-10)$

5. ethambutol

$(1-5)$

6. cycloserine

Bacteriostatic It inhibits the peptidoglycan biosynthesis.

7. streptomycin

$(2-8)$

8. Fluoroquinolone $(0.5-2.5)$

9. Kanamycin $(2-4)$
Type

Bacteriostatic

It int

\section{Mode of action}

Bacteriostatic It inhibits the arabinogalactan biosynthesis.

\author{
Bacteriostatic
}

Bactericidal It inhibits the protein synthesis.

Bactericidal It inhibits DNA synthesis

Bactericidal It interferes with protein synthesis

\section{Site of action}

Cell wall

Arabinogalactan transferases (cell wall)

D-alanine racemase \& AlrA, Ddl (Feng and D-alanine: D alanine Barletta, 2003) ligase (cell wall)

30 s subunit of ribosomal S12 protien and $16 S$ rRNA.

DNA gyrase $A$ and $B$

16S rRNA

\section{Genes involved in the action}

EtaA (Morlock et al., 2003)

embCAB (Sreevatsan et al., 1997)

\section{RpsL, rrs (Spotts and}

Stainier, 1961)

gyr A, gyrB (Andersson and Macgrown, 2003)

Rrs (Kotra et al., 2000)

First-line antituberculosis drugs isoniazid, rifampicin, pyrazinamide, streptomycin, ethambutol

Second-line antituberculosis drugs Antibiotics (cycloserine), thioamides (ethionamide), fluoroquinolones, polypeptides (capreomycin), aminoglycoside (kanamycin, amikacin) (Janin, 2007). All MIC values are obtained from (Zhang and Yew, 2009). 


\subsubsection{Need for intra- macrophage infection assay in TB drug discovery research}

M. tuberculosis is an intracellular pathogen that depends upon the host nutrients for its growth and survival. Phagocytosis of the mycobacterium by alveolar macrophages results in the shift of gene transcription. This result in the alteration of mycobacterium susceptibility towards novel drugs detected from in vitro screens (Eklund et al., 2010). Currently, many in vitro screens are known that are based on growth inhibition and killing of a microbial pathogen (Christophe et al., 2009), but none of these assays can be considered completely efficient. The reasons can be attributed to the lack of resemblance of the commonly used in vitro assays in TB drug discovery with that of the biological system in which the drugs needs to function. Furthermore, the rate of new antimicrobial drug discovery has been slow over the past several years because of the use of ineffective and laborious methods such as colony forming units (CFU) in order to evaluate the inhibition of mycobacterial growth. The slow intracellular bacillary growth and the difficult in vivo infection assay set up may be other reasons hindering the discovery of these types of intra-macrophage specific hits.

All commonly known antituberculosis drugs are originally identified by in vitro screens, with the exception of pyrazinamide (PZA). The mechanism of action of PZA harnesses a unique physiology of the mycobacterium as a novel drug target. The basis of this unique property is the presence of an inefficient efflux system in $M$. tuberculosis. The experimental evidence 
shows that under acidic $\mathrm{pH}$ condition the pyrazinamide (prodrug) is converted to the pyrazinoic acid that lowers the membrane potential. This is followed by influx of protons into the cell causing its cytopasmic acidification. It completely disrupts the membrane potential by affecting its proton motive force. This accumulation of POA and protonated POA which together lower the intracellular $\mathrm{pH}$ to a suboptimal level therefore may inactivate many pathways such as fatty acid synthesis and membrane transport. Weak acids such as benzoic acid, ultraviolet radiation (UV) and sodium azide (a respiratory chain inhibitor) enhance PZA activity (Zhang et al., 2003).

The development of such a biologically relevant intra-macrophage assay will help in the discovery of prodrugs with no in vitro antimicrobial activity, but that target functions only inside biological system either by blocking mycobacterium virulence factors or by modulating the host immune system. There is much less of a chance that the mycobacterium will develop resistance against these kinds of novel antituberculosis drugs. This assay will also help in the elimination of cytotoxic in vitro hits from the synthetic libraries. 


\subsection{J774A.1 macrophages infected with GFP labelled M. smegmatis} as an intra-macrophage infection model of study

Many methods are known to be devised so as to determine the phagocytosed mycobacterium viability. Most commonly known method are colony forming units (CFU) plating involving agar plate culturing of a defined volume of serial dilution of infected macrophage cell lysates followed by CFU analysis. The disadvantages associated with this method is its slow replication time (2-3 weeks for visible colony appearance) and manual labour associated during agar plating and counting (Takii et al., 2002).

Other sensitive methods used for determining the phagocytosed mycobacterium viability are GFP or bioluminiscence based assays. Bioluminiscence is a reporter technology used in both in vivo and in vitro assays that involves production of light by a luciferin-catalyzed reaction. The luciferase enzyme is responsible for the catalysis of the oxidation reaction step of the substrate, generically called luciferin, into oxyluciferin along with the production of light. This property can be used for the study of gene expression and viability in both in vitro and in vivo set-up. Hence, bioluminescence has also been used for antibiotic testing in both in vivo and in vitro assays. The disadvantages are the high cost associated and the need for substrates to be added for the production of chemiluminescence (Andreu et al., 2010). 
Green fluorescent protein (GFP) is isolated from photogenic cells present at the base of the jellyfish (Aequorea victoria) umbrella (Kain, 1999).. It produces light when energy is transferred from a calcium-activated photo protein aeqourin to GFP. GFP is a 238 amino acid long single chain polypeptide (antiparallel beta sheet) surrounded by a three cyclized amino acids Ser-Tyr-Gly (amino acids 65-67) alpha helix chromophore (Kremer et al., 1995). This cyclic form of the chromophore results from the tyrosine oxidation at position 66 by molecular oxygen (Kain, 1999). The stable and unstable GFP are two commonly used reporter markers. Stable GFP can be used for gene expression and protein localization studies. The GFP expression is independent of the species, cofactors, substrates or any gene products found in Aeqourea Victoria (Kremer et al., 1995). Destabilized or unstable (labile) GFP can be used effectively as a transient transcription reporter. Unstable GFP imposes lower toxicity due to prolonged accumulation as it is gradually degraded after synthesis. The unstable GFP has proline, glutamine, serine, and threonine-rich regions between amino acids 423-449 ( $\mathrm{Li}$ et al., 1998). The various advantages associated with the use of GFP in high throughput screening are, its cost effectivness, low toxicity, easy imaging and quantization by confocal microscope, and continuos production during mycobacterial replication that eliminates the need of cell lysis to assess the number of viable bacteria (Moy et al., 2009).

Hence in the present study, a mouse macrophage cell line J774A.1 will be used as an intramacrophage model to study the interaction between GFP- 
labelled M. smegmatis and macrophages, using a screening assay in standard 96-well black-wall glass bottomed microtiter plates. The fate of M. smegmatis inside J774A.1 cells will be determined with respect to their survival inside the macrophage. The reason behind the use of macrophages as an infection model was that they can readily take up the bacteria and are easy to culture and hence can act as an efficient infection model. Furthermore, macrophages are the primary site of infection for the TB infection as discussed in section 1.3. Hence, this will ensure direct validation of many new promising synthetic and natural antituberculosis drugs in their true environment. The $\mathbf{J} 774$ macrophages are a murine cell line isolated from a reticular cell sarcoma. The growth medium used for the J774 cell line was RPMI 1640 medium supplemented with $10 \%$ fetal calf serum (FCS) and 1\% penicillin: streptomycin (Wright et al., 1996). 


\subsection{Project Aims:}

Development of an intra-macrophage infection assay The murine J774 macrophage cell line will be infected for 96 hrs with GFP-labelled pLL192hsp60 M. smegmatis at a multiplicity of infection of 10:1. A minilibrary high-throughput model will be made by using all the previously reported LOPAC in vitro hits against M.smegmatis alone. The library of pharmacologically active compounds library (LOPAC) from Sigma is comprised of 1280 compounds.

Implementation of the intra-macrophage infection assay set-up in the synthetic library screening A synthetic LOPAC library will be screened, and the growth inhibition results obtained from the GFP based screen will be validated using opera high-throughput confocal microscopy.

Development of the cytotoxicity assays The potency of the novel hits obtained from the synthetic library screening will be determined using a standard cell proliferation assay (MTT and Alamar blue).

Detailed follow-up study of the novel hits obtained The follow-up study will involve testing the novel hits obtained from the high-throughput initial screen against GFP-labelled M. smegmatis infected J774 macrophages, against $\mathrm{J} 774$ macrophages to determine potency in mammalian cells and $M$. smegmatis to determine their bactericidal and bacteriostatic action in vitro. 


\section{Chapter 2}

\section{Materials and Methods}




\section{Chapter 2}

\section{Materials and Methods}

\subsection{Development of an intra- macrophage infection assay}

The development of an intra-macrophage infection assay involves the infection of J774 macrophage cells with GFP-labelled pLL192 hsp60 M. smegmatis.

\subsubsection{J774 macrophage cell culture}

Murine macrophage adherent J774A.1 cells (ATCC) were cultured in T-75 $\mathrm{cm}^{2}$ (250 $\mathrm{ml}$ total flask volume) cell culture flasks (Invitrogen). The medium used for cell culture was RPMI-1640 (Invitrogen) supplemented with $10 \%$ fetal calf serum (Invitrogen) and penicillin-streptomycin (penicillin 50 units $/ \mathrm{ml}$ and streptomycin $50 \mu \mathrm{g} / \mathrm{mL}$ ) (Invitrogen). The cells were incubated at $37^{\circ} \mathrm{C}$ in a $5 \% \mathrm{CO}_{2}$ in air atmosphere until the culture had reached approximately $80 \%$ confluence. The cells were then seeded at a concentration of $1 \times 10^{5}$ cells/well in a black-walled glass-bottomed 96 well tissue culture microtiter plate (BD Biosciences) followed by overnight incubation at $37^{\circ} \mathrm{C}$ and $5 \% \mathrm{CO}_{2}$ in air. The medium used for cell seeding in 96-well plates was RPMI 1640 supplemented with $10 \%$ FCS without penicillin-streptomycin. 


\subsubsection{Bacterial strains, plasmids and culture conditions}

Cultures of M. smegmatis harbouring pLL192 hsp60 (Srivastava et al., 2007) were streaked on Luria-Bertani agar plates (LA) supplemented with $50 \mu \mathrm{g} / \mathrm{mL}$ kanamycin and kept in the incubator for 3 days at $37^{\circ} \mathrm{C} . . \mathrm{M}$. smegmatis/ pLL192 hsp60 colonies were inoculated in luria-bertani broth (LB) containing $50 \mu \mathrm{g} / \mathrm{mL}$ kanamycin, $100 \mu \mathrm{g} / \mathrm{mL}$ D-arabinose, and $0.1 \%$ Tween-80 to mid-logarithmic phase at $37^{\circ} \mathrm{C}$ and $200 \mathrm{rpm}$ in a shaking incubator so as to reduce cell clumping. The M. smegmatis/pLL192 hsp60 was then sub-inoculated to an optical density (OD) of 0.1 using a $10 \mathrm{~mm}$ path-length glass cuvette and grown at $37^{\circ} \mathrm{C}$ to an $\mathrm{OD}$ of 1.0 at an absorbance of $600 \mathrm{~nm}$.

The stable GFP-labelled pLL192hsp60 reporter marker is the $E$ coli- $M$. smegmatis shuttle vector having two genes GFPmut2, a mutated form of green fluorescent protein, and a kanamycin resistance gene. These two genes together form a transcription unit downstream of the BamHI site, which allows the insertion of the different promoters. In this case the promoter is a heat shock protein promoter called constitutive hsp60 promoter (Srivastava et al., 2007). GFPmut2 excitation and emission wavelengths are 488 and $597 \mathrm{~nm}$, respectively.

The change in stable GFP reporter marker readings during the incubation time period (96 hours for this thesis) will be used to assess bacterial viability inside the macrophages. 


\subsubsection{Dispersion of $M$. smegmatis clumps}

M. smegmatis/pLL192 hsp60 cells were pelleted and washed three times in phosphate buffered saline (PBS) containing $0.1 \%$ Tween-80 (PBST) by centrifugation at $3000 \mathrm{rpm}$ for $3-5 \mathrm{~min}$ in an ultracentrifuge. The pellet was again resuspended in PBST. The M. smegmatis/pLL192 hsp60 cells were dispersed by passage through a 25-gauge needle (BD Biosciences) followed by low speed centrifugation at $120 \mathrm{rcf}$ (relative centrifugal force) for 5 minutes. The resulting supernatant was transferred to a new tube for use in $\mathbf{J 7 7 4}$ macrophage cell line infections.

\subsubsection{Visualization of the single-cell suspension}

Approximately $10 \mu \mathrm{L}$ of the single-cell suspension was taken from the supernatant and transferred to a microscope slide and examined for clumping using a 100x (oil-immersion) objective in an Olympus Provis AX 70TRF fluorescent microscope (Olympus America Inc) with a fluorescein isothiocyanate (FITC) filter.

\subsubsection{Colony forming units (cfu)}

The colony forming units experimental set-up was performed in order to determine the multiplicity of infection (MOI) for the macrophage infection assay. Ten-fold serial dilutions and viable cell plating onto LA were performed in triplicate on M. smegmatis/ pLL192 hsp60 cell cultures 51| P a g e 
subinoculated overnight from an OD $1.0(\mathrm{~A} 600 \mathrm{~nm})$ cell stock. The plates were incubated at $37^{\circ} \mathrm{C}$ for 3 days at which point the colonies were counted and cfu were determined. The CFU assay gives a measurement of viable bacteria in the stock suspension (Eklund et al., 2010).

Colony forming units $(\mathrm{cfu})=$ Number of colonies

$0.1 \mathrm{~mL}$ plated $\mathrm{x}$ dilution

\subsubsection{Low-throughput macrophage infection assay}

If the cfu in a culture of OD 1.0 at $A 600 \mathrm{~nm}$ is known, the $\mathrm{MOI}$ can be calculated. The $\mathrm{MOI}$ is the number of mycobacterium needed to infect each macrophage for a good GFP signal reading that can be detected by the fluorescent platereader. The macrophage cells were infected with $M$. smegmatis/pLL192 hsp60 at a target MOI of $10: 1$ and incubated at $37^{\circ} \mathrm{C}$ for 4 hours.

The macrophage cells were washed 3-5 times with PBS for the removal of extracellular bacteria. This was followed by the treatment of the infected macrophages with RPMI 1640 supplemented with $10 \%$ FCS and 20 $\mu \mathrm{g} / \mathrm{mL}$ gentamycin. The gentamycin was added to prevent extracellular bacterial growth from residual bacteria in the medium or adherent bacteria on the surface of the macrophage.

To determine the $\mathrm{IC}_{50}$ of the known antituberculosis drugs or the novel drug hits, the given drug was tested in duplicate by performing two-fold 52 | P a g e 
serial dilutions in RPMI 1640 medium supplemented with $10 \%$ FCS and $20 \mu \mathrm{g} / \mathrm{mL}$ gentamycin. The infected macrophages were then incubated for 96 hours at $37^{\circ} \mathrm{C}$ after treatment with drugs Fig 2.1.

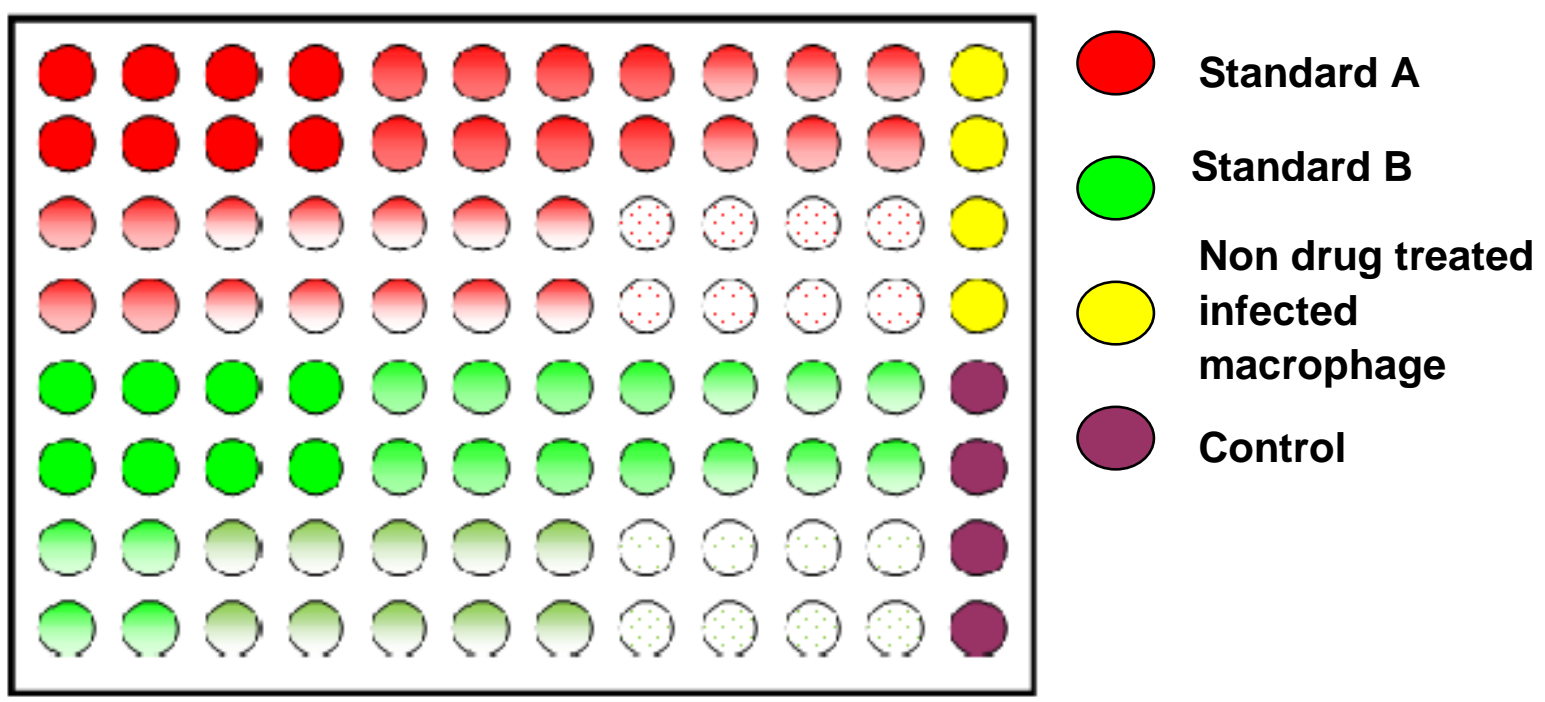

Figure 2.1: Plate layout for the low-throughput intra-macrophage assay. The standards (A and $B$ ) were 1:2 serially diluted in duplicates from left to right direction.

\subsubsection{Development of a mini high-throughput demo library infection} model

The optimization of the low-throughput intra-macrophage assay was made the basis for construction of a mini-highthroughput demo library model. The mini-high-throughput stock library comprised of some of the validated in vitro hits from the LOPAC library (Table 2.1) and common 
antituberculosis drugs in a 96-well plate format at a $200 \mu \mathrm{M}$ stock concentration. All experimental compounds used for making the minilibrary demo model were kindly provided by Christopher H. Miller.

The $\mathrm{J} 774$ cells were seeded at a concentration of $1 \times 10^{5}$ cells/ well in a black-walled glass-bottomed 96-well tissue culture microtiter plate (BD Biosciences) followed by overnight incubation at $37^{\circ} \mathrm{C}$ at $5 \% \mathrm{CO}_{2}$ in air. The medium used for cell seeding was RPMI 1640 supplemented with 10 \% FCS without penicillin-streptomycin. J774 macrophages were infected with M. smegmatis/pLL192 hsp60 at an MOI of 10:1 as already discussed in the low-throughput intra-macrophage infection assay section. This was followed by 3-5 washes with PBS and treatment of the infected macrophages with $180 \mu \mathrm{L}$ of RPMI 1640 supplemented with $10 \%$ FCS and $20 \mu \mathrm{g} / \mathrm{mL}$ gentamycin. The gentamycin was added to prevent the growth of extracellular bacteria.

Twenty $\mu \mathrm{L}$ of the drugs from the 96-well parent minilibrary plate at $200 \mu \mathrm{M}$ was transferred to the above mentioned infected macrophages in $180 \mu \mathrm{L}$ of RPMI 1640 supplemented with 10\% FCS and $20 \mu \mathrm{g} / \mathrm{mL}$ gentamycin. The drug treated infected macrophages were then incubated for 96 hours at $37^{\circ} \mathrm{C}$. After 96 hours, $20 \mu \mathrm{L}$ of Alamar blue (10\% v/v) (Invitrogen) was added, and the plate was incubated overnight at $37^{\circ} \mathrm{C}$ to determine the cytotoxicity of the chemical compounds tested using alamar blue assay. This will be discussed in detail in the following sections 2.2. 


\subsubsection{Implementation of the intra-macrophage infection assay set up for synthetic library screening}

The J774 macrophages were infected with M. smegmatis/pLL192 hsp60 at an $\mathrm{MOI}$ of $10: 1$ as already discussed in the previous sections. Four $\mu \mathrm{L}$ of a $1 \mathrm{mM}$ stock synthetic library concentration was then transferred to column 2-10 of the 96 well black walled glass bottomed plate containing $196 \mu \mathrm{L}$ of antibiotic-free RPMI 1640 supplemented with $10 \%$ FCS and $20 \mu \mathrm{g} / \mathrm{mL}$ gentamycin using a Cybi-Well robotic liquid handling station (Cybio) for a final concentration of $20 \mu \mathrm{M}$. Four known antibiotic controls, namely rifampicin, ethambutol, capreomycin, ciprofloxacin, were established in duplicates in column 1. The solvent control dimethyl sulphoxide and non drug treated infected macrophage control were established in triplicates in coloumn 12. The uninfected macrophage controls in duplicate were established in coloumn 12 (Fig 2.2). The drug-treated, infected macrophages were then incubated for 96 hours at $37^{\circ} \mathrm{C}$ and $5 \% \mathrm{CO}_{2}$ in air. After 96 hours, $20 \mu \mathrm{L}$ of Alamar blue (10\% v/v) [invitrogen] was added, and the plate was incubated overnight at $37^{\circ} \mathrm{C}$ to determine the cytotoxicity of the chemical compounds tested. 


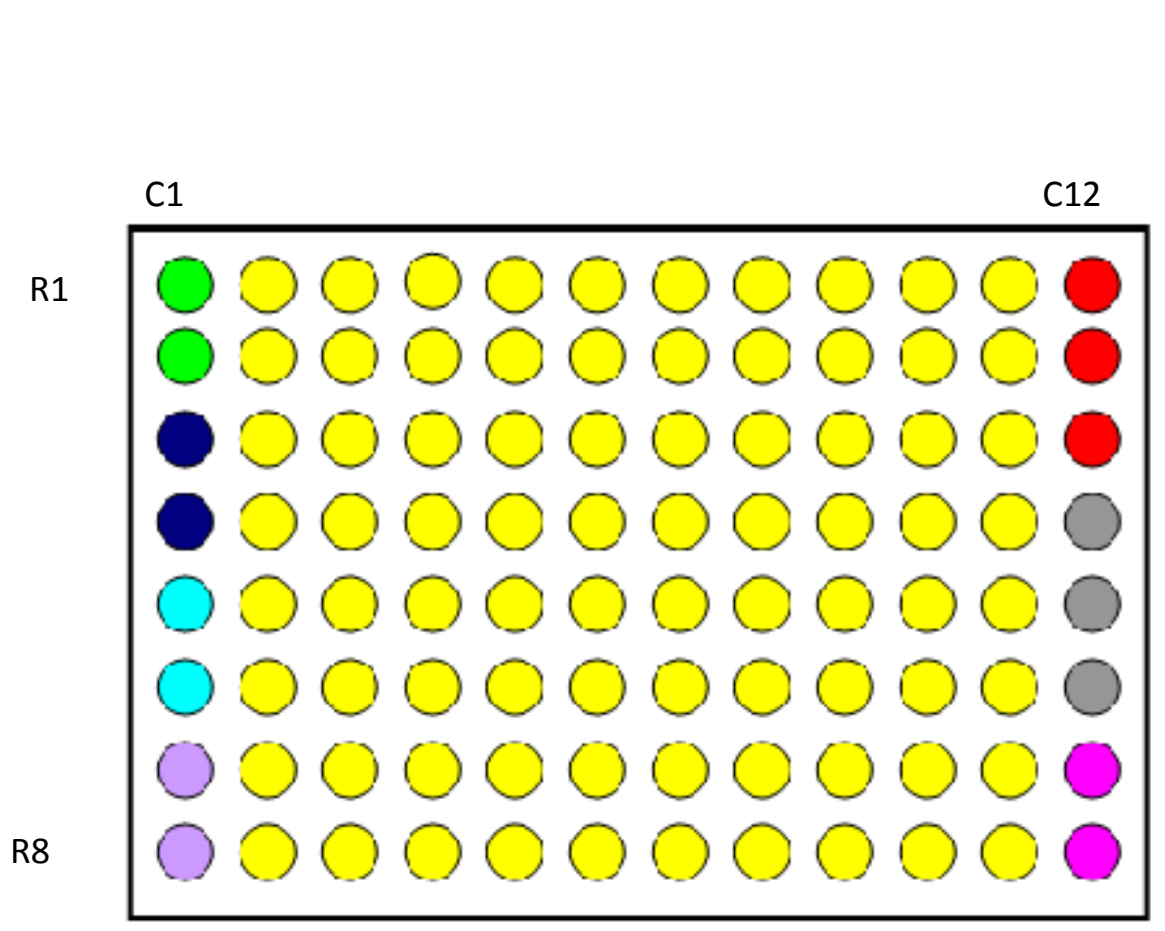

Non drug DMSO

treated infected

macrophages

Non drug treated

infected

macrophages

Control

Rifampicin

Ethambutol

Ciprofloacin

Capreomycin

Standards

Figure 2.2: Plate layout for the high-throughput intra-macrophage assay

2.1.7 Data collection and analysis for intramacrophage infection assay The GFP fluorescence from drug-treated and untreated infected macrophages at 0 and 96 hours was measured using an EnVision ${ }^{\circledR} 2102$ multilabel platereader (Perkin Elmer, Inc) with the Wallace EnVision ${ }^{\circledR}$ Manager 1.12 software program (Perkin Elmer, Inc).The GFP signals was detected using a FITC bottom mirror, with excitation and emission wavelengths of $485 \mathrm{~nm}$ and $510 \mathrm{~nm}$, respectively. Twenty five point scans (5x5) were performed while taking the readings so as to maximize the 
GFP output signal efficiency from infected macrophages and minimise the intra-well variation caused by 'clumping' of bacteria in the culture. The auto-fluorescence from uninfected macrophages and the intrinsic GFP fluorescence readings of infected macrophages in media and solvents were also measured to enable correction for any background signals. The background was later subtracted from the readings for the samples tested. Data were normalised in terms of percentage of control. The percentage of control was calculated by the ratio of the change in GFP fluorescence values between 96 hours and 0 hours in experimental drug-treated, infected macrophages (positive control) to the non-drug treated, but infected macrophage GFP flourescence (negative control) between 96 hours and 0 hours. The dose response $\mathrm{IC}_{50}$ inhibitory curves were plotted using Sigmaplot ${ }^{\circledR} 10.0$ software (version 10.0). A simple scatter plot was created using the duplicate data obtained from the platereader. A log (common) scale was applied to the X-axis which represented the concentrations of the drugs (experimental compounds in two-fold serial diluted). A four-parameter logistic curve was used to fit the plotted data, and $\mathrm{IC}_{50}$ values with standard errors for the respective drugs were calculated against the intra-macrophage assay. A "Hit" selection criterion was set for high throughput screening. Any experimental compounds showing less than $25 \%$ growth was considered as a "hit". 


\subsubsection{Calculation of $Z$ factors for intramacrophage infection assay}

The parameter used to calculate the robustness of the high-throughput screen is called a $Z$ factor. $Z$ factor is calculated by the formula given as follows

$Z$ factors were calculated by:

Z-factor $=1-\left(3^{*}(\sigma\right.$ negative $+\sigma$ positive $) /(\mu$ negative $-\mu$ positive $\left.)\right)$

Where the $\sigma$ and $\mu$ refers to the standard deviation and means of positive and negative controls respectively.

If the:

$Z$ score is $\geq 0.3$ : the high-throughput screen is considered reliable.

$\mathrm{Z}$ score is 0 : there is no difference between the potential hits and the positive or negative controls.

$Z$ score is negative: the experimental results are dominated by noise and the screen needs to be improved or repeated (Zhang et al., 1999).

\subsubsection{Validation of the intra-macrophage infection assay}

After 96 hours of incubation of the infected macrophages with the experimental compounds, the supernatant was discarded, followed by three proper washes with PBS. This helps in the removal of any residual extracellular mycobacterial growth (approximately $10 \%$ of total) during the 
course of the $96 \mathrm{hrs}$ incubation period. The plate was then stained with 50 $\mu \mathrm{L}$ of of labelling stain prepared in Kreb's buffer from an image-iT LIVE plasma membrane and nuclear labeling kit [Invitrogen].

The image-iT kit contents are:

(a) Wheat germ agglutinin (WGA), Alexa fluor 594 conjugate $(1 \mathrm{mg} / \mathrm{mL}$ in PBS) which stains the plasma membrane red (Red fluorescent proteinRFP).

(b) Hoechst 33342 dye $(1 \mathrm{mM})$ which stains the nucleus blue.

The labelling solution was prepared in Kreb's buffer in such a way that the final concentration of Alexa fluor 594 WGA, as recommended by the manufactuerer, was $5 \mu \mathrm{g} / \mathrm{mL}$ and for Hoechst 33342 dye was in the range of 1-2 $\mu \mathrm{M}$. The Kreb's buffer was preferred over the RPMI 1640 culture medium as it minimised the background when observed under the microscope. See Appendix B for instructions to prepare labelling solution.

The sample was incubated with the labelling solution at $37^{\circ} \mathrm{C}$ for 20 minutes followed by removal of the stain. When the staining was complete the sample was washed once again with Kreb's buffer. The sample was mounted in Krebs buffer for viewing with a confocal microscope. 


\subsubsection{Image acquisition by Opera high-throughput confocal microscope for validation of intramacrophage assay}

The confocal high-throughput images were taken with the help of the Opera high-throughput confocal microscope [Evotec Technologies/ Perkin Elmer]. It is currently the only high-throughput microscope available with water immersion lenses and is capable of imaging $>100,000$ quantitative image fields per day. The images were captured from the central position (seven $Z$ stacks at $2 \mu \mathrm{m}$ distance) of each well in the 96 -well plate. The lens magnification used was 20x, NA 0.4 air lenses at a centre focal height of $15 \mu \mathrm{m}$. The 405, 485, $561 \mathrm{~nm}$ lasers were used for DAPI (Hoechst 33342 nucleus stain), GFP (M. smegmatis/pLL192hsp60) and RFP (Alexa fluor 594 WGA plasma membrane stain), respectively. The images were taken with 2 cameras, camera 1 and camera 2, using exposure 1 and 2 of 200 millisecond duration each. The camera 1 filter used two exposures (a) exposure $1-520 / 35 \mathrm{~nm}$ (for GFP) and exposure 2 - 450/ $50 \mathrm{~nm}$ (for DAPI). The camera 2 filter used only one exposure, exposure $1-600 / 40$ $\mathrm{nm}$ (for RFP as already discussed in previous sections). The filter detection dichro was $568 \mathrm{~nm}$ and filter primary dichro was 405/ 488/561/ $640 \mathrm{~nm}$.

The Opera high-throughput confocal microscope is software controlled and the images obtained were sent to a local computer cluster for concurrent analysis and processing. The post-processing was done with MBF_Image $\mathrm{J}$ version $1.43 \mathrm{~m}$, which can be downloaded from. 


\subsubsection{Image $\mathrm{J}$ software analysis}

The images obtained were processed with the help of MBF_Image $\mathrm{J}$ version $1.43 \mathrm{~m}$. The Opera microscope recorded the images in the following order such that the first channel was GFP from the $M$. smegmatis/pLL192hsp60, the second channel was RFP from the macrophages and the third channel was DAPI from the nuclei. All the images were taken in flex file format and put in separate subfolders within a parent folder. It also provides other additional necessary information such as total area, mean fluorescence, standard deviation, and the "integrated density". See Appendix C for the procedures followed to analyse the images obtained by opera high throughput confocal microscope.

The results will help in the comparison of the GFP mean fluorescence of the different acquired images from different experimental test compounds. The GFP mean fluorescence represents the ratio of the corresponding integrated density to the total area. The GFP (mycobacterium) to RFP (macrophages) signal ratio can be also calculated. See Appendix $C$ for display of the images using Image $\mathrm{J}$ software 


\subsubsection{Acquisition of images using Olympus FV1000 confocal} microscope The $\mathrm{J} 774$ macrophages were cultured in $35 \mathrm{~mm}$ glassbottomed dishes with a coverslip (tissue culture Fluorodishes, MatTek, catalogue no: FD35-100) and incubated at $37^{\circ} \mathrm{C}$ until an appropriate (80\%) confluence was achieved. This was followed by infection with GFPlabelled mycobacteria. An Olympus FV1000 confocal microscope was used to acquire images of image-iT stained infected macrophages.

The infected macrophages were stained with image-iT stain as described in the previous sections. The images were acquired with the 20x air lens, $60 x$ water lens or $100 x$ oil immersion lens depending on the magnification required. The $405,473,635 \mathrm{~nm}$ lasers was used for primary use with DAPI (Hoechst 33342 nucleus stain), GFP (M. smegmatis pLL192hsp60) and RFP (Alexa flour 594 WGA plasma membrane stain) respectively. Ten Z stacks were taken. Optimal HV (image intensity) and offset was set between range 700-900 and 7-10 respectively such that some blue spots could be seen on the image acquired. The pixel speed and laser intensity was set depending on the imaging speed needed keeping bleaching effects due to the lasers used in mind. See Appendix $C$ for the instructions to use the Olympus FV1000 confocal microscope. 


\subsection{Cytotoxicity assays}

Cytotoxicity assays provides the measurement of the macrophage survival and proliferation when treated with the novel antituberculosis compounds (Nakayama et al., 1997).

\subsubsection{Cell culture}

The non-adherent human promyelocytic leukemic cell lines (HL-60) [ATCC] and the mouse macrophage adherent cell line (J774) [ATCC] were cultured in T-75 cm ${ }^{2}(250 \mathrm{~mL})$ cell culture flasks [Invitrogen]. The medium used for cell culture of both cell lines was RPMI-1640 [invitrogen] supplemented with 10\% FCS [Invitrogen] and pencillin-streptomycin (pencillin 50 units $/ \mathrm{mL}$ and streptomycin $50 \mu \mathrm{g} / \mathrm{mL}$ ) [Invitrogen]. The cell culture was incubated at $37^{\circ} \mathrm{C}$ in a $5 \% \mathrm{CO}_{2}$ in air atmosphere until it reached approximately $80 \%$ confluence. The novel compounds to be tested in triplicate were two-fold serially diluted in plastic 96-well tissue culture plates [BD Biosciences] in such a way that each well contained 50 $\mu \mathrm{L}$ of the drug. This was followed by the addition of $50 \mu \mathrm{L}$ of cells to give a final cell concentration of 10,000 cells per well.

\subsubsection{Cell counting using a haemocytometer}

The cell counting for both HL-60 and J774 was performed by haemocytometer. The adherent $\mathrm{J} 774$ cell line was detached using a cell 63| P a g e 
scrapper (BD biosciences). Hence it involved one additional step of trypan blue staining (0.4\% w/v stock concentration) [Sigma Aldrich] so as to detect cell damage due to mechanical stress of scrapping. Trypan blue ensures the counting of only viable cells and is useful for cytotoxicity assays. Trypan blue is a blue dye that is impermeable to the cell plasma membrane. Hence, the dead cells will be stained blue and living cells will remain unstained. For the cell counting, $10 \mu \mathrm{L}$ of cell suspension was added to $10 \mu \mathrm{L}$ of trypan blue. Then, $10 \mu \mathrm{L}$ of the mix was pipetted onto one side of the haemocytometer.

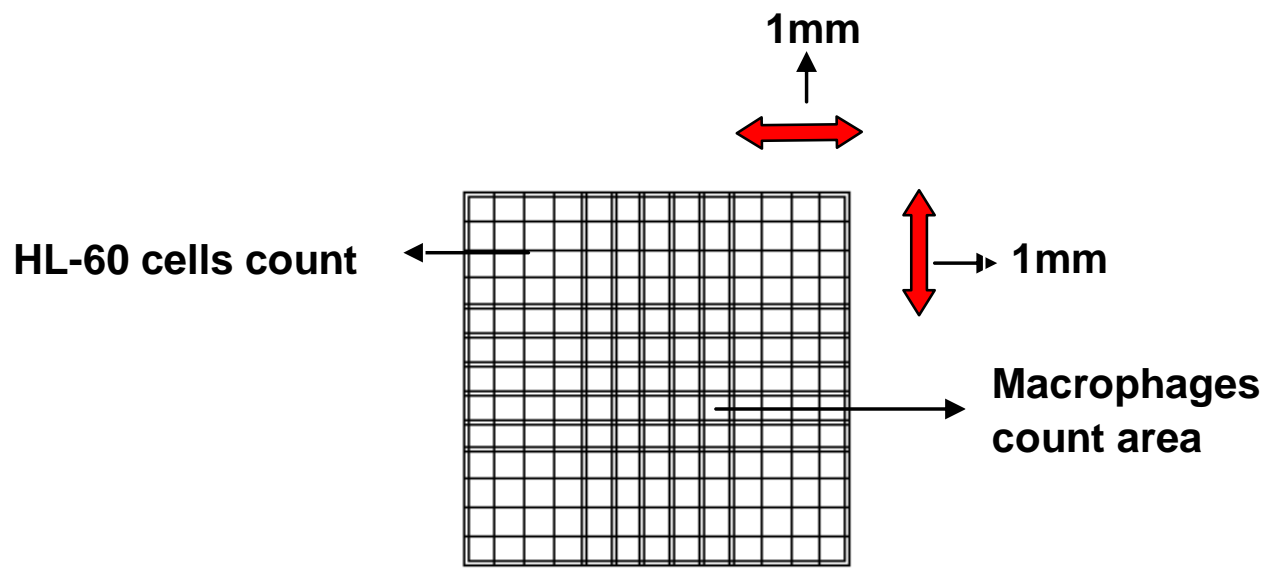

Figure 2.3 Haemocytometer counting chamber.

For HL60 cells The average number of viable cells in the corner 4 squares of the haemocytometer was counted. The volume of the sample under the coverslip is $10 \mu$.

For J774 macrophage cells The average number of viable cells in the centre 25 small squares of the haemocytometer was counted. 
Concentration of $\mathrm{HL}-60$ cells $/ \mathrm{mL}=$ Average number of cells in four corner squares $\mathrm{x}$ dilution factor $\times 10,000$ cells $/ \mathrm{mL}$

Concentration of $\mathrm{J} 774$ cells $/ \mathrm{mL}=$ Average number of cells in the centre 25 squares $\mathrm{x}$ dilution factor $\times 10,000$ cells $/ \mathrm{mL}$

Since the trypan blue was added in a 1:2 ratio, the dilution factor was 2 .

\subsubsection{Cytotoxicity or viability testing}

The average cell count used for the cytotoxicity assay was 10,000 cells/ well. The cells were incubated with 1:2 serially diluted drugs for $48 \mathrm{hrs}$ followed by the addition of Alamar blue [Invitrogen] or 3-(4, 5dimethylthiazol-2-yl)-2, 5-diphenoltetrazolium bromide (MTT) [Sigma] reagents. Both alamar blue and MTT assay were used to test the cytotoxicity of the compounds. The cytotoxic compounds epothilone A (EpoA) [Merck] and mycalamide (Merck) were used as positive controls. A well-known antituberculosis drug with no activity against mammalian cells rifampicin was used as a negative control. All experimental compounds were dissolved in their appropriate solvent (DMSO, water, $\mathrm{CHCl} 3$, ethanol or methanol) and sterilized by passage through $0.22 \mu \mathrm{m}$ pore filtration membranes (Millipore). 


\subsubsection{Alamar blue assay}

Ten $\mu \mathrm{L}$ of Alamar blue (10\% v/v) [Invitrogen] was added to each well after $48 \mathrm{hrs}$ of incubation.

\subsubsection{MTT assay}

Twenty $\mu \mathrm{L}$ of MTT [5 mg/mL in PBS] was added to each well after $48 \mathrm{hrs}$ incubation. The plate was incubated for $2 \mathrm{hrs}$ after addition of MTT followed by addition of $100 \mu \mathrm{L}$ of solubiliser [ $10 \%$ sodium dodecyl sulphate (SDS) in $0.01 \mathrm{~N} \mathrm{HCl]}$. The solubiliser converts insoluble MTT formazan crystals to soluble dye.

The plate was kept in the incubator for $4 \mathrm{hrs}$ after absorbance readings were taken as discussed in section 2.2.4.

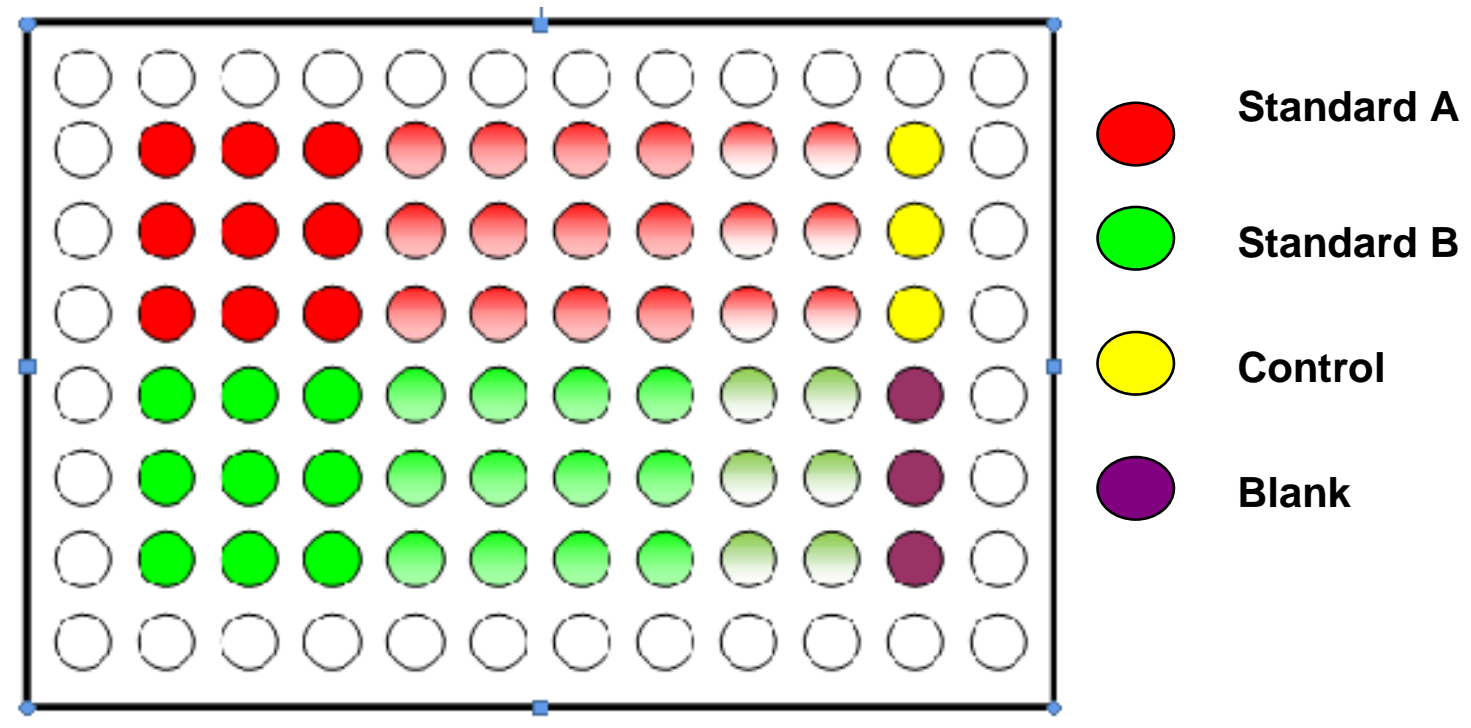

Figure 2.4: Plate layout for the cytotoxicity assays. The standard A and $B$ drugs were 1:2 serially diluted in triplicates from left to right. 


\subsubsection{Comparison of alamar blue and MTT assays}

Alamar blue and MTT assays were compared for the experimental compound diphenyleneidonium chloride against three cell lines such as adherent $\mathrm{J} 774$ macrophage cells and non adherent HL-60 leukaemic cells, and U937 macrophages. U937 is a suspended monocytic macrophage cell line (Wright et al, 1996).

\subsubsection{Data collection and analysis}

The readings obtained from Versamax plate reader (Molecular Dynamics) were taken both colorimetrically at absorbance $570 \mathrm{~nm}$ and fluorometrically at excitation $560 \mathrm{~nm}$ and emission $590 \mathrm{~nm}$ wavelength. The dose response $\mathrm{IC}_{50}$ inhibitory curves were plotted using Sigmaplot ${ }^{\circledR}$ 10.0 software (version 10.0). A simple scatter plot was created using the triplicate data obtained from the plate reader. A log (common) scale was applied to the X-axis which represented the concentrations of the drugs (experimental compounds two-fold serial diluted). A four-parameter logistic curve was used to fit the plotted data, and $I C_{50}$ values for the respective drugs were calculated with standard errors against the cytotoxity assay. Data were normalised in terms of percentage of control. The percentage of control was calculated by expressing experimental drug-treated standard with reference to the non-drug treated negative control. 


\subsection{Mycobacteriostatic assay}

M. smegmatis containing the pLL192 hsp60 plasmid were inoculated into LB supplemented with kanamycin $(50 \mu \mathrm{g} / \mathrm{mL}), 0.1 \%$ Tween 80 and Darabinose $(100 \mu \mathrm{g} / \mathrm{mL})$ to mid-logarithmic phase of optical density (OD) 1.0. The cultures were then diluted to an OD of $0.2\left(8.64 \times 10^{7} \mathrm{CFU} / \mathrm{mL}\right)$ using a $10 \mathrm{~mm}$ path-length glass cuvette at absorbance $600 \mathrm{~nm}$. The perimeter wells were filled with sterile deionised water to prevent evaporation of the media during the 96 hour incubation time. The remaining wells were filled with $50 \mu \mathrm{L}$ LB supplemented with Kan50, $0.1 \%$ Tween 80 and $100 \mu \mathrm{g} / \mathrm{mL}$ D-arabinose. The experimental compounds were tested in duplicate by pipetting $8 \mu \mathrm{L}$ into each test wells of the microtitre plate at a starting concentration of $125 \mu \mathrm{M}$. A two-fold serial dilution was then performed on each test compound starting at the first column of wells, aliquoting $29 \mu \mathrm{L}$ from column 1 into column 2 and so on until column 11 . The $29 \mu \mathrm{L}$ from the last wells of column 11 were again added back to the wells in column 1 . Fifty $\mu \mathrm{L}$ of diluted mycobacterial cell culture was then added to all inner wells $\left(4.3 \times 10^{6} \mathrm{CFU} /\right.$ well) except for the medium control in such a way that the total volume was $100 \mu \mathrm{L}$. In the first column 1 wells, $42 \mu \mathrm{L}$ of mycobacterial cell culture was added. The non drug treated mycobacterial culture was used as negative control showing maximum growth. A standard antituberculosis drug such as rifampicin (Sigma) with a starting concentration of $100 \mu \mathrm{M}$ was used as a positive control. The 96-well plates were then sealed with plateseals (Sigma), glad wrapped and incubated at $37^{\circ} \mathrm{C}$ for 96 hours in a shaker incubator. 
The mycobacteriostatic assays against $M$. bovis and $M$. tuberculosis H37Ra were kindly performed by Mudassar Altaf. The cultures were grown in Middlebrook 7H9 broth supplemented with 10\% OADC (5\% BSA, $2 \%$ dextrose, $0.85 \% \mathrm{NaCl}$ ), $0.5 \%$ glycerol, and $0.05 \%$ Tween 80 to prevent protein denaturation and cell clumping. The $M$. bovis and M. tuberculosis H37Ra cultures were diluted to OD 0.05 using a $10 \mathrm{~mm}$ path-length glass cuvette at absorbance $600 \mathrm{~nm}$. The readings were taken after 14 days for both strains using a Perkin-Elmer Envision platereader. The $\mathrm{IC}_{50}$ values were calculated based on GFP fluorescence and OD for M.bovis and M. tuberculosis H37Ra, respectively. The M.tuberculosis H37Ra strain did not contain any GFP plasmid construct hence the readings based on fluorescence cannot be taken.

\subsubsection{Data collection and analysis}

The GFP fluorescence from drug-treated and untreated mycobacterium wells were measured at 96 hours using an EnVision ${ }^{\circledR} 2102$ multilabel platereader (Perkin Elmer, Inc) with the Wallace EnVision ${ }^{\circledR}$ Manager 1.12 software program (Perkin Elmer, Inc).The GFP signals was detected using a FITC bottom mirror, with excitation and emission wavelengths of $485 \mathrm{~nm}$ and $510 \mathrm{~nm}$, respectively. 25-point scans (5X5) were performed on each well as already discussed in section 2. 1. 9. The dose response $I_{50}$ inhibitory curves were plotted using Sigmaplot ${ }^{\circledR} 10.0$ software (version 10.0). A simple scatter plot was created with the means of the triplicate 
data and its error bars representing the standard errors. A log scale was applied on the $\mathrm{X}$ axis. A four-parameter logistic curve was used to fit the plotted data, and $\mathrm{IC}_{50}$ values for the respective drugs were calculated with standard errors for the mycobacteriostatic assay. Data were normalised by expressing the GFP fluorescence values as a percentage of a non-drug treated mycobacterium (negative control) showing maximum growth.

\subsection{Mycobactericidal assay}

The mycobactericidal assay for $M$. smegmatis containing the pLL192 hsp60 plasmid was kindly performed by Emma Earl. M. smegmatis was inoculated into LB supplemented with kanamycin $(50 \mu \mathrm{g} / \mathrm{mL})$, D- arabinose $(100 \mu \mathrm{g} / \mathrm{mL})$, and Tween-80 $(0.1 \%)$ for 8 days until stationary growth phase was reached. The culture was then diluted to an $\mathrm{OD}_{600}$ of 1.0 with phosphate buffered saline (PBS) using a 10mm length glass cuvette. The whole experimental design was similar to the mycobacteriostatic assay as already described in section 2.3 except the fact that PBS was used instead of LB. After 96 hours of drug treatment, $30 \mu \mathrm{L}$ of resazurin dye $(0.02 \% \mathrm{w} / \mathrm{v})$ was added to each wells. The GFP plate reading was taken fluorometrically using a FITC bottom mirror, at excitation wavelengths of $530 \mathrm{~nm}$ and emission wavelength of $590 \mathrm{~nm}$ as already discussed using EnVision ${ }^{\circledR} 2102$ multilabel platereader. Twenty five point scans $(5 \times 5)$ were performed while taking the readings. Data were normalised in terms of percentage of control and the dose response $\mathrm{IC}_{50}$ inhibitory curves were 
plotted using Sigmaplot ${ }^{\circledR} 10.0$ software (version 10.0) as already discussed in section 2. 1.9. 


\begin{tabular}{|l|c|c|}
\hline \multicolumn{1}{|c|}{ LOPAC compounds } & IC $_{50}(\boldsymbol{\mu M})$ LB & MIC $(\boldsymbol{\mu M})$ LB \\
\hline Bay 11-7085 & $30.60+/-0.59$ & 50 \\
\hline Calcimycin & $1.04+/-0.24$ & 3.125 \\
\hline 4-Chloromercuribenzoic acid & $7.65+/-0.17$ & 25 \\
\hline Clotrimazole & $6.54+/-0.77$ & 12.5 \\
\hline Demeclocycline & $1.88+/-0.24$ & 3.125 \\
\hline Dequalinium analog C-14 & $3.95+/-0.55$ & 6.25 \\
\hline Diphenyleneiodonium & $6.77+/-0.43$ & 6.25 \\
\hline Doxycycline & $0.76+/-0.05$ & 1.56 \\
\hline Idarubicin & $3.61+/-2.01$ & 12.5 \\
\hline Lomefloxacin & $4.33+/-0.10$ & 12.5 \\
\hline LY-367265 & $25.11+/-6.96$ & 50 \\
\hline Methoctramine & $15.90+/-1.98$ & 12.5 \\
\hline Minocycline & $6.77+/-1.12$ & 12.5 \\
\hline Niclosamide & $6.85+/-0.72$ & 12.5 \\
\hline Ofloxacin & $2.03+/-0.65$ & 3.125 \\
\hline 1, 10 Phenanthroline & $41.64+/-0.31$ & 50 \\
\hline Se-methylselenocysteine & $>50$ & $>50$ \\
\hline Trifluoperazine & $12.26+/-0.06$ & 50 \\
\hline WB64 & $8.15+/-1.37$ & 50 \\
\hline
\end{tabular}

Table 2.1: Validated in vitro hits from LOPAC synthetic library that was used in mini library construction. All compounds were dispensed in DMSO at $5 \%$ starting concentration (Miller et al., 2009). 


\section{Chapter 3}

\section{Development of the intra- macrophage infection assay}




\section{Chapter 3}

\section{Development and validation of the intra-macrophage infection assay}

\subsection{Introduction}

There is a growing need of research in the field of TB drug discovery as already discussed in the previous sections. The discovery of novel drugs against TB has gained substantial momentum during the past years because of the high rate of late drug candidate failure during clinical trials. Hence, to avoid such problems it is very important to have a prior knowledge about the candidate drug efficacy inside the human cells.

The primary site of infection for TB is alveolar macrophages. Hence, to evaluate the drug efficacy, a whole cell based intra-macrophage infection assay will be developed in this project (Christophe et al., 2009). The intramacrophage mycobacterium viability will be measured by the use of GFP based reporter marker. The intrinsic fluorescent nature of GFP protein helps to avoid the need for addition of enzyme substrates and lysing of cells, hence, making the assay simple, less expensive, easier for kinetic studies and is also associated with good biosafety features (Collins et al., 1998). The lab workers in many clinical, research, and industrial production companies are exposed to many occupational health risks due to their work 
with infectious materials and cultures. Good biosafety measures are the practices undertaken so as to avoid such biological hazards.

\subsection{Results}

In the present experimental set-up, the J774 macrophage cell line was infected with single-cell suspensions of $M$. smegmatis.

3.2.1 Infection of the J774 macrophage cell line with $M$. smegmatis cell suspension

The J774 macrophage cell lines were seeded at a concentration of $10^{5}$ cells/ well as described in section 2.1.1. These macrophages were infected with M. smegmatis cells at a $\mathrm{MOI}$ of $10: 1$ as described in section 2.1.2 and 2.1.3. The $M$. smegmatis cell suspension were examined for clumping using a 100X (oil-immersion) objective lens in an Olympus provis AX 70TRF flourescent microscope with the FITC filter.

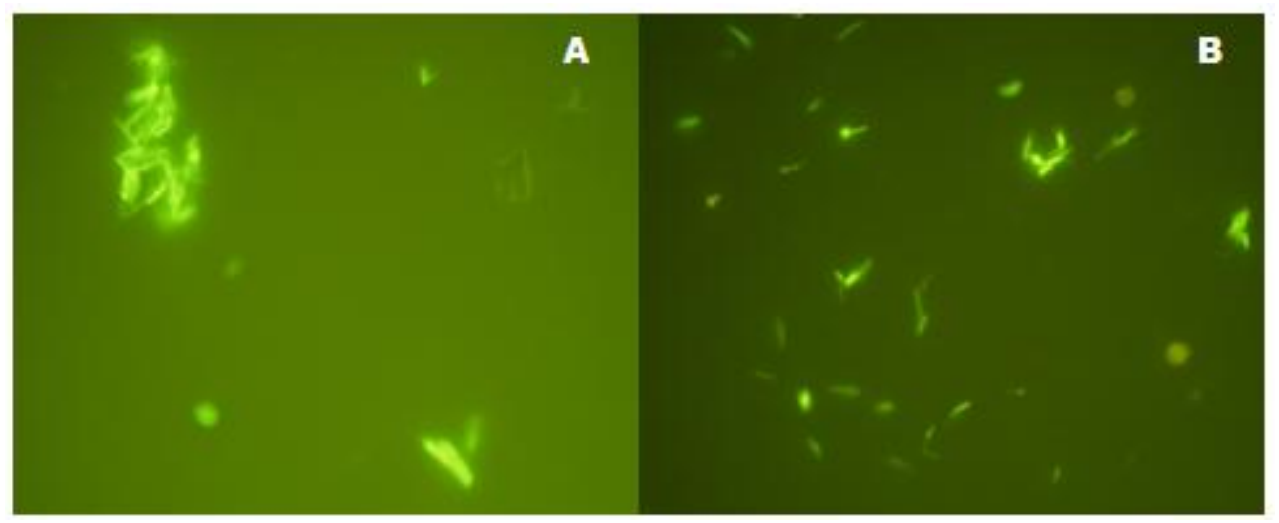

Figure 3.1: (A) Clumped M. smegmatis in the overnight subinoculated culture. (B) M. smegmatis single cell suspension after dispersion. 


\begin{tabular}{|ccc|}
\hline Dilution factor & Amount plated $(\mathbf{m L})$ & $\begin{array}{c}\text { Number of colonies } \\
\text { (Average of } \\
\text { triplicates) }\end{array}$ \\
\hline $10^{-5}$ & 0.1 & 99.33 \\
$10^{-6}$ & 0.1 & 10.67 \\
$10^{-7}$ & 0.1 & 1.66 \\
\hline
\end{tabular}

Table 3.1: Colony forming units of overnight sub inoculated $M$. smegmatis culture of OD 1.

The MOI of the single cell suspension used for the macrophage infection was calculated using colony forming unit (cfu) method as already described in section 2.1.5. Table 3.1 illustrates the results from colony forming units. The colony forming units was calculated by the following formula.

Colony forming units $(\mathbf{c f u})=\quad$ Number of colonies

$0.1 \mathrm{ml}$ plated * Number of dilution

The colony forming units were calculated as: $1.24 * 10^{8} \mathrm{cfu} / \mathrm{mL}$.

Ten microlitres of the single cell suspension with $1.24 \times 10^{8} \mathrm{cfu} / \mathrm{mL}$ was used to infect the $\mathrm{J} 774$ macrophages at cell density of $1 \times 10^{5}$ cells/ well in order to achieve an $\mathrm{MOI}$ of 10:1. Ten $\mu \mathrm{L}$ of mycobacterial cell suspension is considered a negligible volume compared to the total J774 macrophage cell volume in the well of $100 \mu \mathrm{L}$. 


\subsubsection{Development of the low throughput intra-macrophage infection assay against standard antituberculosis drugs}

The intra-macrophage infection assay against the known antituberculosis drugs was implemented as already described in section 2.1.6. Table 3.2 depicts a comparison of the intra-macrophage (in vivo) $\mathrm{IC}_{50}(\mu \mathrm{M})$ with the in vitro $\mathrm{IC}_{50}(\mu \mathrm{M})$ and minimum inhibitory concentration $(\mathrm{MIC})(\mu \mathrm{M})$ values for standard antituberculosis drugs against $M$. smegmatis. Representative dose response curves for the antituberculosis drugs tested in the intra macrophage assay are presented in Fig 3.2. The $\mathrm{IC}_{50}$ curves were normalised to the control. The percentage of control was calculated by expressing the change in the GFP fluorescence values in experimental drug-treated, infected macrophages (positive control) with reference to the non-drug treated, but infected macrophage GFP flourescence (negative control) between 96 and 0 hours. The in vitro $\mathrm{IC}_{50}$ that are simply a measure of direct bactericidal activity and MIC values against $M$. smegmatis were kindly provided by Christopher $\mathrm{H}$ Miller. 


\begin{tabular}{|cccc|}
\hline $\begin{array}{c}\text { Antituberculosis } \\
\text { drugs }\end{array}$ & in vivo $\mathrm{IC}_{50}(\boldsymbol{\mu M})$ & in vitro $\mathrm{IC}_{50}(\boldsymbol{\mu M})$ & MIC $(\boldsymbol{\mu M})$ \\
$\begin{array}{c}\text { Rifampicin } \\
\text { Ciprofloxacin }\end{array}$ & $2.40 \pm 0.85$ & $3.11 \pm 0.51$ & 6.25 \\
Capreomycin & $1.75 \pm 0.88$ & $1.78 \pm 0.71$ & 12.5 \\
Ethambutol & $14.97 \pm 11.7$ & $3.20 \pm 0.13$ & 12.5 \\
& & & 12.5 \\
\hline
\end{tabular}

Table 3.2: Comparison of in vitro and in vivo $\mathrm{IC}_{50}$ for standard antituberculosis drugs growth conditions. 
Rifampicin (IC50 - $2.4021+/-0.8524 \mu \mathrm{M})$

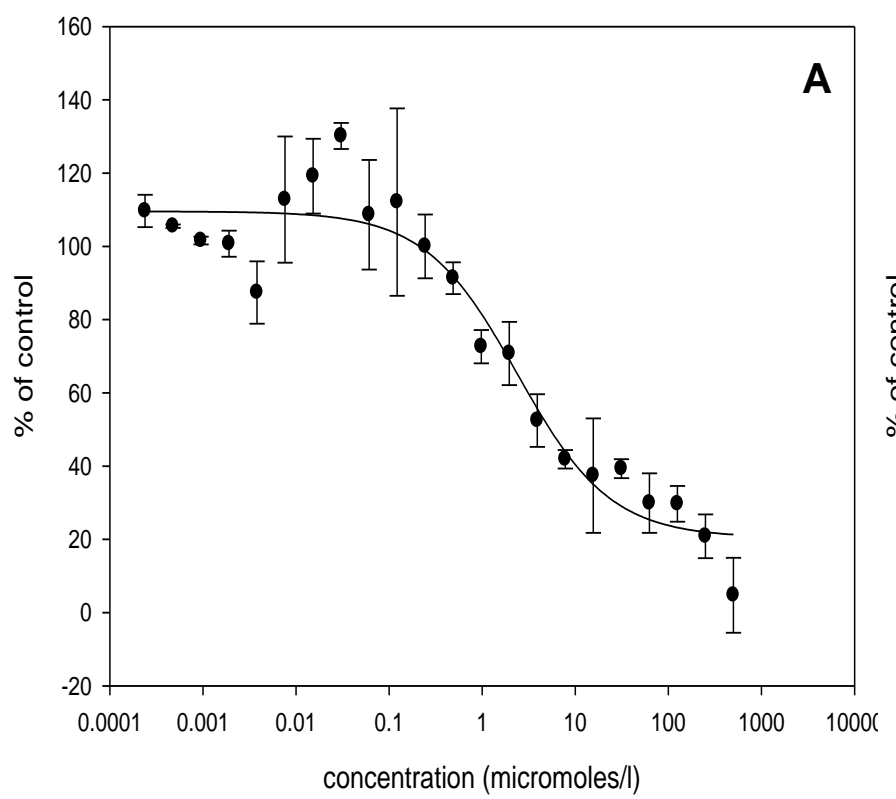

Capreomycin (IC50 - $1.7465+/-0.8779 \mu \mathrm{M})$

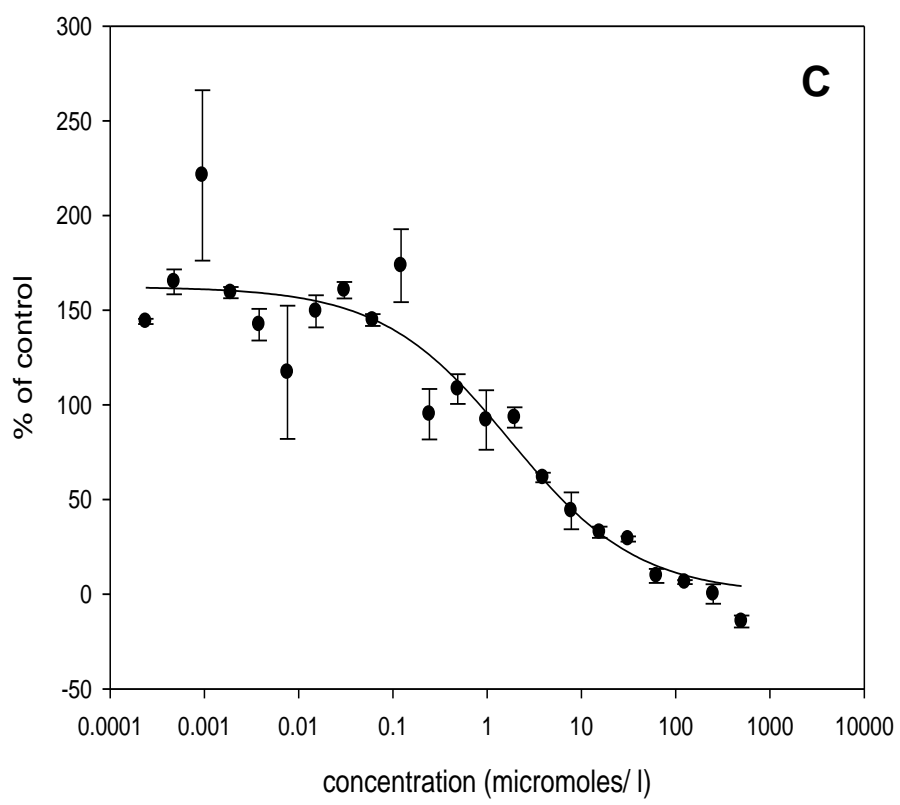

Ciprofloxacin (IC50 - $2.5967+/-0.5533 \mu \mathrm{M})$

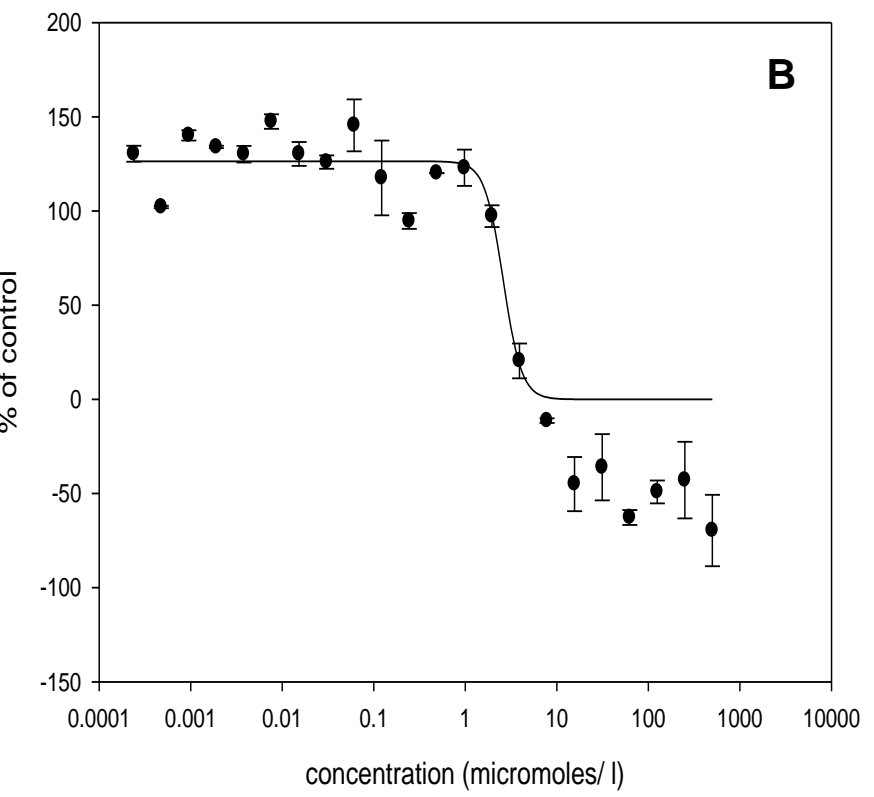

Ethambutol (IC50 - $14.9768+/-11.7093 \mu \mathrm{M})$

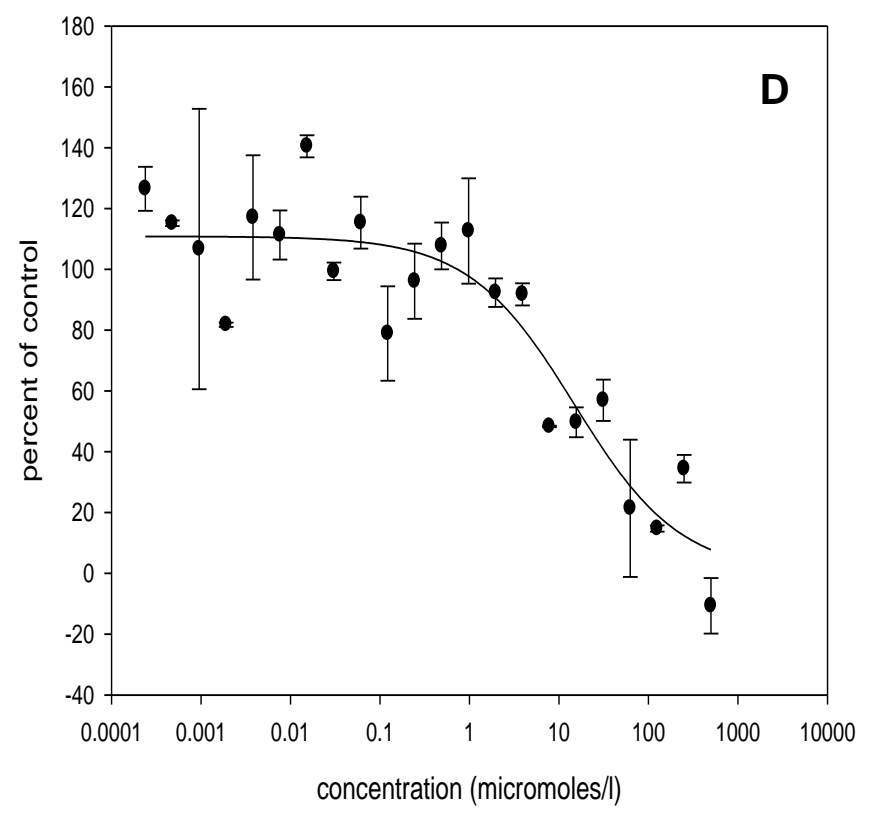

Figure 3.2: Representative dose response $I_{50}$ curves for the standard antituberculosis drugs. 


\subsubsection{Image acquisition using Olympus FV1000 confocal microscope}

Olympus FV1000 confocal microscope was used to acquire image-iT stained GFP-labelled mycobacterium-infected $\mathrm{J} 774$ macrophages as described in (Appendix B ). Figure 3.3 shows the image-iT stained infected macrophages images acquired using an Olympus FV1000 confocal microscope.

It was decided to use this image-iT staining method for further validation by Opera high-throughput confocal microscope as this would help to prove that the GFP signal obtained from the plate reader was specifically coming from inside the macrophages and not from any contaminating extracellular bacteria. It would also help in backing up the readings obtained from the plate reader by using an Image $\mathrm{J}$ script to analyse the opera images. The estimation of the number of macrophages, average number of bacteria per macrophage, average/total/percentage of area of macrophages, average/total/percentage area occupied by bacteria per macrophage, sum of macrophage and bacterial spot intensity per macrophage and estimation of the contribution of bacterial area colocalized with the other colour channel could also be done using the Opera image analysis programmes. 


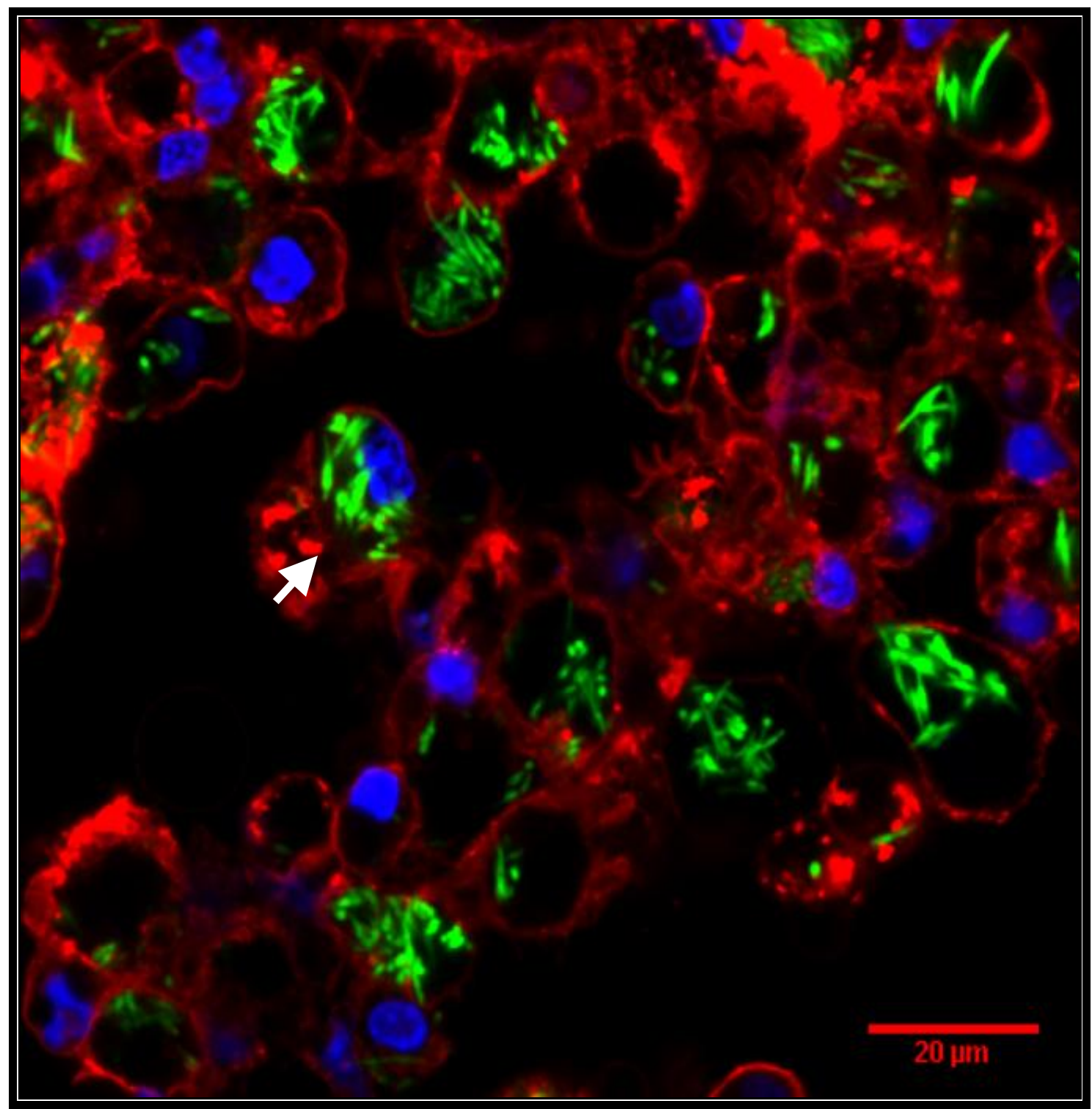

Figure 3.3: Montage of the image acquired by Olympus FV1000 confocal microscope. In this image red is macrophage (Alexa flour stained - RFP) blue is nucleus (DAPI stained) and green is mycobacterium (GFP labeled). The white arrow shows the GFP is coming from mycobacterium inside the macrophages. 


\subsubsection{Development of the mini high throughput demo library model} as a preliminary step for synthetic library screening

A mini high-throughput demo library was prepared using compounds from the LOPAC library that had already been detected and validated previously in in vitro chemical library screens against $M$. smegmatis. The entire test compounds used in this mini library demomodel was dissolved in DMSO, and hence, it will be also important to check the effect of this solvent on macrophage or mycobacterium viability. The in-vtiro $\mathrm{IC}_{50}$ value for DMSO against in mycobacterium was found to be $5 \%$ (Miller et al., 2009). This demo library development was a preliminary step before actual synthetic library screening was performed. The complete list of the compounds used for mini library preparation is given in Table 2.1 along with their in vitro $\mathrm{IC}_{50} \mathrm{~S}$ and MICs against M.smegmatis. Figure 3.4 shows a schematic representation of the procedures followed in the development and validation of the mini-high-throughput demo library screening.

The assay was performed in 96-wp format as previously described in section 2.7.1. The mini high-throughput demo library model was successfully developed but required many major experimental adjustments so as to produce useable data. The percent of control readings in terms of GFP fluorescence, obtained from the Perkin Elmer plate reader using the Wallace EnVision ${ }^{\circledR}$ Manager 1.12 software program (Perkin Elmer, Inc), were validated by the readings obtained from the Opera high-throughput confocal microscope images. 
J774 macrophage cells were seeded at a cell density of $10^{5}$ cells/ well.

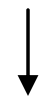

Infect macrophages with Mycobacterium smegmatis at MOI 10:1. Removal of the extracellular mycobacterium by washes.

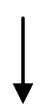

The minilibrary compound stocks were made at concentration: $200 \mu \mathrm{M}$

Dispensing the drugs into the RPMI media so that the working stock concentration: $20 \mu \mathrm{M}$

Treatment of the infected macrophages with the experimental minilibrary drugs at stock concentration: $20 \mu \mathrm{M}$. Incubation time was 96 hours.

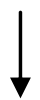

GFP readings were taken at $0 \mathrm{hrs}$ and $96 \mathrm{hrs}$. Percent of control were calculated.

Staining was carried by image-iT live cell staining kit.

Cytotoxity test after 96 hrs - Alamar blue

Images were acquired using opera high throughput confocal microscope.

Analysis of the images to quantify the mycobacterium survival using Image J software.

Figure 3.4: Schematic representation of the mini high throughput infection model 
Table 3.3: Results for the mini high throughput demo library model screening.

\begin{tabular}{|c|c|c|c|c|c|c|}
\hline \multirow{2}{*}{$\begin{array}{l}\text { Name of the compound } \\
\text { Bay 11-7085 }\end{array}$} & \multicolumn{3}{|c|}{$\begin{array}{l}\text { Triplicate readings from } 3 \\
\text { independent minilibrary screening }\end{array}$} & \multirow{2}{*}{$\begin{array}{l}\text { Activity of } \\
\text { the } \\
\text { compound } \\
(-) \text { ve }\end{array}$} & \multirow{2}{*}{$\begin{array}{l}\text { Cytotoxicity } \\
(-) \text { ve }\end{array}$} & \multirow{2}{*}{$\begin{array}{l}\text { Known action } \\
\begin{array}{l}\text { Inhibits cytokine induced lkB (Inhibitor of NFkB) } \\
\text { phosphorylation. }\end{array}\end{array}$} \\
\hline & 71.08 & 62.19 & 114.17 & & & \\
\hline Calcimycin & 7.09 & -47.65 & -37.88 & $(+)$ ve & $(+)$ ve & $\begin{array}{l}\text { Ca2+ ionophore used to potentiate responses to } \\
\text { NMDA, but not quisqualate glutamate receptors. }\end{array}$ \\
\hline Calmidazolium chloride & 58.55 & 71.93 & 50.55 & $(-)$ ve & $(-)$ ve & $\begin{array}{l}\text { Potent inhibitor of calmodulin activation of } \\
\text { phosphodiesterase; strongly inhibits calmodulin- } \\
\text { dependent Ca2+-ATPase. }\end{array}$ \\
\hline Lomifloxacin & -79.79 & -55.19 & -50.7 & $(+)$ ve & $(-)$ ve & DNA gyrase inhibitor. \\
\hline Clotrimazole & 46.73 & 79.54 & 32.04 & $(-)$ ve & $(+)$ ve & Specific inhibitor of $\mathrm{Ca} 2+-$ activated $\mathrm{K}+$ channels. \\
\hline Demeclocycline & -14.14 & -50.10 & -67.64 & $(+)$ ve & $(+)$ ve & $\begin{array}{l}\text { Tetracycline antibiotic; interferes with protein } \\
\text { synthesis. }\end{array}$ \\
\hline $\begin{array}{l}\text { Dequalinium analog } \mathrm{C}- \\
14\end{array}$ & 5.01 & 22.57 & 39.36 & $(-)$ ve & $(+)$ ve & $\begin{array}{l}\text { Selective blocker of apamin-sensitive } \mathrm{K}+ \\
\text { channels. }\end{array}$ \\
\hline Diphenyleneiodonium & -141.06 & -298.62 & -286.44 & $(+)$ ve & $(+)$ ve & Endothelial nitric oxide synthase inhibitor. \\
\hline $\begin{array}{l}\text { Doxycycline } \\
\text { hydrochloride }\end{array}$ & -140.8 & -44.52 & -11.33 & $(+)$ ve & $(-)$ ve & $\begin{array}{l}\text { 6-deoxytetracycline antibiotic; interferes with } \\
\text { protein synthesis. }\end{array}$ \\
\hline
\end{tabular}




\begin{tabular}{|c|c|c|c|c|c|c|}
\hline $\begin{array}{l}\text { Name of the } \\
\text { Compound }\end{array}$ & \multicolumn{3}{|c|}{$\begin{array}{c}\text { Triplicate readings from } 3 \\
\text { independent minilibrary screening }\end{array}$} & \multirow{2}{*}{$\begin{array}{l}\text { Activity of } \\
\text { the } \\
\text { compound } \\
\text { (-) ve }\end{array}$} & \multirow{2}{*}{$\begin{array}{l}\text { Cytotoxicity } \\
(+) \text { ve }\end{array}$} & \multirow[b]{2}{*}{$\begin{array}{l}\text { Inhibits serotonin reuptake; } 5-\mathrm{HT} 2 \mathrm{~A} \text { serotonin } \\
\text { receptor antagonist. }\end{array}$} \\
\hline Ly-367, 265 & 75.12 & 27.67 & 67.41 & & & \\
\hline Luteolin & 14.96 & 10.08 & 22.98 & $(+)$ ve & $(+)$ ve & \\
\hline Methoctramine & 90.95 & 84.81 & 71.51 & $(-)$ ve & $(+)$ ve & $\begin{array}{l}\text { Selective M2 muscarinic acetylcholine receptor } \\
\text { antagonist. }\end{array}$ \\
\hline Minocycline & -16.2 & -42.45 & -89.18 & $(+)$ ve & $(+)$ ve & $\begin{array}{l}\text { Basement membrane protease inhibitor; inhibits } \\
\text { endothelial cell proliferation and angiogenesis. }\end{array}$ \\
\hline Niclosamide & 44.37 & 82.85 & 69.26 & $(-)$ ve & $(+)$ ve & $\begin{array}{l}\text { Protonophoric anthelmintic; uncouples oxidative } \\
\text { phosphorylation. }\end{array}$ \\
\hline Nilutamide & 71.86 & 36.75 & 37.31 & $(-)$ ve & $(-)$ ve & Antiandrogen. \\
\hline $\begin{array}{l}\text { N-Methyl-beta-carboline- } \\
\text { 3-carboxamide }\end{array}$ & 65.25 & 38.70 & 48.59 & $(-)$ ve & $(-)$ ve & GABA-A receptor antagonist. \\
\hline Ofloxacin & -20.39 & -10.32 & -19.17 & $(+)$ ve & $(-)$ ve & $\begin{array}{l}\text { Fluorinated quinolone antibacterial; interferes with } \\
\text { DNA synthesis. }\end{array}$ \\
\hline 1, 10 Phenanthroline & 20.08 & 7.05 & 31.32 & $(+)$ ve & $(-)$ ve & $\begin{array}{l}\text { Metalloprotease inhibitor; chelates iron, zinc and } \\
\text { other divalent metals. }\end{array}$ \\
\hline Droperidol & 91.67 & 61.11 & 74.65 & $(-)$ ve & $(+)$ ve & D1, D2 dopamine receptor antagonist. \\
\hline Idarubicin & -65.01 & -72.08 & -127.28 & $(+)$ ve & $(+)$ ve & Antineoplastic. \\
\hline
\end{tabular}




\begin{tabular}{|c|c|c|c|c|c|c|}
\hline $\begin{array}{l}\text { Name of the } \\
\text { Compounds }\end{array}$ & $\begin{array}{r}\text { Trip } \\
\text { indepen }\end{array}$ & $\begin{array}{l}\text { ate readi } \\
\text { nt minilik }\end{array}$ & $\begin{array}{l}\text { from } 3 \\
\text { screening }\end{array}$ & $\begin{array}{l}\text { Activity of } \\
\text { the } \\
\text { compound }\end{array}$ & Cytotoxicity & Known action \\
\hline Trifluoperazine & 15.73 & 4.54 & 4.89 & $(+)$ ve & $(+)$ ve & $\begin{array}{l}\text { Calmodulin antagonist; dopamine receptor } \\
\text { antagonist; antipsychotic; sedative. }\end{array}$ \\
\hline WB-64 & 98.88 & 59.25 & 40.07 & $(-)$ ve & $(-)$ ve & $\begin{array}{l}\text { Ligand for the allosteric site of the M2 muscarinic } \\
\text { acetylcholine receptor. }\end{array}$ \\
\hline Zinocycline & -114.45 & -163.54 & -71.07 & $(+)$ ve & $(-)$ ve & nil \\
\hline Indatraline & 3.96 & 22.64 & -3.12 & $(+)$ ve & $(+)$ ve & $\begin{array}{l}\text { Potent inhibitor of dopamine, norepinephrine and } \\
\text { serotonin reuptake. }\end{array}$ \\
\hline Sanguinarine & 12.17 & 11.3 & -18.78 & $(+)$ ve & $(+)$ ve & $\begin{array}{l}\text { Inhibitor of } \mathrm{Mg} 2+\text { and } \mathrm{Na}+/ \mathrm{K}+-\mathrm{ATPase} \text {; isolated } \\
\text { from the leaves and stems of Macleaya cordata } \\
\text { and microcarpa. }\end{array}$ \\
\hline $\begin{array}{l}\text { Se- } \\
\text { methylselenocysteine }\end{array}$ & 107.38 & 74.87 & 76.23 & $(-)$ ve & $(-)$ ve & Potent chemopreventive agent. \\
\hline Resveratrol & 64.13 & 48.64 & 16.67 & $(-)$ ve & $(-)$ ve & $\begin{array}{l}\text { Prevents apoptosis in K562 cells by inhibiting } \\
\text { lipoxygenase and cyclooxygenase activity. }\end{array}$ \\
\hline Rilmenidine & 141.90 & 141.25 & 55.61 & $(-)$ ve & $(-)$ ve & Selective 11 imidazoline receptor agonist. \\
\hline Rifampicin & -122.70 & -134.81 & -176.41 & $(+)$ ve & $(-)$ ve & Positive control \\
\hline Capreomycin & -75.63 & -69.91 & -92.15 & $(+)$ ve & $(-)$ ve & Positive control \\
\hline
\end{tabular}


The minilibrary consisted of 28 LOPAC hits previously reported in the in vitro chemical library screens out of which 16 showed $75 \%$ mycobacterium growth inhibition inside the macrophages against intramacrophage screen. The hit rate (14 hits obtained / 28 total number of well screened) for the mini library high throughput screen is calculated as $50 \%$. The Alamar blue reagent was added to the above experiment after 96 hours in order to confirm the cell viability, and it was found that among 14 active compounds, 9 were cytotoxic showing more than $25 \%$ loss in cell viability. Hence the false positive hit rate is calculated as $32.14 \%$ (that is 9 cytotoxic positive hits / 28 total number of well screened).

Therefore, 5 compounds were shortlisted for the low-throughput in vivo macrophage assay set-up: ofloxacin, Iomifloxacin, zinocycline, 1,10phenanthroline and luteolin. Table 3.4 shows a comparison of the in vivo $\mathrm{IC}_{50}$ with that of the in vitro $\mathrm{IC}_{50}$ and $\mathrm{MIC}$ values against $M$. smegmatis.

\begin{tabular}{|llll|}
\hline $\begin{array}{l}\text { Confirmed hits from } \\
\text { minilibrary }\end{array}$ & in vivo $\mathbf{I C}_{50}(\boldsymbol{\mu M})$ & in vitro $\mathbf{I C}_{50}(\boldsymbol{\mu M})$ & $\mathbf{M I C}(\boldsymbol{\mu M})$ \\
Lomifloxacin & $11.13 \pm 1.27$ & $4.33 \pm 0.10$ & 12.5 \\
Ofloxacin & $2.62 \pm 0.38$ & $2.03 \pm 0.65$ & 3.125 \\
1,10 Phenanthroline & $7.45 \pm 0.79$ & $41.64 \pm 0.31$ & 50 \\
Zinocycline & $0.16 \pm 0.06$ & $\mathrm{NA}$ & $\mathrm{NA}$ \\
\hline
\end{tabular}

Table 3.4: Comparison of $\mathrm{IC}_{50} \mathrm{~S}$ of the intra- macrophage minilibrary hits against in vitro IC50s and its MICs. 


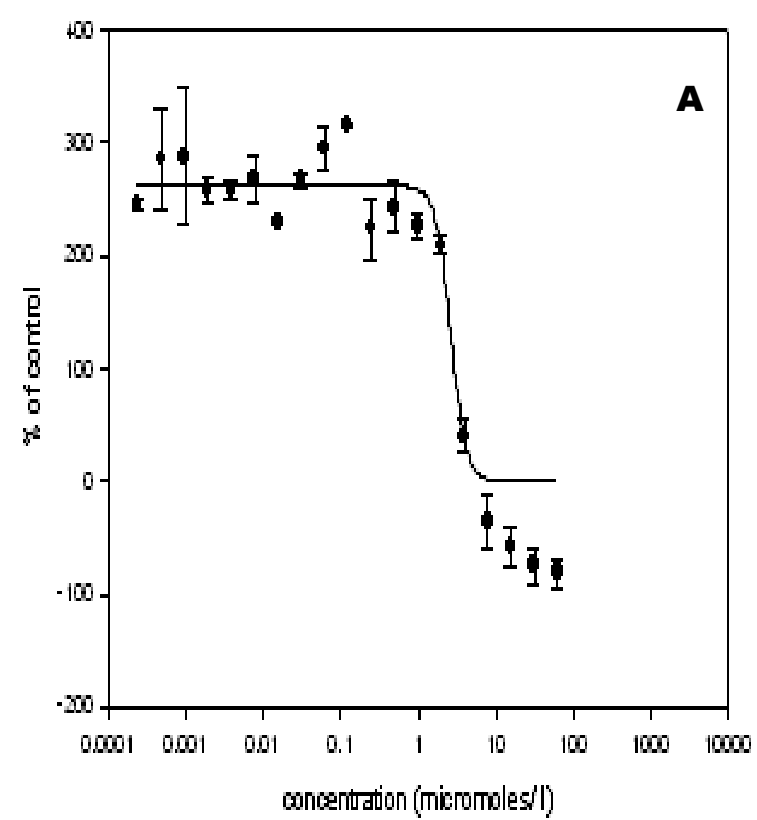

Lomifloxadin (CSD - $11.1265+k-1.2710$ micromolesl)

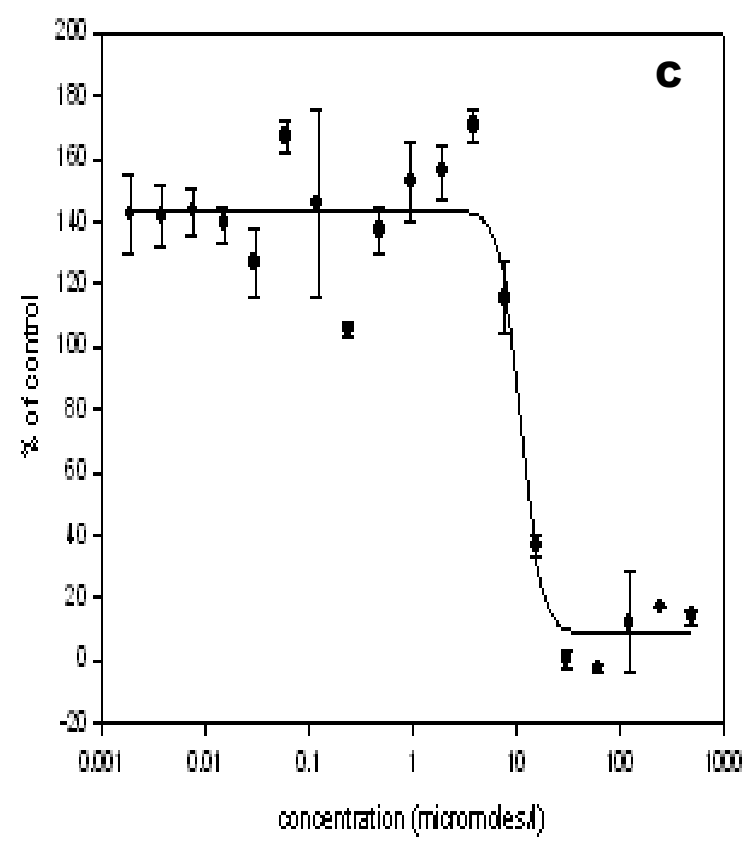

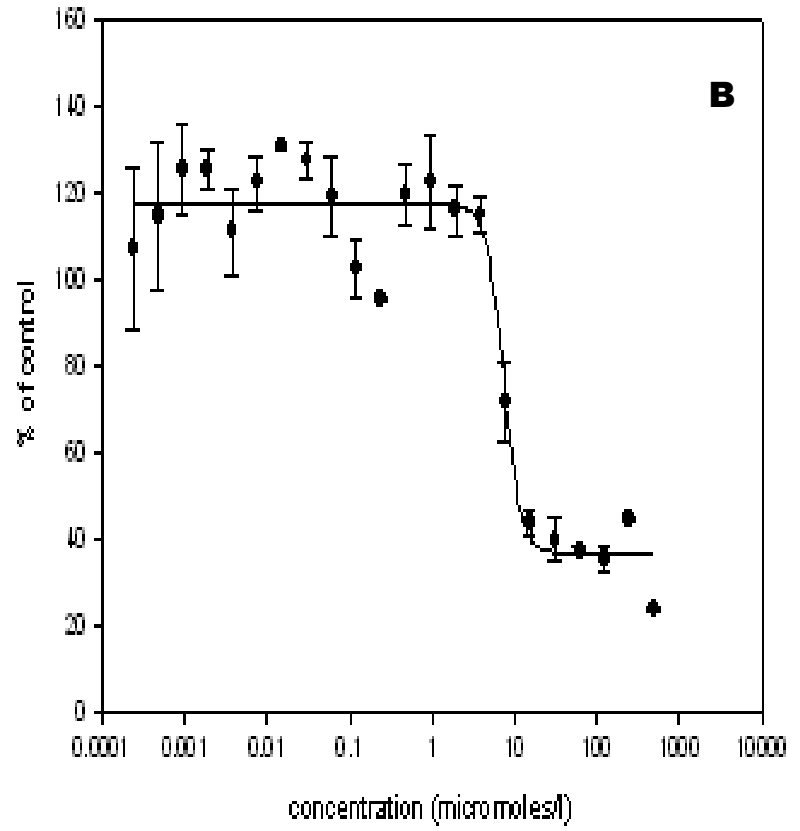

Zinocydine (IC50 - $0.1620+$ - -0.0626 micromoles/)

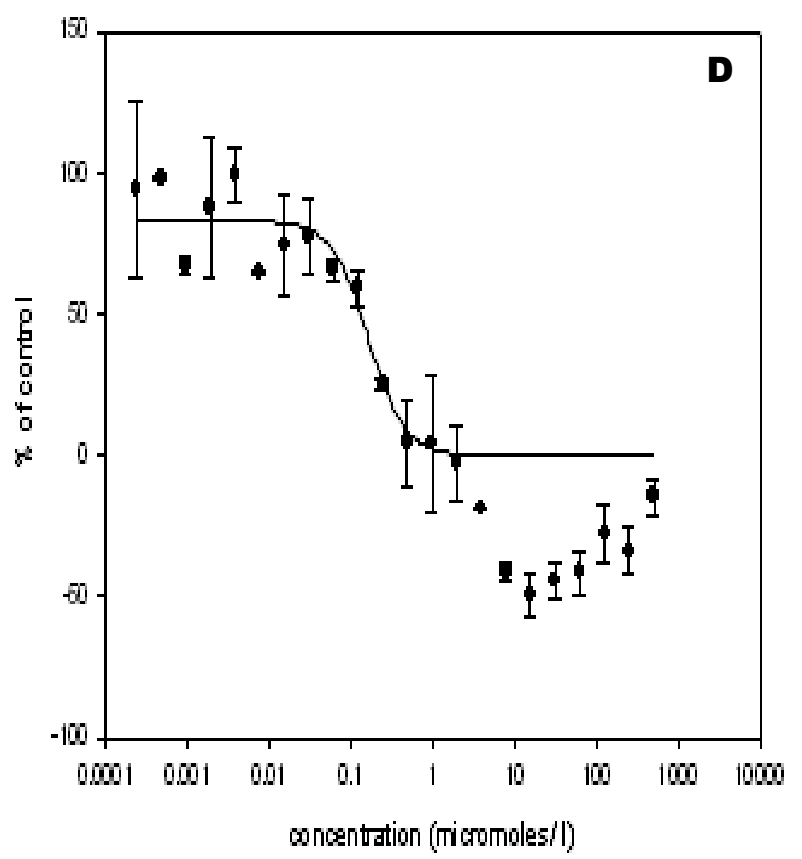

Figure 3.5: Representative dose response $I_{50}$ curves for the minilibrary demo model hits. 


\subsubsection{Validation of the mini high throughput demo model using opera high throughput confocal microscope}

The images from the Opera high-throughput confocal microscope were used for validation purposes. Opera was used to prove that the GFP signals detected by the plate reader were coming from the intracellular mycobacterium and not from any mycobacterium outside the macrophages. The ratio of the GFP fluorescence area to the total area was calculated so as to accurately quantify the mycobacterial growth in each well. As shown in Figure 3.6, in the non-drug-treated infected macrophage wells, the ratio of the GFP fluorescence area to total area was calculated as 9071.83 . The ratio of the GFP fluorescent area to total area from the wells containing macrophages that were treated with the known antituberculosis drug rifampicin and zinocycline (positive hit detected from minilibrary screening) were 2448.033 and 3792.10 respectively. This was followed by the comparison of the ratio of mean GFP to mean RFP among rifampicin, zinocycline and non drug treated infected macrophages that were obtained as $2.118,4.95$ and 21.06 respectively. At last the percent of control were calculated as:

\footnotetext{
Percent of control $=$ Mean GFP/ Mean RFP of the hit ${ }^{*} 100$ Mean GFP/ Mean RFP of the non drug treated infected macrophages
} 


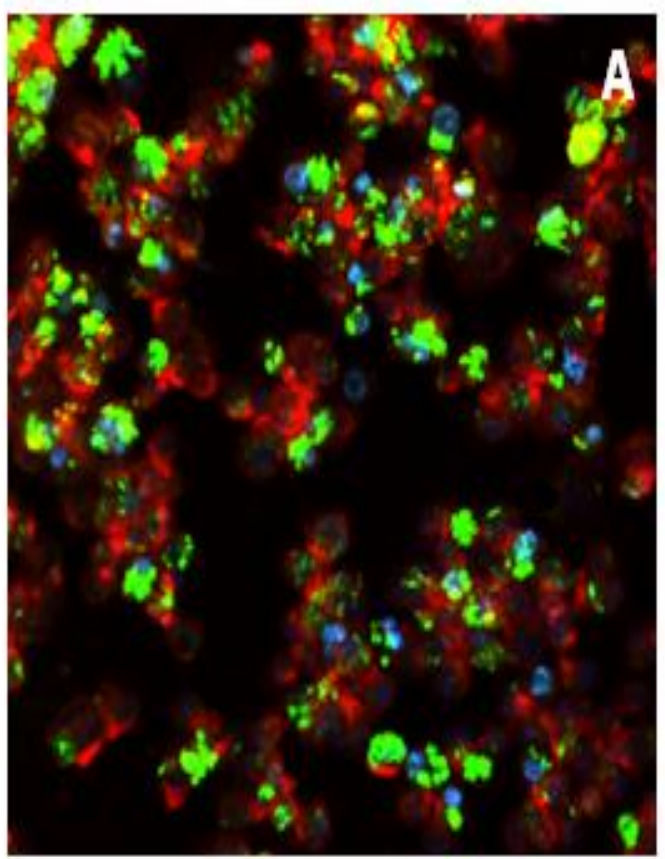

Integrated density GFP/Area $=69525140 / 28400.41=2448033$ Mean GFP $/$ Mean RFP $=2448.033 / 1156.076=2.1175$ Percent of control $=2.1175 / 21.06 \times 100=10.06 \%$

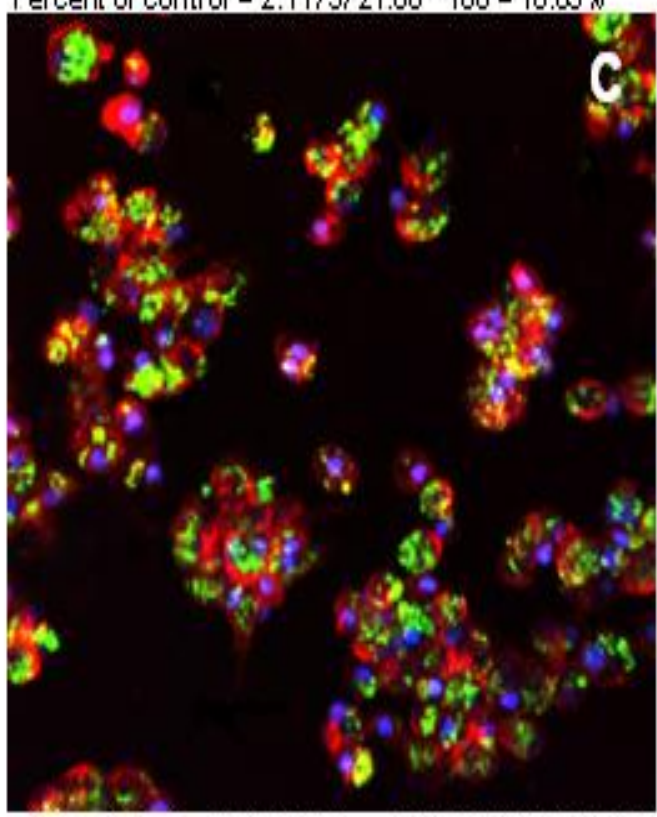

Integrated density GFP/ Area= $93321507 / 24609.43=3792.10$ Mean GFP/ Mean RFP $=3792.10 / 766.46=4.95$

Percent of control $=4.95 / 21.06^{*} 100=23.50 \%$

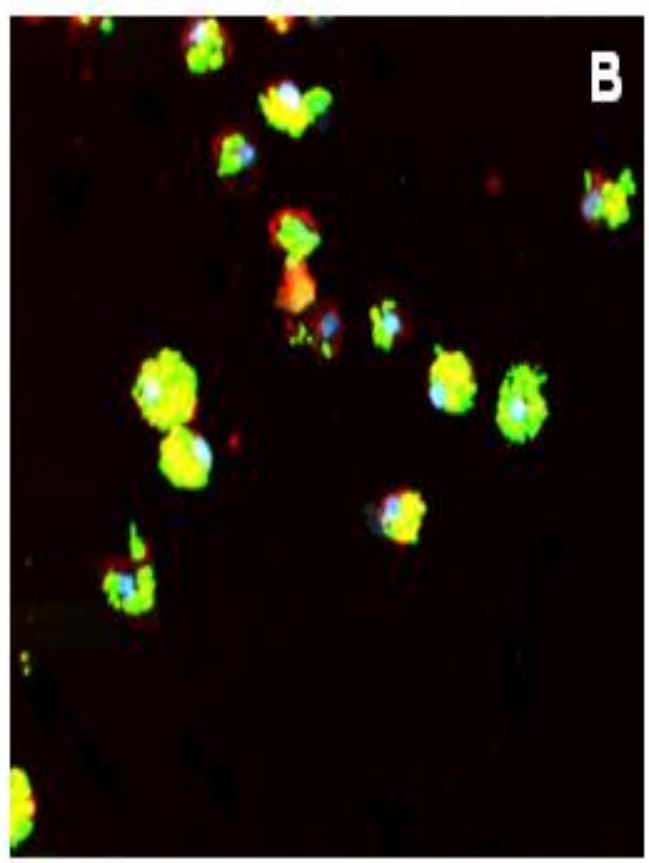

Integrated density GFP/ Area $=62423998 / 6881.08=9071.83$ Mean GFP $/$ Mean RFP $=9071.83 / 43082=21.06$ Percent of control $=21.06 / 21060^{*} 100=100 \%$

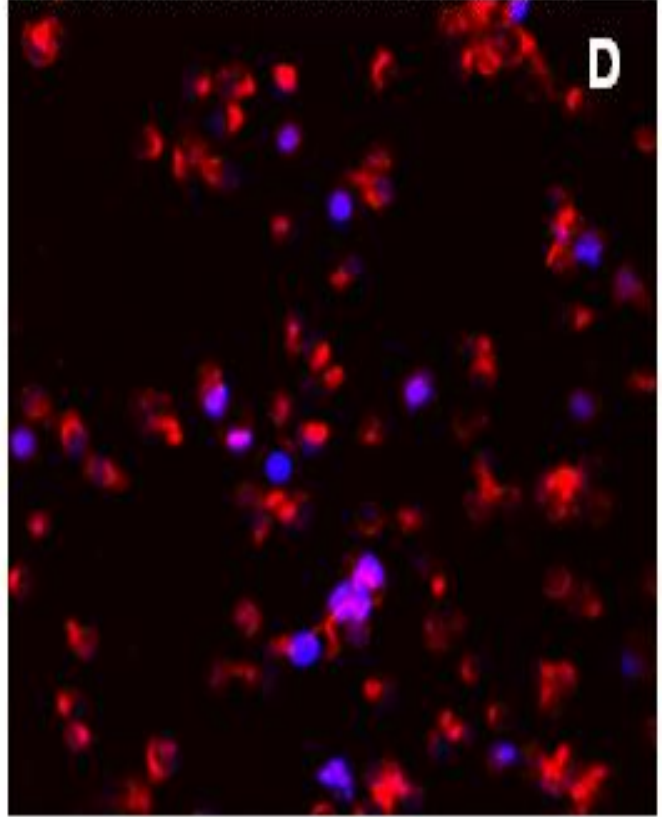

Integrated density GFP/ Area $=1016472 / 1583766=64.18$ Mean GFP $/$ Mean RFP $=64.18 / 417.45=0.15 \%$ Percent of control $=0.15 / 21.06 \times 100=0.71 \%$

Figure 3.6: Image analysis using Opera high throughput acquired pictures (a) rifampicin (b) no drug (c) zinocycline treated macrophage and (d) uninfected macrophage. 
Hence, the percent of control GFP signal for rifampicin and zinocycline obtained from the opera images were $10.05 \%$ and $23.50 \%$ respectively. and can be considered "hit" as been less than 30\% (cut off limit set for opera image analysis results). Table 3.5 shows the detailed image analysis results for all the 28 compounds included in the minilibrary demolibrary model. 
Table 3.5 Opera high throughput confocal microscope results for minilibrary

\begin{tabular}{|c|c|c|c|c|c|c|}
\hline $\begin{array}{l}\text { Compounds (mini } \\
\text { library) }\end{array}$ & $\begin{array}{l}\text { Integrated } \\
\text { density RFP }\end{array}$ & Mean RFP & $\begin{array}{l}\text { Integrated } \\
\text { density GFP }\end{array}$ & Mean GFP & Area (GFP) & GFP/ RFP \\
\hline Bay 11-7085 & 165760018.6 & 1224.714584 & 239089482.4 & 5406.342276 & 44223.88931 & 4.41 \\
\hline Calcimycin & 57819851.47 & 427.2008168 & 36640918.45 & 9059.160495 & 4044.626261 & 21.21 \\
\hline $\begin{array}{l}\text { 4-Chloromercuribenzoic } \\
\text { acid }\end{array}$ & 73766955.08 & 545.0256731 & 106236965.6 & 8160.838899 & 13017.89767 & 14.97 \\
\hline Clotrimazole & 111534447.7 & 824.0700378 & 151901277.6 & 5927.885662 & 25624.86631 & 7.19 \\
\hline Demeclocycline & 55183071.79 & 407.7190229 & 26917349.89 & 5919.909441 & 4546.919198 & 14.52 \\
\hline Dequalinium analog C-14 & 83681809.22 & 618.2813747 & 57071343.63 & 4913.985632 & 11614.064 & 7.95 \\
\hline Diphenyleneiodonium & 114313203.2 & 844.6008168 & 8435147.96 & 2234.650088 & 3774.706386 & 2.64 \\
\hline Droperidol & 65904862.03 & 486.9367558 & 77534640.63 & 7997.380481 & 9695.00461 & 16.42 \\
\hline Idarubicin & 887894372.3 & 6560.189822 & 460876442.5 & 4513.5188 & 102110.2299 & 0.69 \\
\hline Indatraline & 107696150.8 & 795.7108577 & 190955362.7 & 6453.325358 & 29590.22707 & 8.11 \\
\hline Lomifloxacin & 89566109.23 & 661.7574077 & 201915683.7 & 7548.126729 & 26750.43636 & 11.41 \\
\hline Luteolin & 54355886.69 & 401.6073823 & 31319874.05 & 5651.458672 & 5541.909774 & 14.07 \\
\hline Ly-367, 265 & 100115135.7 & 739.6986792 & 130151154 & 6522.544616 & 19954.04581 & 8.81 \\
\hline
\end{tabular}

92 I P a g e 


\begin{tabular}{|c|c|c|c|c|c|c|}
\hline $\begin{array}{l}\text { Compounds (mini } \\
\text { library) }\end{array}$ & $\begin{array}{l}\text { Integrated } \\
\text { density RFP }\end{array}$ & Mean RFP & $\begin{array}{l}\text { Integrated } \\
\text { density GFP }\end{array}$ & Mean GFP & Area (GFP) & GFP/ RFP \\
\hline Minocycline & 70957192.64 & 524.2657995 & 73842245.62 & 5520.567214 & 13375.84396 & 10.53 \\
\hline Niclosamide & 63315356.3 & 467.8042444 & 91757780.18 & 10358.59742 & 8858.12784 & 22.14 \\
\hline Nilutamide & 84735579.75 & 626.0671372 & 180298484.7 & 7989.662852 & 22566.4697 & 12.76 \\
\hline $\begin{array}{l}\text { N-Methyl-beta-carboline- } \\
\text { 3-carboxamide }\end{array}$ & 110449309.4 & 816.0525144 & 197487955.6 & 8778.328376 & 22497.21669 & 10.76 \\
\hline Ofloxacin & 132541383 & 979.2793589 & 213850155.5 & 5541.926093 & 38587.69531 & 5.66 \\
\hline 1, 10 Phenanthroline & 79128299.72 & 584.6378608 & 91979679.35 & 5612.218226 & 16389.18439 & 9.60 \\
\hline Resveratrol & 123135366.6 & 909.7831949 & 283927245 & 6464.681143 & 43919.76011 & 7.10 \\
\hline Rilmenidine & 53410081.19 & 394.6193173 & 44830120.59 & 9258.843788 & 4841.870283 & 23.46 \\
\hline Sanguinarine & 106398589.2 & 786.1238499 & 189079082.1 & 5466.589497 & 34588.12523 & 6.95 \\
\hline Se- methylselenocysteine & 46605797.87 & 344.346006 & 12526421.13 & 7714.780832 & 1623.69112 & 22.40 \\
\hline Trifluoperazine & 61692362.3 & 455.8127857 & 37131084.18 & 4997.388658 & 7430.097341 & 23.46 \\
\hline WB-64 & 44407613.38 & 328.1047638 & 671464.6968 & 2183.861601 & 307.4666895 & 6.65 \\
\hline Zinocycline & 103737139.6 & 766.4597827 & 93321506.96 & 3792.103002 & 24609.43358 & 4.95 \\
\hline
\end{tabular}

93 I P a g e 


\begin{tabular}{|lllllcc|}
\hline Rifampicin & 156470034 & 1156.075719 & 69525139.63 & 2448.032934 & 28400.41025 & 2.12 \\
Capreomycin & 61610476.45 & 455.2077738 & 45893748.41 & 5970.889329 & 7686.250051 & 13.23 \\
Methoctramine & 55730820.99 & 411.7660569 & 24341693.92 & 6156.719004 & 3953.68 & 14.95 \\
\hline
\end{tabular}




\subsection{Troubleshooting}

3.3.1 Choice of correct type of 96 well plate The special poly-D-lysinecoated 96-wp black-walled glass-bottomed (BD Biosciences), were used for the standardization of the intra-macrophage assay. This special plate helped in obtaining an efficient GFP signal, gave better attachment of J774 macrophage cells and showed reduced background fluorescence compared to the normal 96 -well plastic plates. Initially 100 (10x10) point scans were tried when reading the plates at 0 and 96 hrs following the infected macrophages drug treatment; however, the final readings displayed edge of the wall artifacts as the scans were too broad since a single well is only $6.5 \mathrm{~mm}$ in diameter, while each scan was spaced 0.72 $\mathrm{mm}$ apart (giving a total area of $7.2 \mathrm{~mm} \times 7.2 \mathrm{~mm}$ scanned). Hence, 25 $(5 \times 5)$ circular scans were used for the intra-macrophage experimental setup that generated enough data points to provide good readings and never showed the edge effect.

3.3.2 Cell density Different macrophage cell seeding densities $\left(1 \times 10^{4}, 5\right.$ $\times 10^{4}, 1 \times 10^{5}, 5 \times 10^{5}$ cells/ well) were tried to attain a confluent cell density in the cultures. The final working cell density used throughout the experiments was $1 \times 10^{5}$ cells/ well. 
3.3.3 Multiplicity of infection (MOI): A number of different MOls, 2:1, 5:1, 10:1, and 20:1 were tried to attain the best possible change in GFP readings between 0 and $96 \mathrm{hrs}$. The final working $\mathrm{MOI}$ used throughout the experiment was 10: 1 .

3.3.4 Gentamycin concentration Gentamycin is an aminoglycoside antibiotic active against a wide variety of gram-positive and gram-negative bacteria. It was used to prevent the extracellular bacterial growth during the 96 hrs drug treatment. The different gentamycin concentrations used were $20,25,50$, and $100 \mu \mathrm{g} / \mathrm{mL}$ among which $25 \mu \mathrm{g} / \mathrm{mL}$ gentamycin was considered to be the best.

Gentamycin (IC50 - $>4493+j-$ NA micromolesil

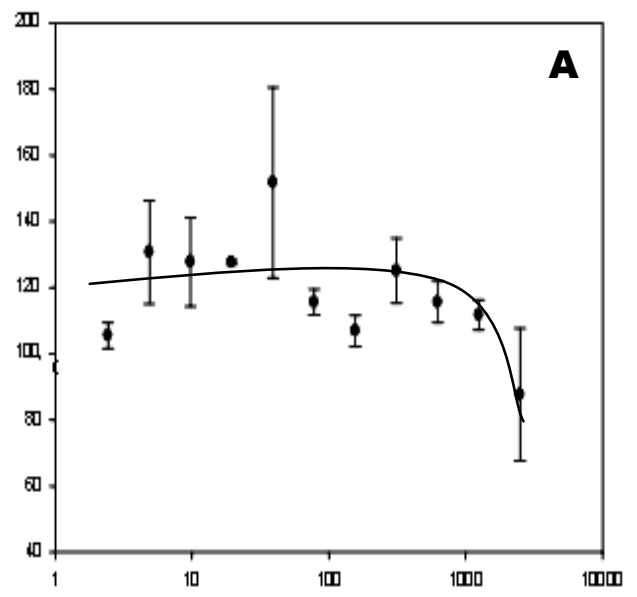

Gentamycin (IC50 = $0.41+/-0.05$ micromoles $/$ ) mycobacterium

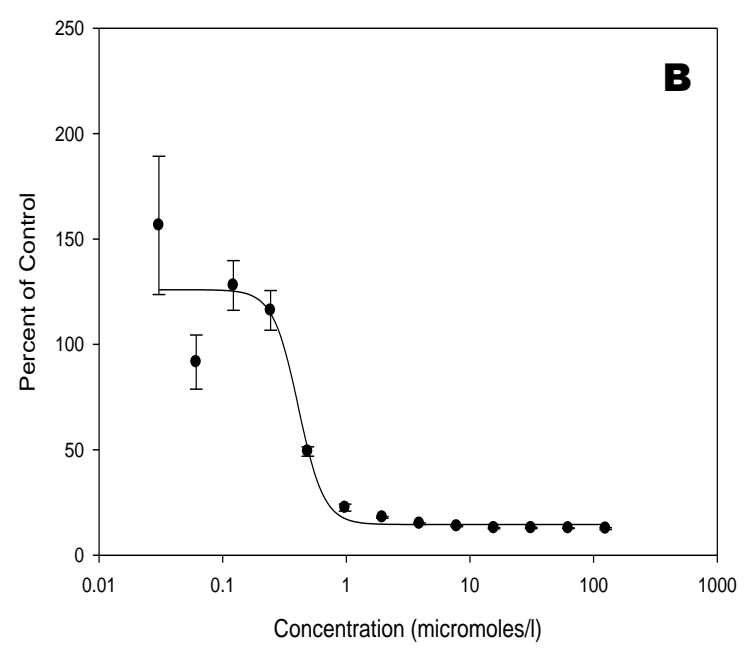

Figure 3.7: $\mathrm{IC}_{50}$ of gentamycin against (A) J774 macrophages and (B) M. smegmatis 
3.3.5 Incubation time Another main factor affecting the standardization of the intra-macrophage assay was the incubation time. The different incubation times used to obtain a good change in GFP between initial and final drug treatment were $0,24,48$ and 96 hrs. The best incubation time selected was 96 hrs which gave a good effect from treatment with the novel drugs on the infected macrophages, resulting in a sigmoidal $\mathrm{IC}_{50}$ curve.

3.3.6 Calculation of IC $\mathbf{C}_{50}$ The stable GFP-labelled plasmid pLL192 hsp60 was used as a marker or reporter to determine the $M$. smegmatis viability/growth inside macrophages. The GFP present at the start of the incubation at 0 hours will still be there at the end till 96 hours, even if the bacterium is dead. Hence, to remove this problem, the $\mathrm{IC}_{50}$ (in terms of percent of control) was calculated by taking the change of GFP signals in drug-treated, infected macrophages between 0 and 96 hours with reference to the change in GFP signal in non-drug-treated infected macrophages (Figure 3.8).

Percent of control $=$ (change in GFP between 0 and 96 hours in drug treated macrophage standards) * 100

(change in GFP between 0 and 96 hours in non drug treated macrophage controls) 
Rifampicin (0 hrs: black 24 hrs: red)

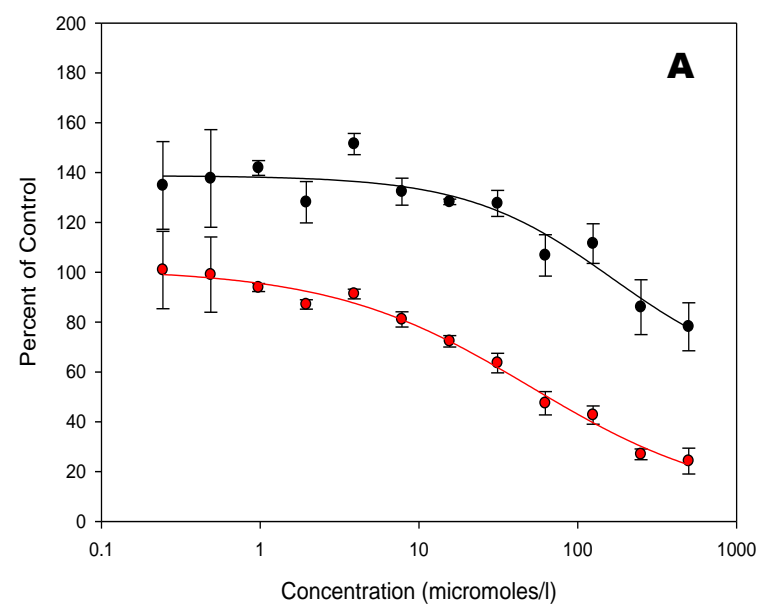

Capreomycin ( black: 0 hrs, red: 24 hrs)

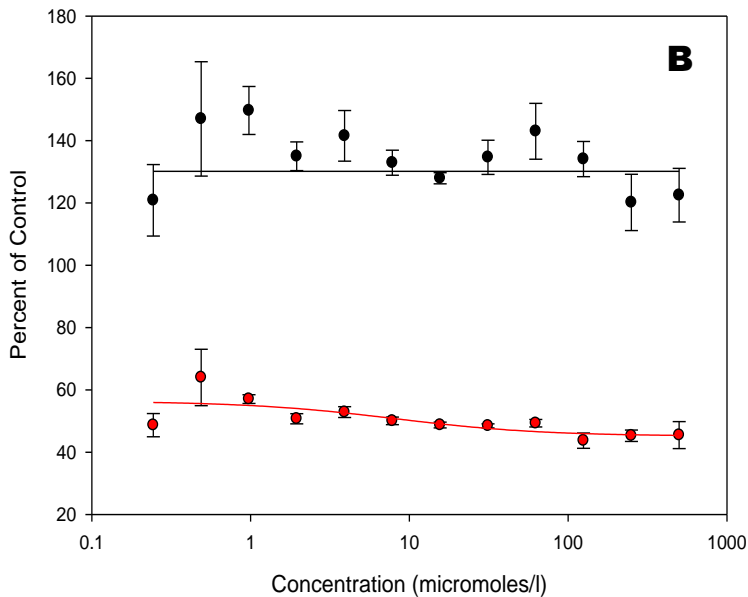

Figure 3.8: $\mathrm{IC}_{50}$ dose response curves at 0 hours (black) and 96 hours (red) for (A) rifampicin (B) capreomycin.

\subsubsection{Quenching effects of certain novel or known antimycobacterial} drugs In some drugs such as rifampicin (known first-line antituberculosis drug) quenching effects were seen at high concentrations and interfered with the GFP readings obtained. These types of drugs can be alternatively tested for $\mathrm{IC}_{50}$ values by other methods such as: (a) by lysing the macrophages and performing colony-forming unit assays (b) using microbial ATP detection kits since all viable cells need ATP to stay alive and perform various functions or (c) using the colorimetric resazurin or Alamar blue viability assays. 
3.3.8 Dimethyl sulphoxide (DMSO) concentration Due to the experimental need to dissolve many of the drugs in DMSO, it was important to test the cytotoxicity of DMSO against the J774 macrophage cell line.Testing the $\mathrm{IC}_{50}$ of the DMSO against $\mathrm{J} 774$ macrophage cells would ensure that the $\mathrm{IC}_{50}$ curve obtained for the novel antimycobacterial drugs was purely because of the effect of the drugs themselves and not due to any effects of the solvent on growth or viability. Any minor background obtained from the DMSO or the macrophage autoflourescence itself were subsequently deducted uniformly from all the readings by setting appropriate controls.

DMSO (IC50 - $6.17+/-1.55$ (microlitres/ well)

Dimethyl Sulphoxide (IC50 = 0.76 microlitres $/$ well)
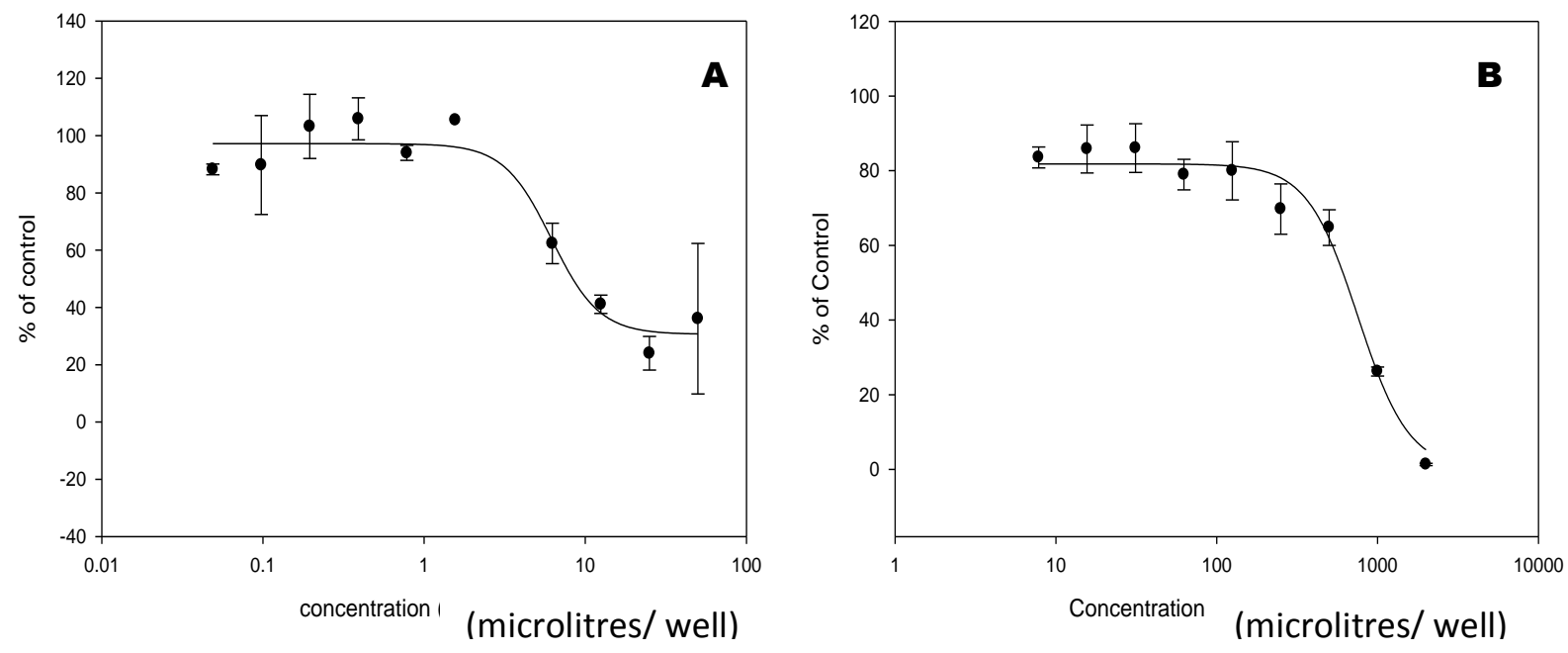

Figure 3.9:Dose response curves $\left(\mathrm{IC}_{50}\right)$ of DMSO against $(\mathrm{A}) \mathrm{J774}$ macrophage (B) HL60 cells. 


\subsection{Discussion}

The mycobacterium can survive and actively replicate inside macrophages or other phagocytic cells for prolonged periods of time. Previous research has established the fact that the phenotype and transcriptional profile of the intra-macrophage mycobacterium is completely different to the extracellular mycobacterium (Christophe et al., 2009). A large number of genes are over expressed and temporarily regulated at the same time inside the macrophages under different stimuli. Therefore, it is really difficult to characterize one specific factor as a novel drug target against which antituberculosis drugs can be developed. M. tuberculosis is an obligate intracellular pathogen that utilizes host nutrients for its survival and replication. Phagocytosis of mycobacterium by macrophages also leads to the gene transcription shift resulting in its altered drug susceptibility (Eklund et al., 2010). The mycobacterium also needs energy production pathways to remain alive as already discussed in the introduction chapter. Also the in vitro assay has very little resemblance with the biological system in which the drug needs to function. This results in high number of cytotoxic compounds with poor pharmacokinetic properties in the synthetic libraries. Hence, an intra-macrophage infection assay was developed so as to detect novel antituberculosis compounds with bactericidal acitivity in its true environment (Zhang et al., 2006). This type of macrophage infection assay may also help in the discovery of novel drugs that target host-pathogen interactions or pathogenesis of tuberculosis or functions that are important for in vivo survival or virulence $100 \mid \mathrm{P}$ a g e 
or host immunity activators (Moy et al., 2009). For example, liquefication of solid necrotic lesions is a key step for TB infection spreading. The TB infection can be prevented from spreading by inhibiting this process. This thesis elucidates the importance of infection assays as a primary and secondary screen against different mycobacterium sp. It will also aid in the discovery of compounds that are host immune enhancers. These type of whole cell based screens based on various TB biological conditions such as an acidic $\mathrm{pH}$ and hypoxic conditions can also be used so as to develop different type of new assays. These environments can again help in the discovery of novel antituberculosis drugs (Zhang et al., 2006).

Hence, the development of an intra- macrophage assay provide a novel, critical tool for screening of drugs that inhibit mycobacterium in the intramacrophage environment. This type of intra-macrophage infection assay could become a standard primary assay for testing the in vivo drug efficacy against mycobacterium and also a secondary assay after the initial selection of active compounds from an in vitro screen. It would also help in the elimination of cytotoxic compounds in the initial stages and also drugs that are ineffective inside macrophages. Thus, it will help in the characterization of novel antimycobacterial drugs that are specifically active inside the host macrophages but cannot be detected in standard in vitro assays. It will also enable in the understanding of complex hostpathogen interactions that would be impossible to study in in vitro assays (Christophe et al., 2009) 
The low-throughput intra-macrophage assay was successfully standardized using known antituberculosis drugs such as rifampicin, capreomycin, ciprofloxacin and ethambutol. The extracellular mycobacterium was removed by PBS washes as any presence of such mycobacterium can be a hurdle for the successful set up of the intramacrophage assay. Gentamycin at $25 \mu \mathrm{g} / \mathrm{ml}$ concentration was used so as to prevent any extracellular mycobacterium growth during the long 96 hour incubation time. Therefore, non-drug treated and DMSO controls were set up in the assays. It was found that DMSO had a minor or no effect on the experimental readings at the given test (20 $\mu \mathrm{M}$ DMSO) concentration.

This was followed by the development and validation of a mini-highthroughput demo model against intra- macrophage screening set-up. The high-throughput screens (HTS) involve the screening of large numbers of compounds in singlets (or duplicates). The advantages associated with HTS are its speed, efficiency, low reagent consumption, and large scale set-up (Brock et al., 1999). Hence, the HTS set-up requires adequate sensitivity, reproducibility and accuracy so as to distinguish among a very large number of compounds and identify active compounds ("hits"). False positives may arise due to many reasons that involve poor intramacrophage GFP labelled mycobacterial growth during $96 \mathrm{hrs}$ incubation, quenching effects, and cytotoxicity of the test compounds, macrophage culture conditions and manual error due to mycobacterium addition at MOI 10:1. False negative cases may arise due to many reasons that involve extracellular mycobacterium growth, manual error 102 | P a g e 
during addition of mycobacterium at $\mathrm{MOI} 10: 1$ or autoflourescence of macrophages or the compound tested (Moy et al., 2006).

The validation step involved the imaging of wells using an opera highthroughput confocal microscope followed by the image analysis using the Image $\mathrm{J}$ script so as to quantify the signals coming from the mycobacterium (GFP) and macrophages (RFP) in terms of a GFP/RFP ratio as already discussed in section 3.5. The intra-macrophage assay can be also validated by means of a traditional cfu method. It will also help in the detection of the bactericidal activity of the novel antimycobacterial drugs to lyse the macrophages after 96 hours. This cfu method is often tedious and labour intensive, but it can help in the $\mathrm{IC}_{50}$ calculation of the coloured compounds that show quenching effects at high concentrations. Many ATP bioluminescence kits are also available as an alternative for the cfu method. These kits are based on the principle that the number of viable mycobacterium is directly proportional to the bioluminescence emitted.

The percent GFP flourscence obtained from the Perkin Elmer plate reader for standard antituberculosis drugs such as rifampicin and capreomycin were -144.36 and -79.23 respectively at $25 \mu \mathrm{M}$. The reasons behind can be the drug tested may be cytotoxic (confirmed by alamar blue viability testing), strong GFP quencher (for example, rifampicin) or highly bactericidal against intramacrophage mycobacterium destroying the GFP during the 96 hours incubation time. This intramacrophage treatment variation can be reduced 
by replacing 96-wp with completely automated 384-well format assay for screening large numbers of compounds in a short time. This would involve dispensing of the GFP labelled mycobacteria by a large particle sorter followed by automated imaging using a confocal microscope and analysis of the acquired images using Image $\mathrm{J}$ software analysis. The automation and miniaturization of several steps in the intra-macrophage assay would hence help in improving the screening rate and its accuracy (Moy et al., 2009).

The values were validated by opera highthroughput microscope images analysis readings. The opera readings for rifampicin and capreomycin were 2.12 and 13.23 in comparison to the non drug treated infected macrophage (negative control) reading 21.06 showing that the experimental set up was successful. This also showed that the GFP flourescence obtained was due to the intracellular mycobacterium and not because of any extracellular mycobacterium.

The intramacrophage hits obtained from mini library demo model screening were ofloxacin, lomifloxacin, 1, 10 phenanthroline and zinocycline. The intramcrophage GFP readings for ofloxacin, lomifloxacin, 1, 10 phenanthroline and zinocycline at $20 \mu \mathrm{M}$ concentration were $-16.62,-61.89$, 19.48 and -116.35 respectively. The GFP readings for the above mentioned minilibrary intramacrophage hits were validated using opera images that are 5.66, $11.41,9.60$ and 4.95 respectively and percent of control were calculated. These intramacrophage $\mathrm{IC}_{50}$ values were also compared to the 
in vitro $\mathrm{IC}_{50}$ values (Table 2.1). There were no significant differences in ofloxacin and lomifloxacin $\mathrm{IC}_{50}$ values. But, intramacrophage $\mathrm{IC}_{50}$ value for 1,10 phenanthroline was found to be 11.41 and much less than the in vitro $I_{50}$ value of 41.64 . The reason behind may be some enzymes or some compound inside the macrophage that might be activating 1,10 phenanthroline's bactericidal activity against $M$. smegmatis activity. Ofloxacin is similar in activity to ciprofloxacin, acting as a broad spectrum antibiotic that inhibits DNA gyrases, type II and IV, topoisomerases important for cell division. Lomefloxacin is a difluorinated quinolone, and its in vitro activity has been compared with that of ofloxacin, a DNA gyrase inhibitor. 1, 10-Phenanthroline is reported to be a biologically active metal chelator (Brennan et al., 2008).

The parameter used to calculate the high-throughput screen robustness is called the $Z$ factor. The $Z$ factor for capreomycin was 0.405 and for rifampicin was 0.416 . This $Z$ factor value shows that the mean score of the control population was separated by several standard deviations. Hence it proves that the minilibrary results were reliable and thus sets a strong preliminary basis for the real synthetic library screening (Zhang et al., 1999). The robustness of the screen can also be assessed by other methods such as

Coefficient of variation $(\% \mathrm{CV}=\sigma / \mu * 100)$ that can be defined as the measure of the precision relative to the mean value, calculated for the maximum and minimum signals. An acceptable limit is $<15 \%$. 
Signal to noise ratio (S:N), signal to background ratio (S:B) and signal window (SW).

$\mathrm{S}: \mathrm{N}=\mu \max -\mu \min / \sigma \min$

$\mathrm{S}: \mathrm{B}=\mu \max / \mu \min$

$\mathrm{SW}=\mu \max -\mu \min -3(\sigma \max +\sigma \min ) / \sigma \max$

$\boldsymbol{\mu}$ mean of the assay signal $\boldsymbol{\sigma}_{d}$ standard deviation of the difference in log potency max maximum signal min minimum signal. 


\section{Chapter 4}

\section{Implementation of Cytotoxicity Assays in Intramacrophage Assay Development}




\section{Chapter 4}

\section{Implementation of Cytotoxicity Assay in Intramacrophage \\ Assay Development}

\subsection{Introduction}

Cytotoxicity assays provide a measurement of cell survival and proliferation. The assessment of a given drug toxicity can be performed against different cell lines from different tissues by the help of cytotoxicity or viability assays in early stages. The need to characterise the toxicity of a potential novel compound before further drug development has led many pharmaceutical companies to screen large compound libraries for their cytotoxicities. These cellular screens can limit the need for animal experimentation, prevent precious novel compounds wastage and help in idenifying potential cytotoxic compounds in early stages of drug development process. Cytotoxity assays are mainly based on the measurement of three parameters, metabolic function, membrane integrity and cell number (Hamid et al., 2004).

\subsection{Different types of known cytotoxicity assays}

4.2.1 Alamar blue assay The Alamar blue assay is based on the conversion by mitochondrial enzymes of the cell permeable nonfluorogenic blue resazurin into the fluorogenic pink resorufin. The extent of the conversion into pink fluorogenic resorufin is proportional to the number 
of viable cells. Cell numbers can be quantitatively estimated by optical density (at absorbance $570 \mathrm{~nm}$ ) or fluorescence (at $560 \mathrm{~nm} \mathrm{Ex/590} \mathrm{nm}$ Em filter settings). The Alamar blue assay is:

(a) Simple to use, non-radioactive and non-toxic.

(b) Sensitive in detecting cell numbers as low as 50 cells/well and as high as 50,000 cells/well.

(c) No additional reagents are required before addition of the Alamar blue (Nakayama et al., 1997).

(d) Aqueous (water soluble) in nature hence can be performed in largescale high-throughput screening (Al-Nasiry et al., 2007).

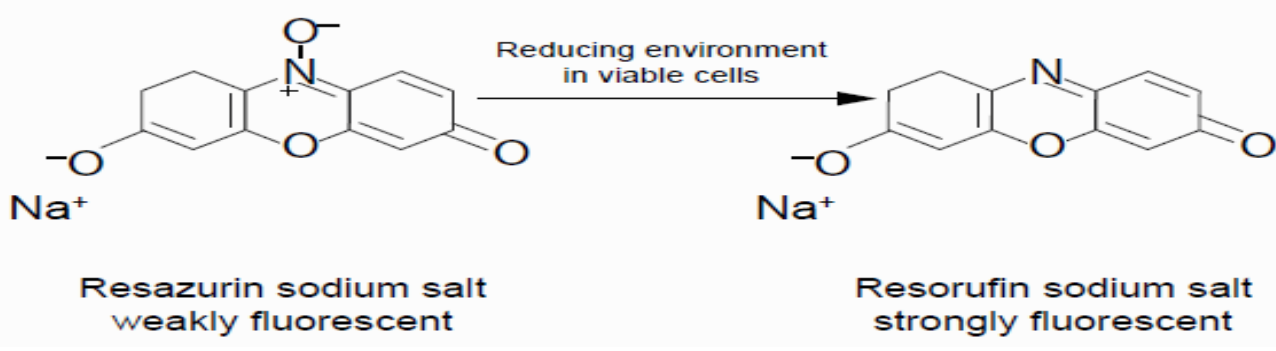

Figure 4.1: Conversion of resazurin into resorufin

4.2.2 MTT assay The MTT $(3-[4,5$ - dimethylthiazol -2-yl] -2, 5 diphenyl tetrazolium bromide) assay is based on the principle of conversion of the yellow tetrazolium salt into a non-soluble purple formazon by mitochondrial succinate dehydrogenases of viable cells. It was performed first as described by Mosmann (Berridge et al, 1996). A solubilizer solution (usually dimethyl sulphoxide, an acidified ethanol 
solution, or sodium dodecyl sulfate in diluted hydrochloric acid) is used to dissolve the insoluble formazons into blue colored solutions whose absorbance is measured at wavelength $570 \mathrm{~nm}$. The MTT assay detects cytotoxicity based on the functional state of the cell mitochondria. MTT assays are widely used in the quantitation of cytotoxic and growth inhibitory activities of cell, and help in the differentiation of cytostatic and cytotoxic effects when used in conjunction with viable cell counts such as the trypan blue assay. The MTT assay is simple, reproducible, reliable and economical for the toxicity testing of different compounds (Kasugai et al., 1990 and Freimoser et al., 1999).
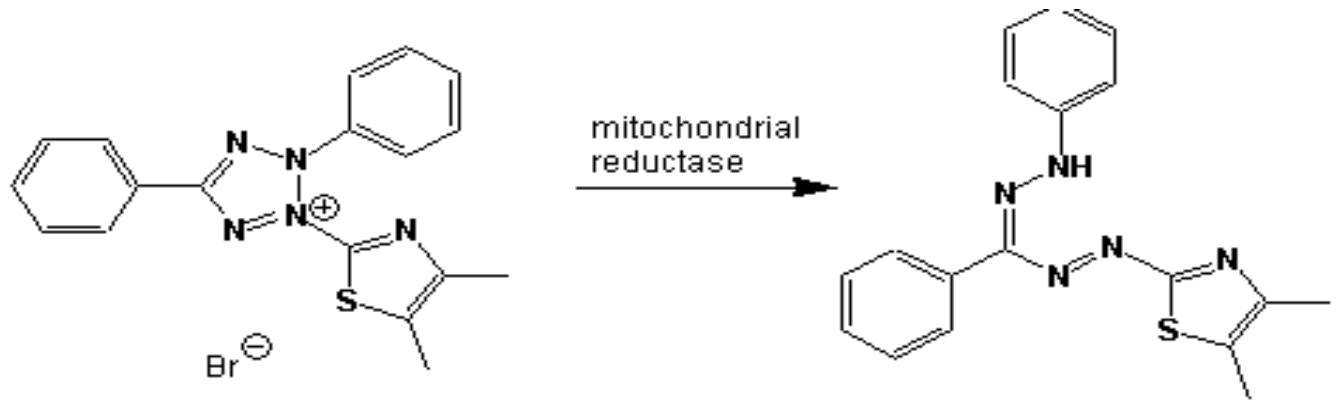

Figure 4.2: Conversion of MTT dye to insoluble formazon (Liu and Nair, 2010). 


\subsubsection{Other tetrazolium assays are:}

XTT assay XTT (2,3-bis(2-methoxy-4-nitro-5-sulphophenyl)-5[(phenylamino) carbonyl]-2H-tetrazolium hydroxide) is based on the priniciple of conversion into coloured formazan by mitochondrial succinoxidase and cytochrome P450 systems and flavoprotein oxidase (Kuhn et al., 2003).

WST-1 assay WST-1 (4-[3-(4-iodophenyl)-2-(4-nitrophenyl)-2H-5tetrazolio]-1, 3-benzene disulfonate) assay is based on the principle of conversion into soluble coloured formazon by mitochondrial succinate tetrazolium reductase. The WST-1 reaction can be quantified in 0.5 to 4 hours (Ngamwongsatit et al., 2008).

One of the major drawbacks of the MTT is that to obtain a good signal, overnight incubation time is involved, which can lead to false positives and increased chances of mammalian cells getting contaminated. Such disadvantages can be overcome by Alamar blue or WST-1 type assays that are associated with short incubation times (Ngamwongsatit et al., 2008).

4.2.3 Adenosine triphosphate (ATP) measurement assay ATP is present in all metabolically active cells and can act as a viability marker. Dead cells loose their ability to synthesize ATP when they undergo necrosis or apoptosis. This is responsible for their reduced ATP levels 
which can be detected by both colourimetric and fluorometric methods (Maioli et al., 2009).

\subsubsection{Lactate dehydrogenase (LDH) measurement assay The} cytotoxicity of the chemical compounds can also be measured by quantifying the plasma membrane damage. This type of assay is based on the fact that the amount of stable cytoplasmic enzyme activity detected in the culture supernatant is directly proportional to the number of viable cells. This can be further quantified by both colourimetric and fluorometric methods (Maioli et al., 2009).

The reason to choose Alamar blue and MTT cytotoxicity assays in this current project over other assays can be described as follows. Alamar blue assay readings can be taken both colorimetrically and fluorometrically. Unfortunatly, MTT assay readings can only be taken colorimetrically. Therefore, MTT assay cannot be used for calculating the $\mathrm{IC}_{50}$ for coloured compounds accurately such as rifampicin. The reason behind can be the colour of the rifampicin hinders with the colour of reduced MTT dye (soluble formazon) resulting from viable cells metabolism. The Alamar blue assay is a real time assay that can be used for kinetics study as it is nontoxic. On the another side MTT assay is an end point assay and hence cannot be used over a timed exposure as it involves the addition of the solubiliser so as to dissolve the insoluble formazon formed. Both dyes are 
reduced by mitochondrial enzyme activity by accepting electrons from NADPH, FADH, FMNH, and NADH (Al-Nasiry et al., 2007). But alamar blue assay is considered to be more sensitive than the MTT assay as it can also be reduced by cytochromes which are not possible in the case of MTT reduction. MTT assay is associated with long incubation period that makes the cell based assays more prone to contamination (Ngamwongsatit et al., 2008). The main advantage associated with MTT is that it is cheaper than any of the other tetrazolium or metabolic (ATP, LDH) assays used. Both Alamar blue and MTT assay produces quality data and relevant end point and hence can be used for high throughput screening. In this project we used alamar blue and MTT assay in order to identify and rank cytotoxic compounds from the synthetic libraries based on their potential cytotoxicity. Alamar blue assay provides higher sensitivity as it is homogenous in nature and can detect cell densities as low as 200 cells/ well (Hamid et al., 2004).

\subsection{Results}

The MTT and Alamar blue assay were compared against three different cell lines. Many experimental compounds provided from different sources along with their solvents were tested using different cytotoxicity assays. These cytotoxicity assays were used to calculate the $\mathrm{IC}_{50}$ of the compounds, and the different potencies were then compared to the known antituberculosis compounds. 
4.3.1 Comparison of MTT and Alamar blue assay in different cell lines Diphenyleneiodonium chloride (DPI) was tested against different cell lines to compare MTT with the Alamar blue assay.

\begin{tabular}{|lrc}
\hline Type of cell line & \multicolumn{1}{l}{ MTT } & $\begin{array}{r}\text { Alamar blue }(\mu \mathrm{M}) \\
{\left[\mathrm{IC}_{50}(\mu \mathrm{M})+/-\mathrm{SE}\right]}\end{array}$ \\
HL 60 & {$\left[\mathrm{IC}_{50}(\mu \mathrm{M}) \pm \mathrm{SE}\right]$} & $2.09 \pm 2.85$ \\
J774 & $3.50 \pm 3.90$ & $9.20 \pm 13.2$ \\
U937 & $3.51 \pm 1.52$ & $1.93 \pm 3.96$
\end{tabular}

Table 4.1: Comparison between MTT and alamar blue assay based on the IC50 values of diphenyleneiodonium chloride against 3 different cell lines.

\subsubsection{Cytotoxicity assays against current antituberculosis drugs}

Some of the common antituberculosis drugs along with their solvents and known cytotoxic compounds (mycalamide and epothilone A) were tested for their $\mathrm{IC}_{50}(\mu \mathrm{M})$ dose-response curves against the HL60 (Human leukaemic) cell line. Table 4.2 shows the $\mathrm{IC}_{50}(\mu \mathrm{M})$ values along with their standard errors for these known antituberculosis drugs, cytotoxic compounds and their solvents. 


\begin{tabular}{|l|l|l|}
\hline Compound series & Compound name & \multicolumn{1}{|c|}{ IC50 $(\mu \mathrm{M}) \pm$ SE } \\
\hline \multirow{2}{*}{$\begin{array}{l}\text { Antituberculosis } \\
\text { drugs }\end{array}$} & Isoniazid & $326.2 \pm 0.02$ \\
\cline { 2 - 3 } & Pyrazinamide & $>200$ \\
\hline & Ciprofloxacin & $78.37 \pm 24.54$ \\
\hline & Ethambutol & $1150 \pm 94$ \\
\hline Solvents & Rifampicin & $>500$ \\
\hline & DMSO & $0.806 \pm 0.116 \mu \mathrm{l} /$ well \\
\hline & Methanol & $0.73 \pm 9.59 \mu \mathrm{l} /$ well \\
\hline & Ethanol & $1.03 \pm 31.26 \mu \mathrm{l} /$ well \\
\hline Cytotoxic \\
compounds & Chloroform & $0.82 \pm 1.655 \mu \mathrm{l} /$ well \\
\hline & Mycalamide & $0.73 \pm 0.07 \mathrm{nM}$ \\
\cline { 2 - 3 } & Epothilone A & $6.74 \pm 2.85 \mathrm{nM}$ \\
\hline
\end{tabular}

Table 4.2: IC50 values $(\mu \mathrm{M})$ along with their standard errors (SE) for known antituberculosis compounds, their solvents and cytotoxic compounds. (nM) refers to nanomoles/ I using MTT assys.

\subsubsection{Cytotoxicity assays against LOPAC compounds}

Large number (1280) compounds of a library of pharmacologically active compounds (LOPAC) [Sigma] were kindly screened in vitro against $M$. smegmatis by Christopher $\mathrm{H}$ Miller. The hits obtained were validated and tested against HL60 cells in order to determine their cytotoxicity. These in 
vitro validated hits against $M$ smegmatis were used in order to construct the mini library demo model.

\begin{tabular}{|l|l|}
\hline \multicolumn{1}{|c|}{ LOPAC compounds } & \multicolumn{1}{|c|}{ IC $_{50}(\mu \mathrm{M}) \pm$ SE } \\
\hline 4-Chloromercuribenzoic acid & $34.55 \pm 0.10$ \\
\hline Clotrimazole & $2.37 \pm 0.12$ \\
\hline Demeclocycline & $>100$ \\
\hline Dequalinium analog C-14 & $1.26 \pm 0.11$ \\
\hline Diphenyleneiodonium & $3.6 \pm 0.73$ \\
\hline Droperidol & $27.52 \pm 6.27$ \\
\hline Idarubicin & $8.27 \pm 1.69$ \\
\hline Lomefloxacin & $335.72 \pm 2750.48$ \\
\hline LY-367265 & $25.21 \pm 5.07$ \\
\hline Luteolin & $13.50 \pm 0.80$ \\
\hline Methoctramine & $39.20 \pm 41.87$ \\
\hline Minocycline & $6.37 \pm 1.30$ \\
\hline Ofloxacin & $112.19 \pm 132.12$ \\
\hline 1, 10 Phenanthroline & $1.95 \pm 0.08$ \\
\hline Se-methylselenocysteine & $25.68 \pm 8.81$ \\
\hline Trifluoperazine & $8.71 \pm 0.81$ \\
\hline WB64 & $90.26 \pm 9.11$ \\
\hline Zinocycline & $13.41 \pm 1.61$ \\
\hline Rilmedine hemifumarate & $63.01 \pm 28.24$ \\
\hline Sanguinarine & $0.138 \pm 6.19$ \\
\hline Resveratrol & $16.11 \pm 1.82$ \\
\hline & \\
\hline
\end{tabular}

Table 4.3: $\mathrm{IC}_{50}$ values $(\mu \mathrm{M})$ along with their standard errors (SE) for LOPAC compounds dissolved in DMSO using alamar blue assy. 


\subsection{Discussion}

A cytotoxicity assay provides important information about the potency of the hits detected from intra-macrophage assay. There are many cytotoxicity assays presently available as already discussed. These assays are based on ATP measurement (Untch et al., 1994), MTT (Mosmann 1983) and other tetrazolium salts, alamar blue, membrane integrity/ LDH release (Korzeniewski and Callewaert, 1983) assays, trypan blue dye exclusion, etc. None of these assays, however, can be reliably compared with standard in vivo toxicity measurements because of the many complex and interrelated parameters inside the body that may affect a drug's mechanism of action, cytotoxicity and ADME (absorption, distribution, metabolism and elimination) at its site of action. However, cytotoxicity assays can play an important role in comparing and ranking novel compounds.

Cytotoxicity is also the most unpredictable property of a given drug candidate as it can be cell or organ-type specific. Hence the selection of the type of cell line screened is an important criterion and depends on the kind of cytotoxicity assays to be performed (Hamid et al., 2004).

This chapter also compares the performance of the Alamar blue and MTT assays against different test compounds based on their $\mathrm{IC}_{50}$ values. The results were consistent between the two cytotoxicity assays used. Since both assays rely on enzymatic transformations that may be modulated by some of the test compounds, the misinterpretation of results in some cases needs to be considered. This misinterpretation may generate false 
positives and false negative values in terms of $\mathrm{IC}_{50}$ values. For example, dicumarol, a well-known anticoagulant and an inhibitor of quinine reductase type 1 , shows a partial effect on the modulation of both Alamar blue and MTT by transformation of both the end points to the corresponding metabolites (Hamid et al., 2004).

During both the colorimetric assays, direct microscopic observations of the cells were made. This helped in the physical detection of the drug effects in the form of cell disruption into fragments and detachment in the adherent cell lines. For example, exposure to daunorubicin can cause cell detachment, but these detached cells continued to transform MTT into formazan. Thus, the cell detachment effect of the drug would go unnoticed (Hamid et al., 2004).

All test compounds were dissolved in their appropriate solvents. Hence there was a need to know whether these solvents had any effect on the cell lines itself. It was found that the effect of the solvents on cell viability was negligibile at the concentrations used and any minor effect on absorbance can be taken as a background and subtracted from all readings. The antituberculosis drugs were tested for their cytotoxicity and were established as negative controls; whereas, the known cytotoxic compounds mycalamide A and epothilone A were established as positive controls for cytotoxicity. Table 4.3 shows the cytotoxicity of the LOPAC in vitro hits detected against $M$. smegmatis used for mini library construction against $\mathrm{HL}-60$ cell lines. Some of the $\mathrm{IC}_{50}$ values have standard errors more than the actual readings. This can be because of slight manual 
experimental error, conditions under which the experiment was run or in some cases the Sigma plot software that was used to calculate the $\mathrm{IC}_{50}$ values.

The test compounds of interest from the intramacrophage assay will be those with high potency towards $M$. tuberculosis and low cytotoxicity towards the different cells lines tested. These novel intramacrophage specific hits will be taken for further back validation tests. This back validation tests against different known mycobacterium species and cell lines will enable to determine the pure intramacrophage hits that cannot be picked in any of the in vitro assays.

Hence, cytotoxicity assays can be also used as secondary assays after establishment of the intra-macrophage assay. This can help in demonstrating that the inhibition of the bacterial growth inside the macrophages is purely due to the antibacterial property of the novel intramacrophage hit and not because of the cytotoxicity of the compound tested. 
DIP $(I C 50=3.51+/-1.52$ micromoles/l $)$

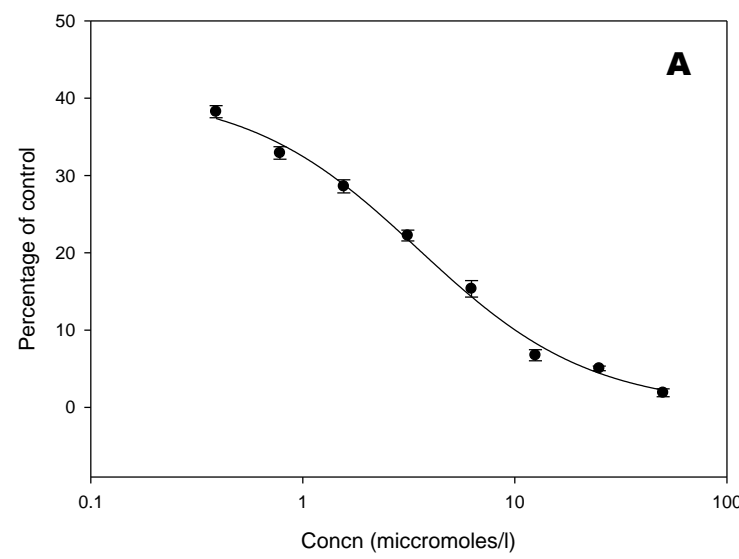

DIP $($ IC50 = $2.50+/-3.90$ micromoles $/$ )

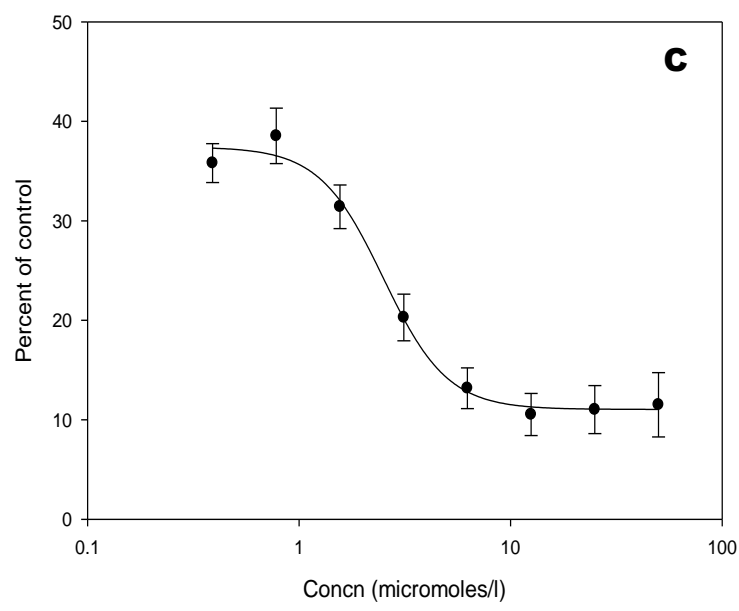

DIP $($ IC50 = $1.14+/-4.46$ micromoles/l)

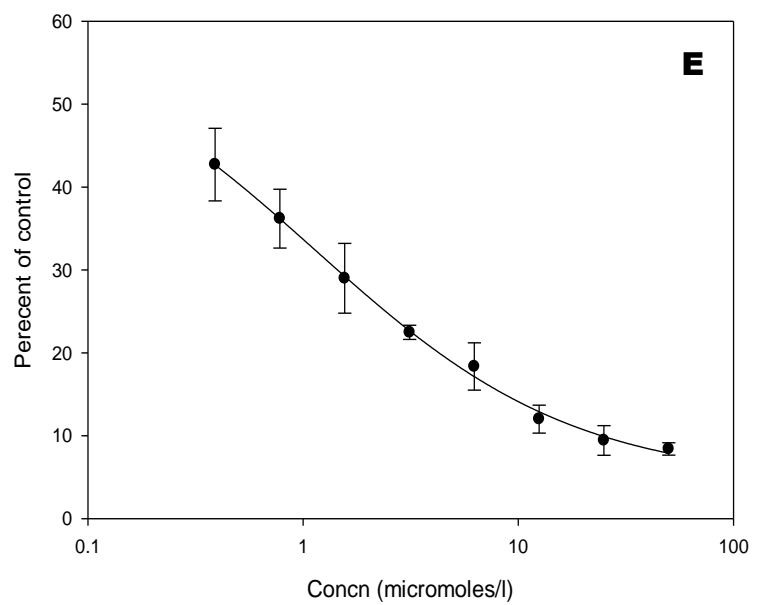

DIP $($ IC50 = $9.20+/-13.2$ micromoles/l)

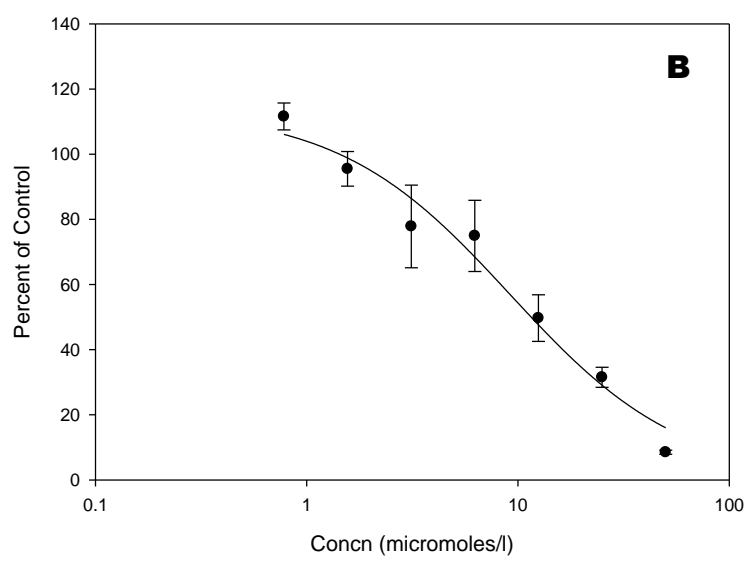

DIP $($ IC50 = $2.09+/-2.85$ micromoles/l)

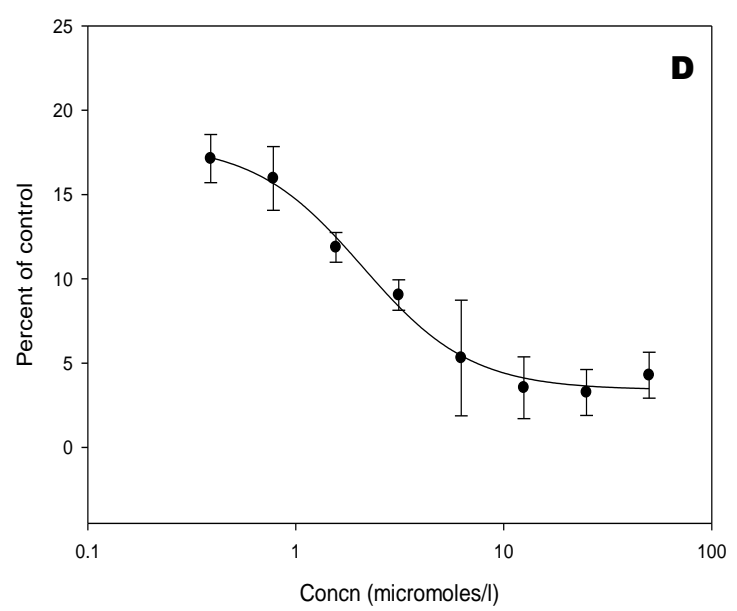

DIP $($ IC50 = $1.93+/-3.96$ micromoles $/ L)$

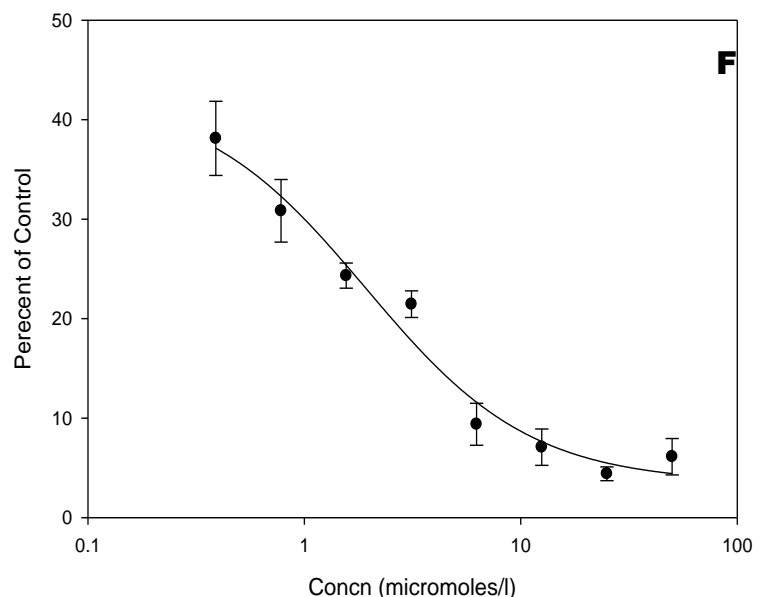

Figure 4.3: Comparative IC50 dose response curves between MTT and Alamar blue assay for DPI against HL60 (A, B), J774 (C, D), and $\mathrm{U} 937$ (E, F) - 

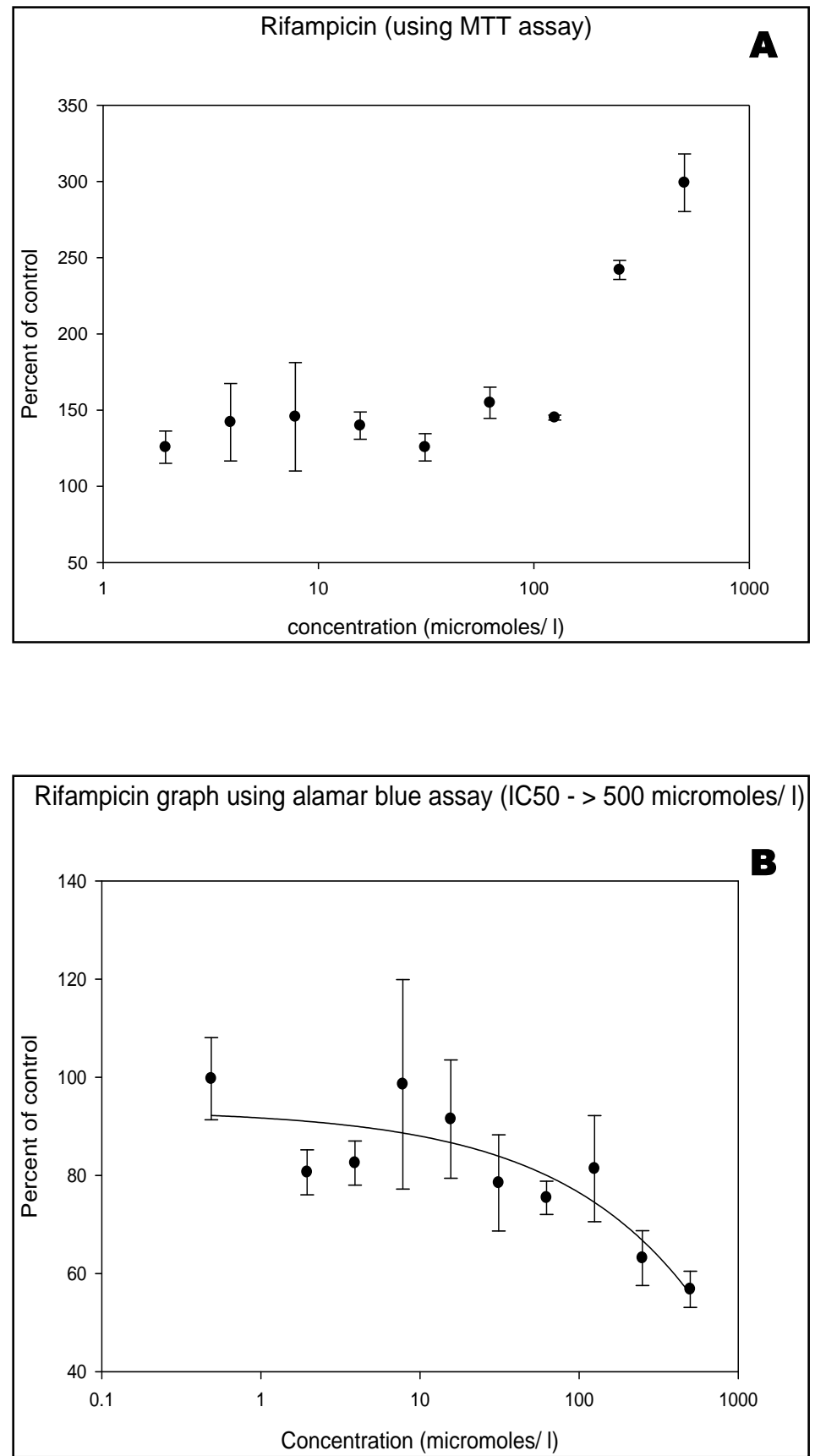

Figure 4.4: Comparison of rifampicin (colored compound) $\mathrm{IC}_{50}$ graphs against both (A) MTT and (B) Alamar blue assay. It shows the interference of the color with the colorimetric MTT assay readings.This interference can be removed by alamar blue assay (flurometric and colorimetric assay). 


\section{Chapter 5}

\section{Application of intra- macrophage assay in synthetic library screening}




\section{Chapter 5}

\section{Application of intra-macrophage assay in synthetic library screening}

\subsection{Introduction}

The overall aim of this project was to develop an intra-macrophage assay identify novel compounds that are specifically active inside the macrophages but are not detectable in in vitro assays. In order to test as many compounds as possible in a given time, a high-throughput method was employed, whereby thousands of compounds could be tested for their effect against in an intra-macrophage infection assay. Using a liquid handler robot, a large number of compounds can be dispensed to separate wells of a 96-well plate followed by incubation for 96 hours with macrophages infected with $M$. smegmatis.

This research project is based on the concept that the intra-macrophage infection assay will pick novel compounds that are specifically intramacrophage and cannot be detected in any of the in vitro assays. As already discussed in the previous chapters, many in vitro screens are known that are based on growth inhibition and killing of a microbial pathogen, but none of these assays can be considered completely efficient. The reason behind this is that these screens may yield compounds that are very cytotoxic or ineffective to the microbial pathogens inside the cell and exposed to a very different environment. 
Hence there was the need for the development of such an intramacrophage assay that will be associated with the discovery of novel drugs that may either act by targeting host-pathogen interactions or by enhancing the host immune system or inhibiting the pathogen's virulence factors.

The synthetic library high- throughput screening was developed following the successful standardization and validation of mini library highthroughput demo model. Three libraries were available for screening, LOPAC, National institute of health $(\mathrm{NIH})$ and Spectrum collections, but due to time constraints, only one library was used for screening purposes. In order to ascertain that there was no inhibition of intra-phagosomal mycobacterial growth from the solvent used to dissolve the compound libraries, a negative control was included containing the same volume of DMSO added in three wells of each plate instead of a compound. As a positive control, to show the effect of compounds that inhibit the intramacrophage mycobacterial growth, some common antibiotics were added in duplicate to each plate. $Z$ factors were calculated in order to determine the robustness of the high-throughput synthetic library screening.

Intra-macrophage hits that were not picked in any of the previous in vitro assays were back tested as well for their authenticity. This validation was performed by Opera high-throughput image analysis which proved that the GFP readings obtained were because of the intra-macrophage mycobacteria and not from any extracellular mycobacteria. These images 
were also used for GFP/RFP ratio calculations to back up the plate reader GFP readings. The in vitro assays such as bacteriostatic and bactericidal assays against $M$. smegmatis and bacteriostatic assays against $M$. bovis, M.H37Ra were performed on the intra-macrophage hits. Finally, cytotoxicity assays were also performed on these novel intra-macrophage hits so as to prove that the hits were not cytotoxic at the same concentrations tested.

\subsection{Results}

The LOPAC library was screened in triplicate so as to confirm the hits obtained. The Alamar blue reagent was added to the above experiment after 96 hours in order to confirm the potency of the novel intramacrophage hits tested. Table 5.1 shows the GFP readings in triplicates for 61 intra-macrophage hits showing $25 \%$ growth of phagocytosed $M$. smegmatis and $75 \%$ inhibition of $M$. smegmatis growth at $20 \mu \mathrm{M}$. This table also illustrates some of the important features of these novel intra-macrophage hits along with their cytotoxicity properties at the above concentration tested. This will help in shortlisting of these novel hits that can be proceeded for low throughput intra-macrophage assay on the basis of (a) how effectively the novel hit knocks out the intramacrophage mycobacterium and (b) potency. 
Table 5.1: Results for LOPAC library screening

\begin{tabular}{|c|c|c|c|c|c|}
\hline Compound & \multicolumn{3}{|c|}{$\begin{array}{c}\text { Triplicate readings from } 3 \\
\text { independent LOPAC library } \\
\text { screening }\end{array}$} & Cytotoxicity & Known action \\
\hline 4- Amino-1, 8- napthalamide & -36.88 & -45.55 & 28.43 & $(-)$ ve & Poly(ADP-ribose) polymerase (PARP) inhibitor. \\
\hline Bromoacetyl alprenolol methane & -21.09 & -47.88 & 15.47 & $(-)$ ve & Alkylating beta adrenoceptor antagonist. \\
\hline CGS-21680 hydrochloride & 20.65 & 25.8 & 8.61 & $(-)$ ve & A2a adenosine receptor agonist. \\
\hline Epibestatin hydrochloride & 5.45 & 12.94 & -48.92 & $(-)$ ve & $\begin{array}{l}\text { Metallo-protease inhibitor; aminopeptidase } \\
\text { inhibitor. }\end{array}$ \\
\hline S(-)-DS 121 dihydrochloride & -14.42 & 24.01 & -13.18 & $(-)$ ve & $\begin{array}{l}\text { Dopamine autoreceptor antagonist with some } \\
\text { selectivity for the D3 dopamine receptor binding } \\
\text { site. }\end{array}$ \\
\hline 3-n-propyl xanthine & 13.54 & 1.107 & 17.63 & $(-)$ ve & $\begin{array}{l}\text { Weak competitive antagonist at both } \mathrm{A} 1 \text { and } \mathrm{A} 2 \\
\text { adenosine receptors }\end{array}$ \\
\hline 3'-4' dichlorobenzamil & 13.05 & 20.41 & 2.41 & $(-)$ ve & $\mathrm{Na}+/ \mathrm{Ca} 2+$ exchanger inhibitor. \\
\hline lodoacetamide & 22.93 & 3.52 & EXP & $(-)$ ve & $\begin{array}{l}\text { Alkylating reagent for cysteine and histidine } \\
\text { residues in proteins; irreversible protein inhibitor. }\end{array}$ \\
\hline
\end{tabular}




\begin{tabular}{|c|c|c|c|c|c|}
\hline Compound & \multicolumn{3}{|c|}{$\begin{array}{c}\text { Triplicate readings from } 3 \\
\text { independent LOPAC library } \\
\text { screening }\end{array}$} & \multirow[t]{2}{*}{ Cytotoxicity } & Known action \\
\hline Kynurenic acid & 13.04 & 16.44 & EXP & & $\begin{array}{l}\text { Excitatory amino acid receptor antagonist; blocks } \\
\text { kainic acid-induced neurotoxicity; metabolite of } \\
\text { tryptophan }\end{array}$ \\
\hline Lonidamine & 11.26 & 8.311 & EXP & $(-)$ ve & $\begin{array}{l}\text { Inhibits the energy metabolism of neoplastic cells } \\
\text { by interfering with mitochondrial hexokinase, } \\
\text { cellular respiration, and glycolysis; damages cell } \\
\text { and mitochondrial membranes. }\end{array}$ \\
\hline Loxoprofen & 3.96 & 22.64 & -3.14 & $(-)$ ve & $\begin{array}{l}\text { Non-steroidal anti-inflammatory (NSAID) drug; } \\
\text { analgesic. }\end{array}$ \\
\hline ( \pm ) - PPHT hydrochloride & 17.1 & -53.92 & EXP & $(-)$ ve & Potent D2 dopamine receptor agonist. \\
\hline Protriptyline hydrochloride & 1.07 & 17.14 & 9.13 & $(-)$ ve & Norepinephrine reuptake blocker. \\
\hline Naloxonazine dihydrochloride & -1.45 & -19.71 & 23.22 & $(-)$ ve & Potent mu1 opioid receptor antagonist. \\
\hline Tyrphostin A9 & 19.27 & 0.467 & -15 & $(-)$ ve & Selective PDGF tyrosine kinase receptor inhibitor \\
\hline $\begin{array}{l}\text { 3-Tropanyl -3, 5- } \\
\text { dichlorobenzoate }\end{array}$ & 9.97 & 12.45 & 14.63 & $(-)$ ve & Selective 5-HT3 serotonin receptor antagonist. \\
\hline N- Vanillylnonanamide & 1.62 & 20.25 & 22.48 & $(-)$ ve & $\begin{array}{l}\text { Synthetic analog of capsaicin with similar } \\
\text { bioactivity }\end{array}$ \\
\hline
\end{tabular}




\begin{tabular}{|c|c|c|c|c|c|}
\hline Compound & \multicolumn{3}{|c|}{$\begin{array}{c}\text { Triplicate readings from } 3 \\
\text { independent LOPAC library } \\
\text { screening }\end{array}$} & \multirow[t]{2}{*}{ Cytotoxicity } & \multirow[b]{2}{*}{$\begin{array}{l}\text { Synthetic glucocorticoid agonist; inducer of gene } \\
\text { expression and apoptosis }\end{array}$} \\
\hline Triamcinolone & 3.299 & 7.2 & -32.35 & & \\
\hline TTNPB & 24.82 & -4.54 & 14.77 & $(-)$ ve & $\begin{array}{l}\text { Selective and highly potent retinoic acid analog } \\
\text { with affinity for retinoic acid receptors (RAR) } \\
\text { alpha, beta, and gamma }\end{array}$ \\
\hline TCPOBOP & 12.23 & -17.27 & 21.7 & $(-)$ ve & $\begin{array}{l}\text { Constitutive androstane receptor (CAR) agonist; } \\
\text { most potent known member of the phenobarbital- } \\
\text { like class of CYP-inducing agents }\end{array}$ \\
\hline TFPI hydrochloride & -21.76 & -0.81 & 0.02 & $(-)$ ve & $\begin{array}{l}\text { Nitric oxide synthase (NOS) inhibitor selective for } \\
\text { neuronal isoform }\end{array}$ \\
\hline Tulobuterol hydrochloride & 10.07 & -9.67 & 7.33 & $(-)$ ve & $\begin{array}{l}\text { beta-Adrenoceptor agonist related to structurally } \\
\text { to terbutaline; bronchodilator }\end{array}$ \\
\hline Spiroxatrine & -6.28 & 15.73 & -0.15 & $(-)$ ve & Partial 5-HT1A serotonin receptor agonist \\
\hline Nomifensine maleate & -14.86 & -15.51 & -33.05 & $(-)$ ve & Dopamine reuptake inhibitor; antidepressant \\
\hline PRE-084 & -65.01 & 19.11 & -7.61 & $(-)$ ve & $\begin{array}{l}\text { Potent and highly selective sigma1 receptor } \\
\text { agonist }\end{array}$ \\
\hline Phenylephrine hydrochloride & 21.95 & 4.24 & -2.21 & $(-)$ ve & $\begin{array}{l}\text { alpha1 Adrenoceptor agonist; mydriatic; } \\
\text { decongestant }\end{array}$ \\
\hline Piceatannol & 3.65 & 13.65 & 8.1 & $(-)$ ve & Non-receptor kinase Syk and Lck inhibitor \\
\hline
\end{tabular}

128 | P a g e 


\begin{tabular}{|c|c|c|c|c|c|}
\hline \multirow[t]{2}{*}{ Compound } & \multicolumn{3}{|c|}{$\begin{array}{c}\text { Triplicate readings from } 3 \\
\text { independent LOPAC library } \\
\text { screening }\end{array}$} & \multirow{2}{*}{$\begin{array}{l}\text { Cytotoxicity } \\
\text { (-) ve }\end{array}$} & \multirow{2}{*}{$\begin{array}{l}\text { Known action } \\
\text { Competitive and reversible inhibitor of } \\
\text { phospholipase A2 (PLA2) }\end{array}$} \\
\hline & -3.86 & 11.47 & EXP & & \\
\hline Triprolidine hydrochloride & -46.24 & 18.45 & -28.42 & $(-)$ ve & Potent $\mathrm{H} 1$ histamine receptor antagonist \\
\hline $\begin{array}{l}\text { 1-Phenyl-3-(2-thiazolyl)-2- } \\
\text { thiourea }\end{array}$ & -2.04 & 24.66 & 24.41 & $(+)$ ve & Dopamine beta-hydroxylase inhibitor \\
\hline Podophyllotoxin & 18.91 & 3.83 & EXP & $(+)$ ve & $\begin{array}{l}\text { Antineoplastic glucoside; inhibitor of microtubule } \\
\text { assembly }\end{array}$ \\
\hline SU 6656 & -689.3 & -526.1 & -1612 & $(+)$ ve & Selective Src family kinase inhibitor. \\
\hline Mevastatin & 14.18 & -6.61 & NA & $(+)$ ve & $\begin{array}{l}\text { Antibiotic; inhibits post-translational prenylation of } \\
\text { proteins such as Ras and geranylation of Rho }\end{array}$ \\
\hline Tomoxetine & 4.26 & 11.32 & 14.56 & $(+)$ ve & Norepinephrine reuptake blocker \\
\hline $\begin{array}{l}\text { Na-p-Tosyl-L-lysine chloromethyl } \\
\text { ketone hydrochloride }\end{array}$ & 16.49 & 2.72 & -23.54 & $(-)$ ve & $\begin{array}{l}\text { Adenylyl cyclase inhibitor; blocks the LPS- or } \\
\text { cytokine-induced activation of nuclear factor kB } \\
\text { (NFkB) }\end{array}$ \\
\hline T-0156 & 24.8 & -6.5 & -15.28 & $(-)$ ve & Potent phosphodiesterase V (PDE V) inhibitor \\
\hline Tamoxifen citrate & 20.09 & 9.38 & 10.4 & $(-)$ ve & $\begin{array}{l}\text { Anti-estrogen; relatively selective protein kinase } \\
\text { C inhibitor }\end{array}$ \\
\hline
\end{tabular}

EXP: refers to unavailability of results due to experimental errors.

$129 \mid \mathrm{P}$ a g e 
In total, 1280 compounds of the LOPAC library were screened against the intra-macrophage assay out of which 61 compounds showed activity. The hit rate for LOPAC synthetic library is calculated as $4.765 \%$. Among these 61,17 hits had already been reported in the in vitro screens. The Alamar blue reagent was added to the above experiment after 96 hours in order to confirm the cell viability, and it was also found that 25 active hits were cytotoxic to the $\mathrm{J} 774$ macrophage cell line. The false positive hit rate is calculated as $19.51 \%$. The low throughput screening was carried out on the remaining 19 compounds that were active and not cytotoxic. Figure 5.1 shows the $\mathrm{IC}_{50}$ dose response curves for 4 intra-macrophage hits out of 19 compounds tested on low throughput screening. 4-amino 1,8 naphthalamide showed the best activity against the intramacrophage mycobacterium. Other three compounds epibestatin hydrochloride, nomifensine maleate, and $\mathrm{N}$-vanillylnonamide showed some activity against intramacrophage mycobacterium below $50 \mu \mathrm{M}$ concentration and hence reported in the results section. The table 5.2 shows the comparison of in vivo $\mathrm{IC}_{50}$ values with those of the in vitro bactericidal and bacteriostatic $\mathrm{IC}_{50}$ values against $M$. smegmatis, $M$. bovis and $M$. H37Ra. The cytotoxicity of the intra-macrophge specific hits was also determined against the $\mathrm{J} 774$ macrophage cell line using the alamar blue assay. 
Table 5.2: Back validation of the intra - macrophage hits against different mycobacterium species (M. smegmatis, M. bovis, M. H37Ra) and their potency against $\mathbf{J 7 7 4}$ macrophage cell line.

\begin{tabular}{|c|c|c|c|c|c|c|}
\hline $\begin{array}{c}\text { Intramacrophage } \\
\text { hits }\end{array}$ & $\begin{array}{c}\text { in vivo IC50 } \\
(\mu \mathrm{M})\end{array}$ & $\begin{array}{l}\text { in vitro } M . \\
\text { smegmatis } \\
\text { activity }(\mu \mathrm{M})\end{array}$ & $\begin{array}{c}\text { in vitro } \\
\text { bactericidal } \\
\text { activity against } \\
\text { M. smegmatis } \\
(\mu \mathrm{M})\end{array}$ & $\begin{array}{c}\text { in vitro } M . \\
\text { bovis activity } \\
(\mu \mathrm{M})\end{array}$ & $\begin{array}{l}\text { in vitro } M \text {. } \\
\text { H37Ra activity } \\
(\mu \mathrm{M})\end{array}$ & $\begin{array}{c}\text { J774 } \\
\text { macrphage } \\
(\mu \mathrm{M})\end{array}$ \\
\hline $\begin{array}{l}\text { 4-Amino 1, } 8 \\
\text { naphthalimide }\end{array}$ & $8.2135+/-3.09$ & $>50$ & $>50$ & $>50$ & $>50$ & $>50$ \\
\hline $\begin{array}{l}\text { Nomifensine } \\
\text { maleate }\end{array}$ & $14.58+/-35.8$ & $>50$ & $>50$ & $>50$ & $>50$ & $>50$ \\
\hline $\begin{array}{l}\mathrm{N}- \\
\text { Vanillylnonamide }\end{array}$ & $194.55+/-218.5$ & $>50$ & $>50$ & $>50$ & $>50$ & $>50$ \\
\hline
\end{tabular}

NA: refers to the high standard errors against the $\mathrm{IC}_{50}$ values that can be due to manual errors during this infection lab experimental set up. 

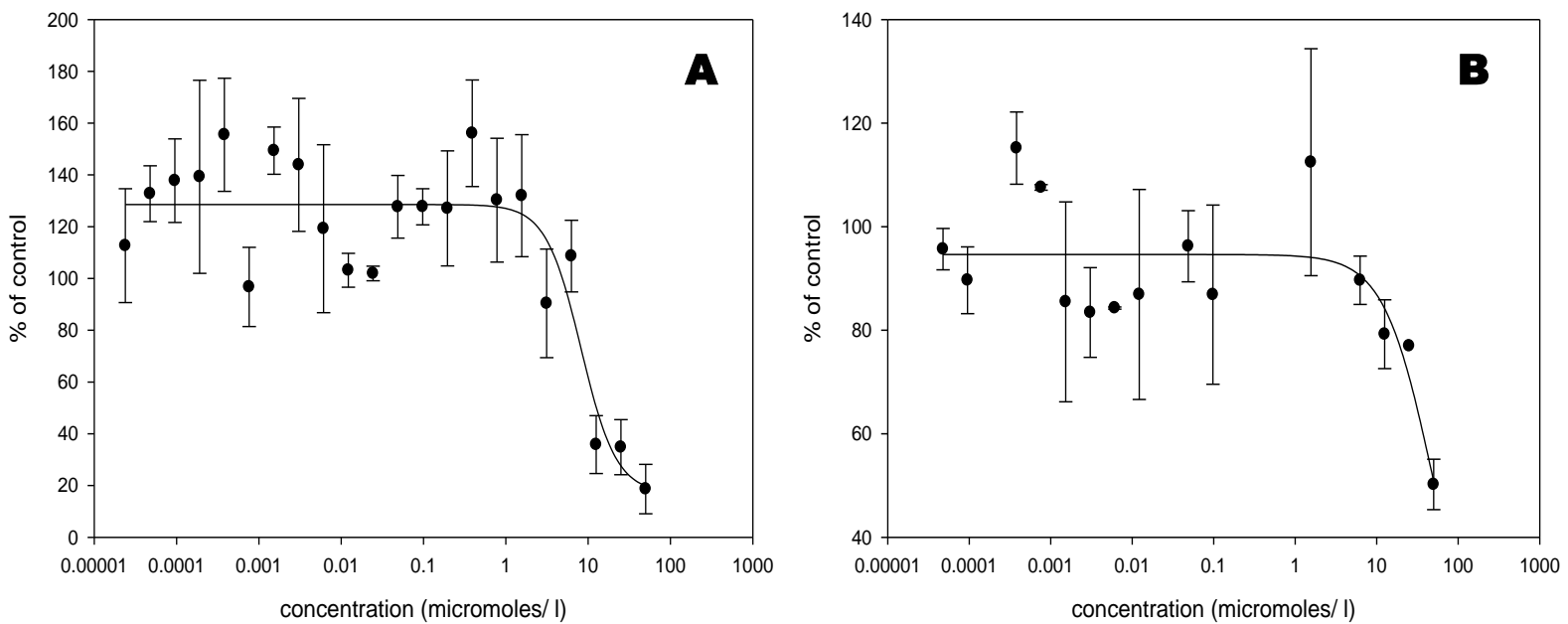

Nomifensine maleate (IC50 - 14.58 +/- NA micromoles/ I)

N-VanillyInonanamide (IC50 - 194.55 +/- NA micromoles/l)
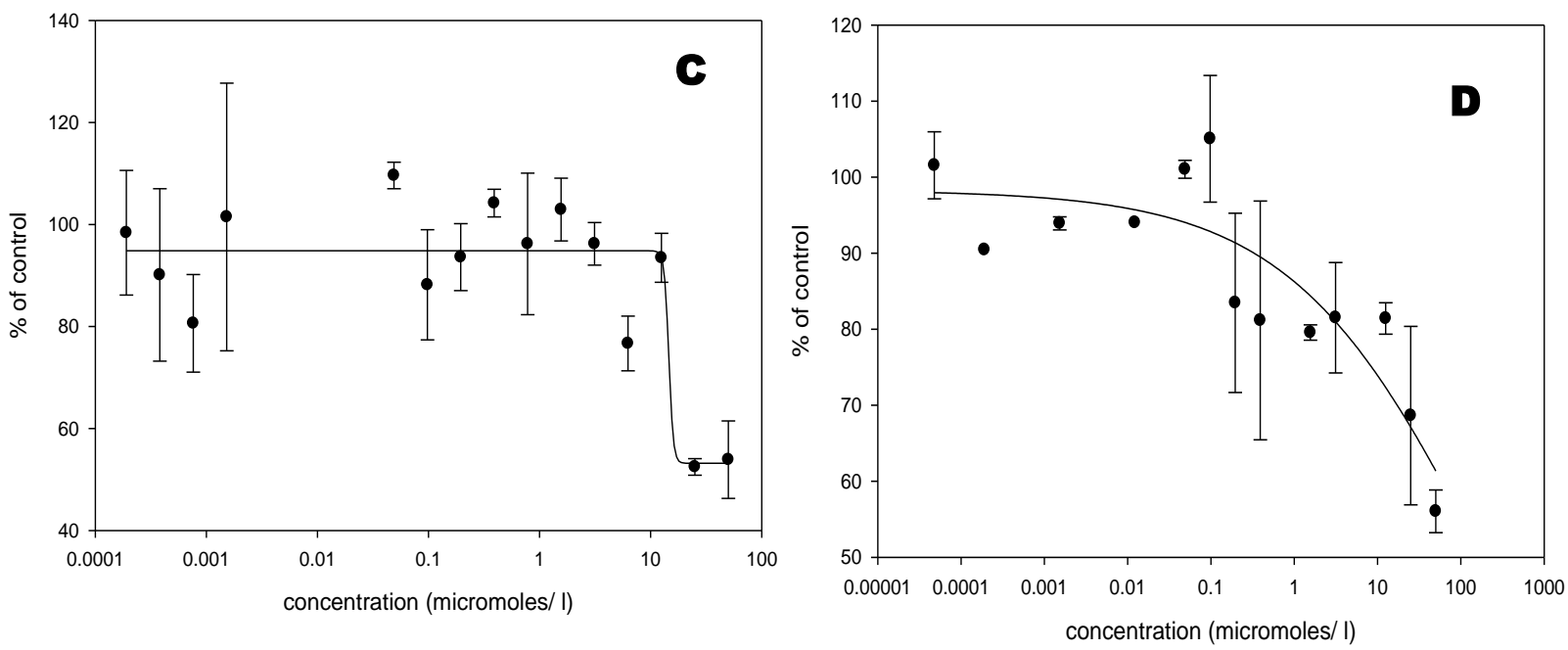

Figure 5.1: Representative dose response $I_{50}$ curves for intramacrophage specific hits. 


\subsubsection{Validation using opera high-throughput confocal images}

The images obtained from opera high-throughput confocal microscope were used so as to prove that the above GFP based $\mathrm{IC}_{50}$ values are obtained because of intracellular mycobacterium and not because of any extracellular bacterium. As already discussed in section 3.2.5, a $30 \%$ cut off was set for a novel intramacrophage antimycobacterial compound to be considered as a "hit" based on opera image analysis. Table 5.3 illustrates the mean GFP/ mean RFP ratio for the intramacrophage hits. This table also compares the mean GFP values obtained for the "hits" obtained with the non drug treated infected macrophages and positive controls (antituberculosis drugs such as capreomycin and ciprofloxacin) treated infected macrophages. Figure 5.2 shows the comparison between the images obtained for the novel intramacrophage hits reported from this project, positive controls with non drug treated infected macrophages. 

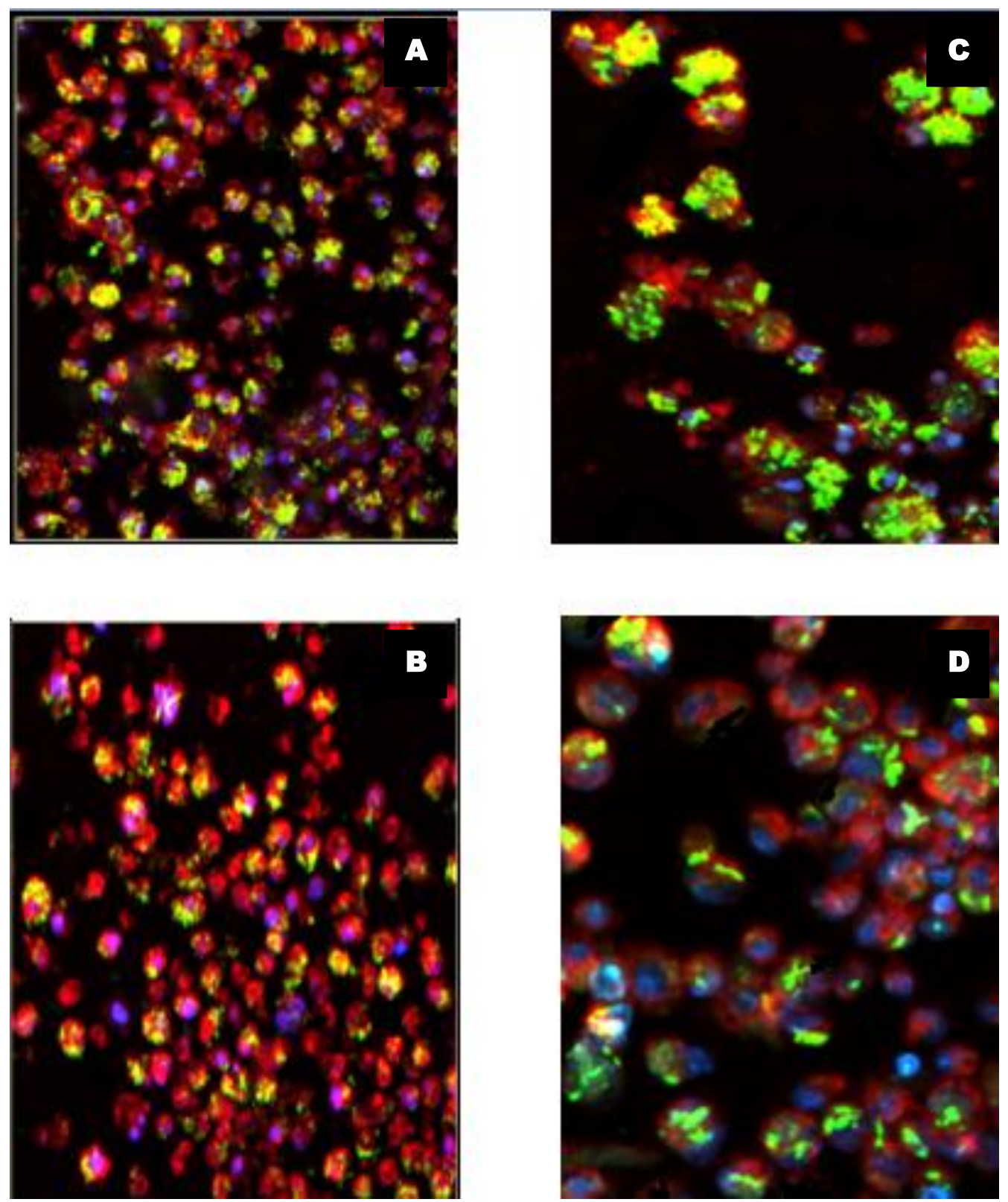

Figure 5.2: Opera images for intra-macrophage hits in comparison with the control drugs treated infected macrophage (A) 4-amino 1, 8 naphthalamide (B) Nomifensine maleate (C) Capreomycin (D) Ciprofloxacin (Pg. 131) (E) Uninfected macrophages (F) Non drug treated infected macrophage (Pg 133). 
Table 5.3: Opera high throughput confocal microscope results for synthetic library (LOPAC) screening.

\begin{tabular}{|c|c|c|c|c|c|c|}
\hline Intramacrophage hits & $\begin{array}{l}\text { Integrated } \\
\text { density RFP }\end{array}$ & Mean RFP & $\begin{array}{l}\text { Integrated } \\
\text { density GFP }\end{array}$ & Mean GFP & Area (GFP) & GFP/ RFP \\
\hline 4-Amino 1, 8 naphthalimide & 159106765.28 & 1176.01 & 327318366.01 & 5797.74 & 56456.22418 & 4.93 \\
\hline Epibestatin hydrochloride & 84059948.61 & 621.0752501 & 136736659.2 & 5408.293566 & 25282.77311 & 8.71 \\
\hline Nomifensine maleate & 68685842.76 & 507.4839763 & 83229758.09 & 4683.483931 & 17770.90715 & 9.23 \\
\hline $\mathrm{N}$ - Vanillylnonamide & 71027984.24 & 524.7888418 & 64512836.84 & 4956.65626 & 13015.39454 & 9.45 \\
\hline $\begin{array}{l}\text { Non drug treated infected } \\
\text { macrophage }\end{array}$ & 36540856.19 & 269.99 & 38772529 & 6911.95 & 5609.40 & 25.06 \\
\hline Capreomycin & 101771929 & 752.1577956 & 183357913 & 5938.445853 & 30876.41405 & 7.89 \\
\hline Ciprofloxacin & 133226915.6 & 984.3444032 & 55980345.85 & 2078.201524 & 26936.91887 & 2.11 \\
\hline
\end{tabular}




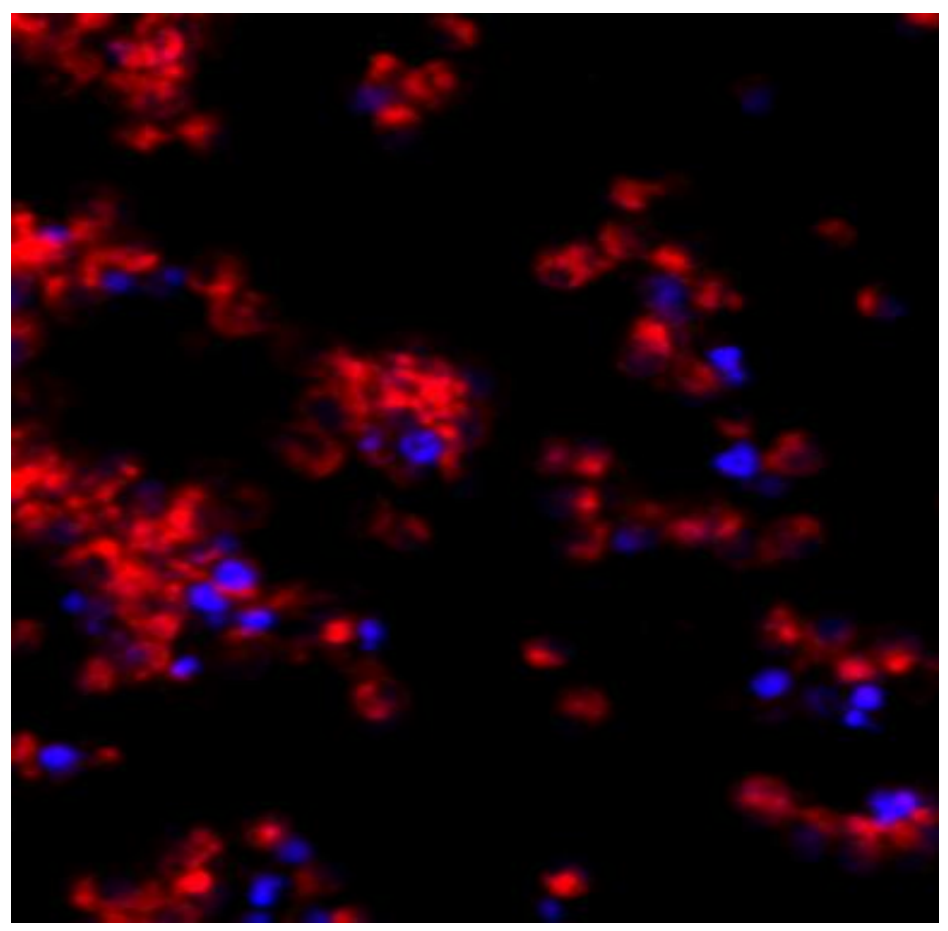

E. Uninfected macrophages

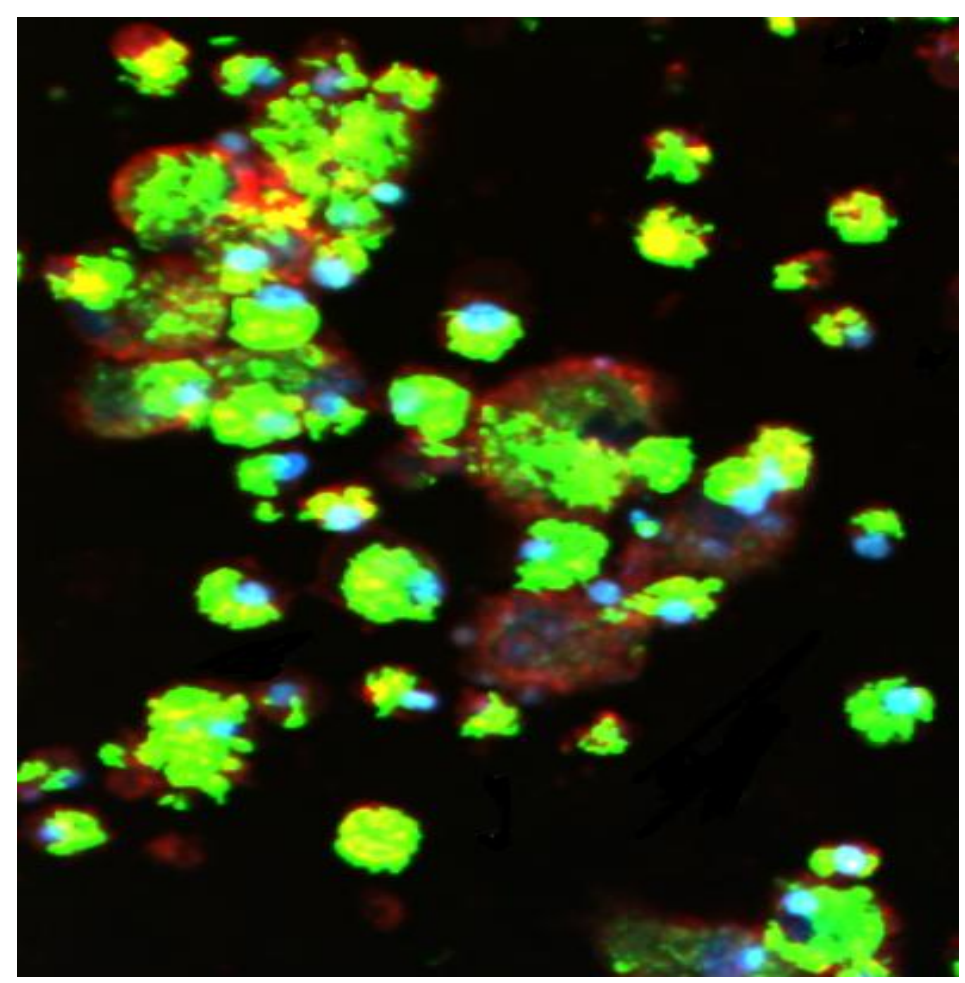

F. Non drug treated infected macrophages 


\subsection{Discussion}

The LOPAC library was screened in triplicate so that the intra-macrophage hits obtained can be confirmed. The readings were taken using the Envision plate reader and were further validated using the images obtained using the Opera confocal microscope as already discussed.

We identified four compounds as already mentioned in section 5.2 that have a confirmed intramacrophage antimycobacterial activity but which were not any known antibiotics, structural analogues of antibiotics, or compounds with documented antimicrobial activity. These compounds were of high interest as they inhibited mycobacterial growth inside the macrophage but were not picked up in any of the in vitro screens against M. smegmatis, M. bovis or M.H37Ra. The novel intramacrophage hits detected for their selective intra-macrophage antimycobacterial activity were 4-amino 1, 8 naphthalimide; epibestatin hydrochloride, nomifensine maleate, and $\mathrm{N}$-vanillylnonanamide.

The compound 4-amino 1, 8 naphthalimide is a known poly (ADP ribose) polymerase-1 [PARP-1] inhibitor. PARP-1 is a nuclear protein that binds to single-strand DNA to form PAR polymers. This PAR formation helps in preventing DNA breakage, chromatin structure alteration and DNA repair and homologous recombination. Despite all of these significant functions of PARP-1, it is not essential for cell viability. The reason for this is that PARP-inhibition leads to ATM (ataxia telangiectasia mutated) and DNA dependent protein kinase (DNA-PK) activation that is responsible for 
homologous recombination repair to continue DNA replication processes (Bryant and Helleday, 2006). The ATM is a member of a family of large proteins characterised by their C-terminal phosphatidyl-inositol kinase (PI3K) like domain (Morrison et al., 2000). 4- amino 1, 8 naphthalamide is water insoluble and can enter cells by different pathways. It acts by inhibition of the bacterial DNA gyrase and DNA topoisomerase (Fuente et al., 2006). It may act against the intramacrophage mycobacterium by the process autophagy as already discussed in the section 1.4.8. It may also be responsible for the activation of the macrophages/ monocytes by inducing TNF- $\alpha$ production that in combination with IFN- $y$ is further responsible for the phagolysosomal fusion.

$\mathrm{N}$-vanillylnonanamide is a synthetic analogue of capsacin with similar chemical and pharmacological effects (Liu., 2009). Capsaicin (8-methyl-Nvanillyl-6-nonenamide) is a pungent bioactive compound present in different capsicum fruits such as hot green and red peppers (Tsuchiya., 2001). It is synthesized by the amidation of vanillylamine hydrochloride with nonanoic anhydride in supercritical carbon dioxide $\left(\mathrm{SC}-\mathrm{CO}_{2}\right)$ in the presence of lipase enzyme. This property is probably due to the lipophilic alkyl chain that allows the molecule to penetrate through the lipid cell membrane (Liu., 2009). It acts against the intramacrophage mycobacterium by changing the membrane fluidity so as to exert nonneuronal antibacterial and antiplatelet actions (Tsuchiya., 2001). 
Epibestatin hydrochloride is an aminopeptidase inhibitor. It is the metallodependent integral transmembrane protease first isolated by Pfleiderer and Celliers from the pig kidney. It is known to exist in both membrane bound and soluble forms. The soluble aminopeptidase is present in plasma/serum and urine, and membrane bound aminopeptidases are distributed outside the hematopoietic system. The dysregulated expression of aminopeptidases is associated with several diseases such as rheumatoid arthritis, multiple sclerosis, systemic lupus erythematosus and pulmonary sarcoiosis. Epibestatin is a slow binding competitive inhibitor of aminopeptidases. This binding is further known to induce cytokine secretion from macrophages that may be the underlying mechanism for the killing of the phagocytosed mycobacterium by activated macrophages. (Bauvois and Dauzonne., 2005).

Nomifensine maleate is a tricyclic antidepressant (TCA) which blocks dopamine and norepinephrine reuptake. A known antimycobacterial agent called iproniazid also showed similar antidepressant effects in depressed patients suffering from tuberculosis (Papakostas., 2006). But Nomifensine maleate was withdrawn from the market in the year 1980 as it was seen to be associated with renal failure and haemolytic anaemia. 


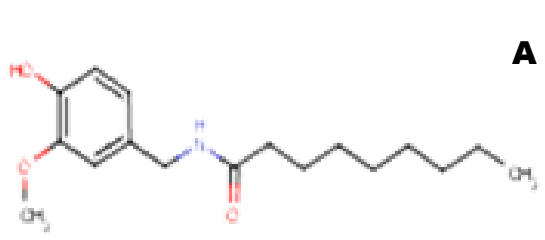<smiles>CC1C[C@H](C(=O)O)NC(=O)[C@H](O)[C@@H](N)Cc2ccccc2O1</smiles><smiles>C[NH+]1Cc2c(N)cccc2C(c2ccccc2)C1</smiles><smiles>CC(=O)/C=C\C(=O)O</smiles><smiles>Nc1ccc2c3c(cccc13)C(=O)NC2=O</smiles>

Figure 5.3: Strutures of the intamacrophage specific hits (a) Nvanillylnonanamide (c) Nomifensine maleae and (d) 4-amino 1, 8 naphthalamide. Structural information taken from website http://chem.sis.nIm.nih.gov/chemidplus/.

The $I_{50}$ for 4 amino 1,8 naphthalamide, epibestatin hydrochloride, nomifensine maleate and $\mathrm{N}$-vanillylnonanamide were calculated as 8.21 +/- 3.09, 47.475 +/- NA, 14.58 +/- NA and 194.55 +/- NA respectively. 4 amino 1, 8 naphthalamide showed the best activity among the four intramacrophage hits reported. It showed $80 \%$ inhibition during the course of 96 hour treatment with the novel drugs in comparison with the other inhibitors reported that was just $40 \%$ or less (Figure 5.1). It was also 
showed that the above mentioned intra-macrophage hits were not reported in any of the in-vitro assays against different mycobacterium species including $M$. smegmatis. It was also showed that the novel intramacrophage hits reported in this project was not cytotoxic against the J774 macrophages at the above drug concentration $(50 \mu \mathrm{M})$ tested (Table 5.2). The percent of control calculated using opera images for four intramacrophage hits 4 -amino 1,8 naphthalamide, epibestatin hydrochloride, $\mathrm{N}$-vanillylnonanamide and nomifensine maleate are $19.67 \%$, $34.75 \%, 37.70 \%$, and $36.83 \%$ in comparison with the controls capreomycin and ciprofloxacin that are $31.48 \%$ and $8.41 \%$.

The $\mathrm{Z}$ factors for the synthetic library were also calculated and were found to be 0.645 for rifampicin, 0.388 for capreomycin and 0.797 for ciprofloxacin. This proved that the synthetic library high-throughput screening results were reliable. 
Chapter 6

General Discussion 


\section{Chapter 6 \\ General Discussion}

\subsection{General discussion}

The aim of this thesis was to develop an intra-macrophage infection assay for characterizing novel anti-TB compounds. As already discussed in the previous chapters there is a growing need for research in the field of TB drug discovery. Hence different cell based and in vitro assays are used so as to discover novel anti-TB drugs and their targets. Currently, about 614 and 194 essential genes are known necessary for mycobacterium in vitro and in vivo survival, respectively. These are essential genes, genes responsible for mycobacterial persistence and energy production pathways can act as novel antimycobacterium drug targets (Zhang et al., 2003).

The development of the intramacrophage assay involved colony forming units (CFU) measurement as a primary step so as to calculate the MOI 10:1. The macrophages (seeded at cell density $10^{5}$ cells/ well) were infected by GFP labelled M. smegmatis and incubated at $37^{\circ} \mathrm{C}$ for $96 \mathrm{hrs}$. The intramacrophage infection assay was initially standardised against known antituberculosis drugs. The intramacrophage $\mathrm{IC}_{50}$ values for rifampicin, ciprofloxacin, capreomycin and ethambutol were found to be 2.40, 2.60, 1.75 and 14.97 respectively. These values were compared with the in-vitro 
values and no significant differences were found between the in-vivo and in-vitro $\mathrm{IC}_{50}$ values except for ethambutol (Table 3.2).

This was followed by the development and validation of minilibrary demo high throughput screen. The mini-high-throughput library comprised of some of the validated in vitro hits from the LOPAC library (Table 2.1) and common antituberculosis drugs in a 96-well plate format. This was also followed by the cytotoxicity assays in order to determine the potency of the compounds included in the minilibrary. The validation was achieved by the Opera high throughput confocal microscope images as already discussed. Positive control measurements (growth inhibition) were carried out identically except for inclusion of known antibiotics at a final concentration of $20 \mu \mathrm{M}$. Negative control measurement (100\% growth) was achieved identically without addition of any antibiotic/ test compounds. Also effects of DMSO were studied in macrophages as it was the vehicle for compound dispersion. There was a very little effect of DMSO seen on phagocytosed mycobacterium (Figure 3.9). Gentamycin was used at a concentration of 25 $\mu \mathrm{g} / \mathrm{ml}$ so as to prevent the extracellular mycobacterium growth without effecting the growth of phagocytosed mycobacterium. The screening was done in triplicates with test compounds at $20 \mu \mathrm{M}$ final concentration. Compounds producing $>75 \%$ mycobacterium growth inhibition were considered as hits. This resulted in four compounds with positive activity against intramacrophage mycobacterium and no cytotoxicity. The intramacrophage $\quad \mathrm{IC}_{50}$ values for ofloxacin, lomifloxacin, 1,10 phenanthroline and zinocycline were 2.62, 11.13, 7.45 and 0.16 
respectively. These values were validated from opera images obtained from high throughput confocal microscope (Figure 3.6). Again the in-vitro and intramacrophage $\mathrm{IC}_{50}$ values were compared (Table 3.4). Significant differences were found in 1,10 phenanthroline in-vitro and in-vivo $I_{50}$ values which were found to be 7.45 and 41.64 respectively.

The successful set up of minilibrary demomodel development and validation was followed by actual LOPAC synthetic library screening. The outcome of LOPAC synthetic library involved the discovery of five intramacrophage specific hits that were not detected in any in vitro assays yet. The $\mathrm{IC}_{50}$ values for the intramacrophage hits obtained such as 4-amino 1, 8 naphthalamide, $\mathrm{N}$-vanillylnonanamide and epibestatin hydrochloride were 8.2, 194.55 and 47.475 respectively (Table 5.2). These compounds were validated from opera high throughput images (Figure 5.2). All of these reported compounds were associated with low cytotoxicity along with significant antimycobacterial property against the phagocytosed mycobacterium. Hence in future these can be further prodeeded for the drug development. Some of the known interesting facts about these compounds are described in the following sections.

Novel antibacterial dyes derived from naphthalamide are known to be used in the textile industry because of their bactericidal activity against both gram positive and negative bacterium (Khodaei et al., 2009). A series of the naphthalimide polyamine conjugates were synthesized and their in vitro $I_{50}$ values were calculated and compared. It was found that the potency of 
naphthalimde was elevated with the substitution of the amine functional group. 1,8 Naphthalimde and 4 amino 1,8 naphthalimide have been tested as pharmacophores previously and reported to be the least toxic against different cell lines with $\mathrm{IC}_{50}=>50 \mu \mathrm{M}$ (Tian et al., 2009). Naphthalamide is also known to inhibit E.coli and Pseudomonas aeruginosa with a percent of inhibition at $12.5 \mu \mathrm{M}$ of 100 and 40, respectively (Fuente et al., 2006).

$\mathrm{N}$-vanillylnonanamide is a known antibacterial, anti-inflammatory, analgesic, antinociceptive and antioxidant. It is reported to be as a better antibacterial agent than ampicillin with a zone of inhibition of $10.6 \mathrm{~mm}$ and $9.00 \mathrm{~mm}$ respectively against the gram negative bacterium E.coli. The MIC of capsacin against different bacteria ranges from 33-82 $\mu \mathrm{M}$ concentration (Tsuchiya., 2001).

Epibestatin hydrochloride is known to induce macrophage cytokine secretion at low concentration of $2.9 \mu \mathrm{M}$ that is further responsible for its activation. This can enhance the antimycobacterial potential of the macrophages (Bauvois and Dauzonne, 2006).

Green fluorescent protein was proved to be an efficient marker in detection of intramacrophage hits that were not be detected by any in vitro assays before. Another sensitive reporter that can be used that is approximately equivalent to GFP is the bioluminescence-based luciferase enzyme system as already discussed. The long duplication time of a mycobacterium renders the bioluminescence more advantageous for such screening 
assays than the use of traditional colony forming units (CFU) measurements.

Structural-activity relationship studies can be also carried out on these intra-macrophage specific hits. Many analogues of these hits detected from the intra-macrophage assays can be made by changing the chemical substituents during the synthesis of the compounds. This can be followed by testing of these structural analogues with different in vitro assays against different $M$. species, human and animal cell lines along with the intramacrophage assays developed as well. This will provide more information about the role of the chemical substituents necessary for the antimycobacterial property of the novel antituberculosis drugs.

The intra-macrophage assay can also be followed by a whole animal live infection screening step for the detection of both narrow and broad spectrum antibiotics. This whole animal assay would help in the detection of the in vivo efficacy of the compounds and also characterise prodrugs that are modified by the host to form an active antimycobacterial compound. It will also help in the study of complex biological processes such as growth, reproduction, aging and immunity.

Some known examples of animal infection models are described as Caenorhabditis elegans infected with human pathogens such as Enterococcus faecalis, Pseudomonas aeruginosa, Salmonella enterica etc (Moy et al., 2006). These organisms can be studied for different purposes in $C$. elegans by just replacing the food source according to the type of 
pathogens and monitoring the host survival. The simplicity of such assay set up enables high throughput screening, chemical and genetic analysis. The comparison of antibiotic treated and non drug treated E. faecalis infected nematode showed better host survival in drug treatment (Moy et al., 2006).. This screening model can be used for the identification of natural and synthetic compounds that promotes host survival. This type of infection assay will also help in the estimation of the in vivo drug efficacy. It will also aid in the discovery of novel drugs that target the host pathogen interaction.

Other common whole live animal infection models are known that uses many human pathogens that have low species specificity as they can infect a wide range of hosts from insects, nematodes and fish to mammals. The significance of using such non-mammalian models in whole animal infection assays is because of their already sequenced complete genome and ease of culture. These non mammalian models rely on universal virulence factors similar to that of the real biological system study models. Non-mammalian animal models that can be used for mycobacterial infection studies are the cellular slime mold amoeba $D$. discoideum, the nematode Caenorhabditis elegans, the insect Drosophila melanogaster and the fish Danio rerio. $D$. discoideum can be used to illustrate the molecular basis of phagocytosis and phagosome maturation (Kurz and Ewbank, 2007). D. melanogaster possesses a well-studied innate immunity that can help in the understanding of innate mechanisms in mammals and the mechanisms of pathogen evasion by the host immune system (Kurz and Ewbank, 2007). $D$. 
rerio is used for illustrating genetic screens for bacterial virulence genes in vertebrates with a fully developed immune system (Kurz and Ewbank, 2007). The virulence of a number of human pathogens such as Pseudomonas aeruginosa, Salmonella typhimurium, Listeria monocytogenes, Yersinia pestis and Vibrio cholerae are known to be studied using such whole animal infection models (Kurz and Ewbank, 2007). These non mammalian models will enable us to elucidate the complex host pathogen interactions and virulence factors. .

Recent advances in drug discovery also involve the implication of polymeric [Poly (dimethylsiloxane)] chip-based microdevices (PDMS) in the development of the both intra-macrophage and live animal infection assays. PDMS is reported to be non-toxic, inexpensive, gas impermeable and supportive of both adherent and suspended cell culture with no observable cross-contamination between adjacent cell chambers. It is also compatible with the high resolution automated multicolour imaging for both live and fixed cells and hence will help in the dynamic analysis of drug induced cytotoxicity. It will make the validation step using the image analysis software faster than in the present assay set-up.

At last to conclude this thesis presents the intramacrophage assay as an alternative that may be used in the discovery of several promisisng novel inhibitors that target host pathogen interactions or pathogenesis of tuberculosis or functions that are important for in vivo survival, virulence or host immunity activators (Moy et al., 2009). 


\section{Appendix A}

(I) Image - iT stain:

$1 \mathrm{mg} / \mathrm{ml}$ of wheat germ agglutinin or alexa flour 594 conjugate in phosphate buffer saline (PBS) and $1 \mathrm{mM}$ hoechst 33342 dye.

(II) $1 \mathrm{X}$ Krebs buffer recipe $(\mathrm{gm} / \mathrm{I})$ :

$\mathrm{NaCl}-7.5972, \mathrm{KCl}-0.0970, \mathrm{CaCl}_{2}-0.2442, \mathrm{MgSO}_{4} .6 \mathrm{H} 2 \mathrm{O}-0.2742$,

$\mathrm{KH}_{2} \mathrm{PO}_{4}-0.163$, HEPES - 2.603 and Glucose $(\mathrm{pH} 7.4)-1.8016$.

This mixture is sterile filtered before use.

(III) 1X Phosphate buffer saline (gm/ I) (PBS):

$8 \mathrm{gm}$ of $\mathrm{NaCl}, 0.2 \mathrm{gm}$ of $\mathrm{KCl}, 1.44 \mathrm{gm}$ of $\mathrm{Na} 2 \mathrm{HPO} 4,0.24 \mathrm{gm}$ of $\mathrm{KH}_{2} \mathrm{PO}_{4}$

Adjust $\mathrm{pH}$ to 7.4. The mixture was autoclaved before use.

(V) MTTreagent: $5 \mathrm{mg} / \mathrm{ml}$ in PBS.

(VI) MTT solubiliser: $10 \%$ sodium dodecyl sulphate (SDS) in $0.01 \mathrm{~N} \mathrm{HCl}$. 


\section{Appendix B:}

\section{(I) Image acquisition of image-iT stained, infected macrophages}

The $\mathrm{J} 774$ macrophages were cultured in $35 \mathrm{~mm}$ glass-bottomed dishes with a coverslip (tissue culture Fluorodishes, MatTek, catalogue no: FD35$100)$ and incubated at $37{ }^{\circ} \mathrm{C}$ until an appropriate (80\%) confluence was achieved. This was followed by infection with GFP-labelled mycobacteria. An Olympus FV1000 confocal microscope was used to acquire images of image-iT stained infected macrophages.

The infected macrophages were stained with image-iT stain as described in the previous sections. The images were acquired with the 20x air lens, $60 x$ water lens or $100 x$ oil immersion lens depending on the magnification required. The 405, 473, $635 \mathrm{~nm}$ lasers was used for primary use with DAPI (Hoechst 33342 nucleus stain), GFP (M. smegmatis pLL192hsp60) and RFP (Alexa flour 594 WGA plasma membrane stain) respectively. Ten Z stacks were taken. Optimal HV (image intensity) and offset was set between range 700-900 and 7-10 respectively such that some blue spots could be seen on the image acquired. The pixel speed and laser intensity was set depending on the imaging speed needed keeping bleaching effects due to the lasers used in mind. 
(I) Olympus FV 1000 Confocal microscope image acquisition using image - iT stain:

(a) Put the specimen slide with coverslip facing down. The image has to be acquired using the lowest magnification 20X, 40X, $60 \mathrm{X}$ and then to $100 \mathrm{X}$.

(b) Gets the image into focus using the transmitted lamp. First top left buton in Image acquisition control box (IAC)

(c) Click on epi flourscence - second left button in IAC.

(d) Click on dyelist - third left button in IAC. A dyelist box will come up. Select lasers to be used and then apply.

(e) Pixel setting and laser setting should be kept as low as $2.0 \mu \mathrm{s} /$ pixel and $5 \%$ in acquisition setting box (AS).

(f) Take off Kalman filter in IAC.

(g) To view the image - click xy repeat, focusX2 and focusX4. If the sample bleaches fast select focusX4.

(h) Go ctrlH to get HiLo to set intensity.

(i) Adjust image intensity using HV in IAC. Optimal HV setting lies between $700-900$.

(j) Set laser intensity, HV and Offset by focussing up and down your sample. 
(k) To peform z stack. Select depth in IAC. Clear start/ end in AS box, deselect step sizes and slices. Put 0 in step size and press enter. Set start and end. Set slices or step size as required.

(I) Set pixel speed (for example $4 \mu \mathrm{s} /$ pix in AS. Select Kalman, sequential in IAC. For image acquisition using $\mathrm{z}$ stacks use $\mathrm{XYZ}$ or else use $\mathrm{XY}$ repeat.

(m) Click on series done when imaging is complete.

(n) Put color and scale bar using different buttons on left side of 2D view.

(o) Save image as oib by right clicking on 2D view - save select folder - name image - save. 


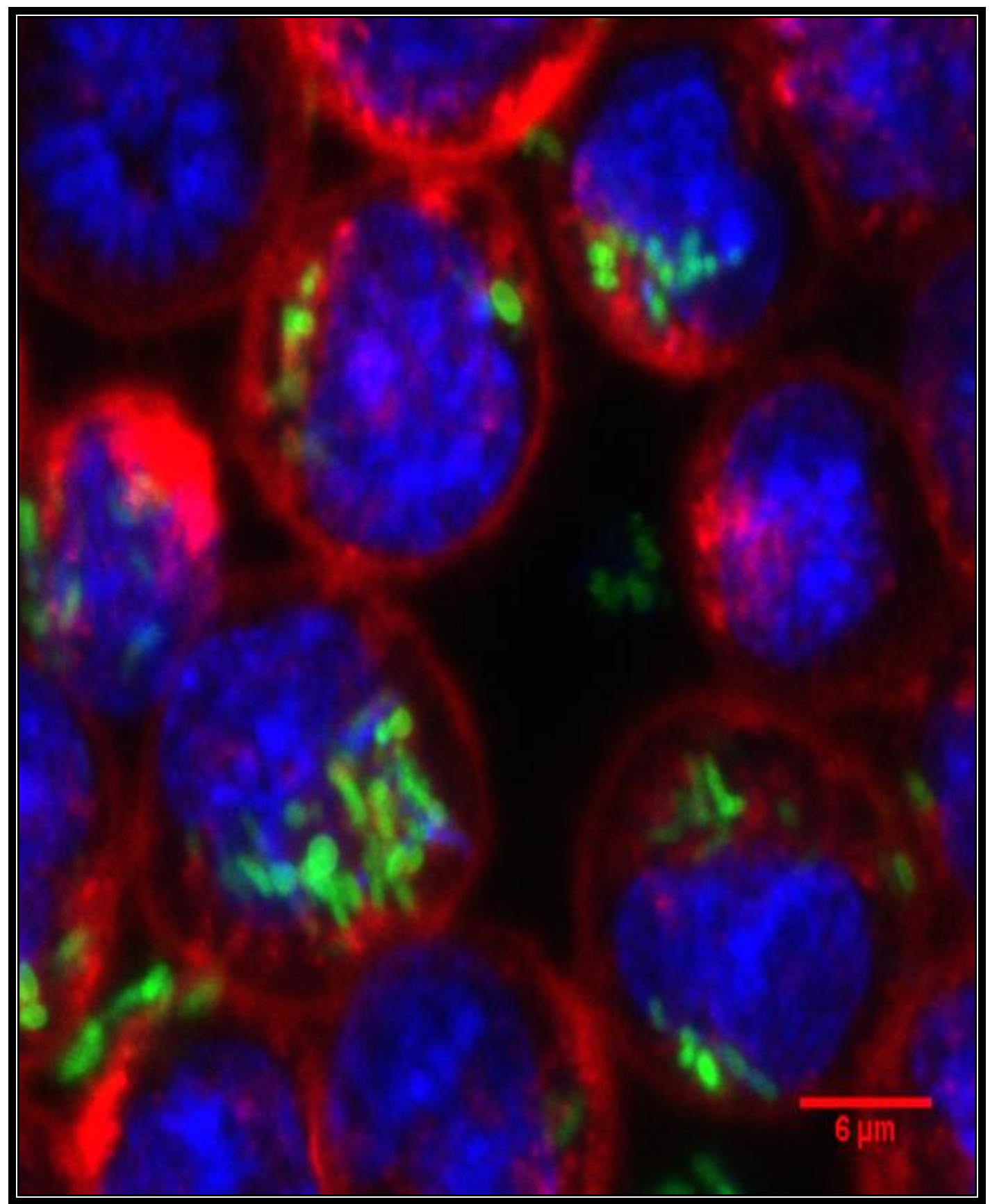

Figure 7.1 Montage of the image acquired by Olympus FV1000 confocal microscope. In this image red is macrophage (Alexa flour stained - RFP) blue is nucleus (DAPI stained) and green is mycobacterium (GFP labeled). 


\section{Appendix C:}

\section{(I) Image J software analysis (Procedure)}

The procedures followed for image analysis for the specific acquired images are:

a) Install Image $\mathrm{J}$ and run it.

b) Go to "File" - > "Open" and select one of the flex files.

c) A dialog box will pop up, which has a whole lot of options in it.

d) Enter the following settings: "View stack with" - > Standard Image J and "stack order" - > XYCZT and under "colour options" tick "RGB colorize channels" and "autoscale".

e) Close the flex file.

f) Go to "Plugins" - > "Macros"- > "Run" and select the macro densitometry script file.

g) It should prompt to the parent folder with flex files in different subfolders.

h) Select the top-level parent folder and it will work through all of the subfolders opening any flex files it finds and run the macro script on them.

i) The results obtained will be in the order: GFP (bacteria), RFP (macrophages) and DAPI (nuclei). It provides additional necessary information such as total area, mean fluorescence, standard deviation, and the "integrated density". 
(II) Display of images using image $\mathrm{J}$ software:

For display purposes, the acquired images were passed through the following steps.

(a) Go to image $->$ color - >split channels. It will split the image into three channels resulting in GFP from channel 1, RFP from channel 2, and DAPI from channel 3 and each channel comprising of $7 \mathrm{Z}$ stacks.

(b) Image $->$ stacks $->Z$ project [start=1 to stop=7 projection $=[$ sum of max Intensity]" for each of the three channels.

(c) Image - > Adjust - > brightness/ contrast - > set threshold - > apply LUT. This will drag the minimum threshold to the maximum enhancing the brightness/ contrast of the images acquired.

(d) Image - > color - > merge channels.

These adjustments resulted in a final image in which GFP (green) was the mycobacterium, RFP (red) was the macrophage and the DAPI (blue) was the nucleus. 


\section{Appendix D:}

IC50 dose response curves (Chapter 4)

\section{(I) Antituberculosis drugs}

Isoniazid (IC50 - $326.2+/-0.02 \mu \mathrm{M}$ )

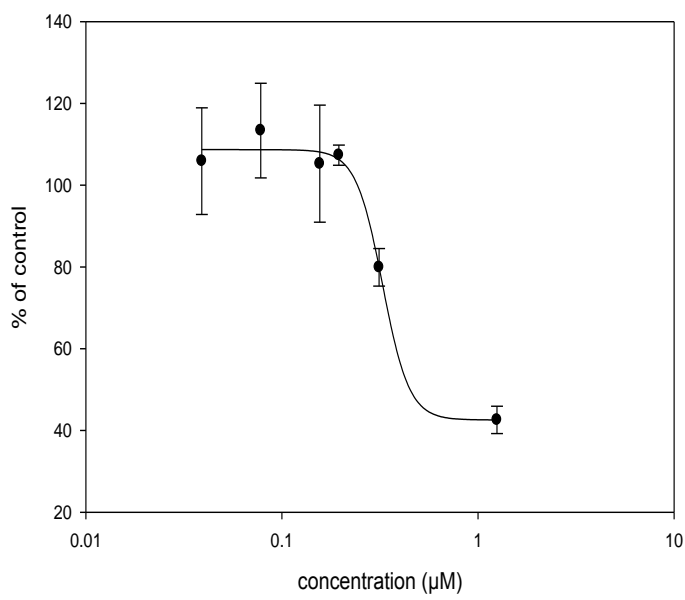

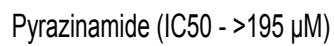

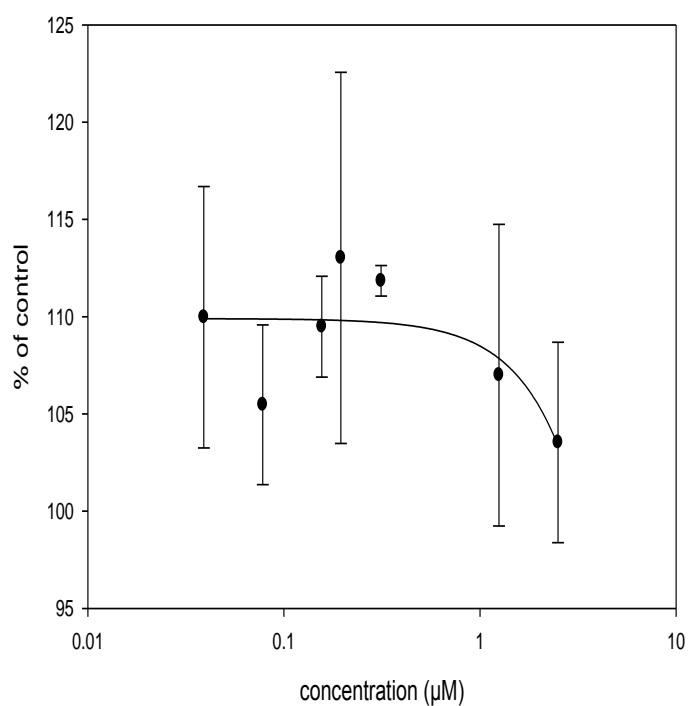

Ciprofloxacin (IC50 - $78.34+/-24.54 \mu \mathrm{M})$

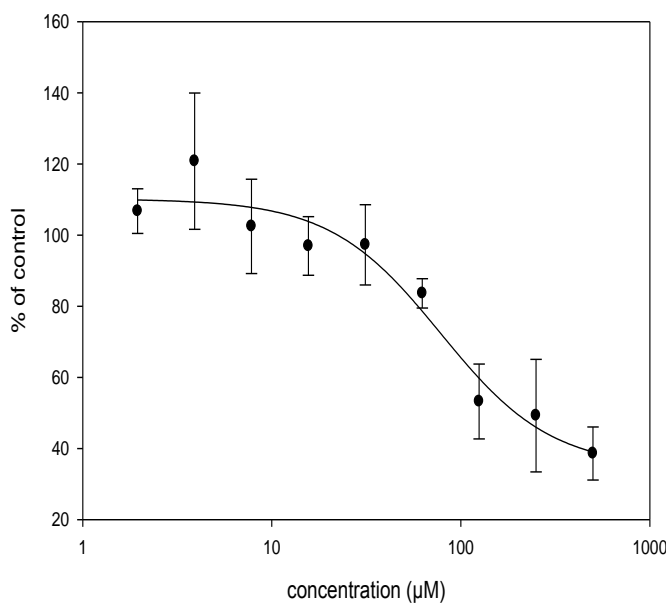

Ethambutol (IC50 $=1.15+/-0.094 \mathrm{mM})$

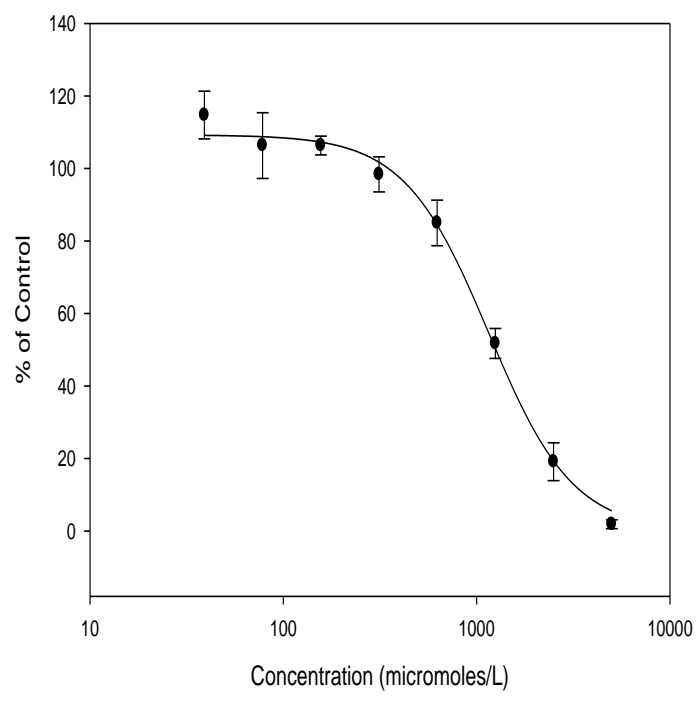




\section{(II) Solvents}

Dimethyl sulphoxide (IC50 - $0.806+/-0.116 \mu l /$ well)

Chloroform (IC50 $=0.82+/-1.655 \mu$ l/well)
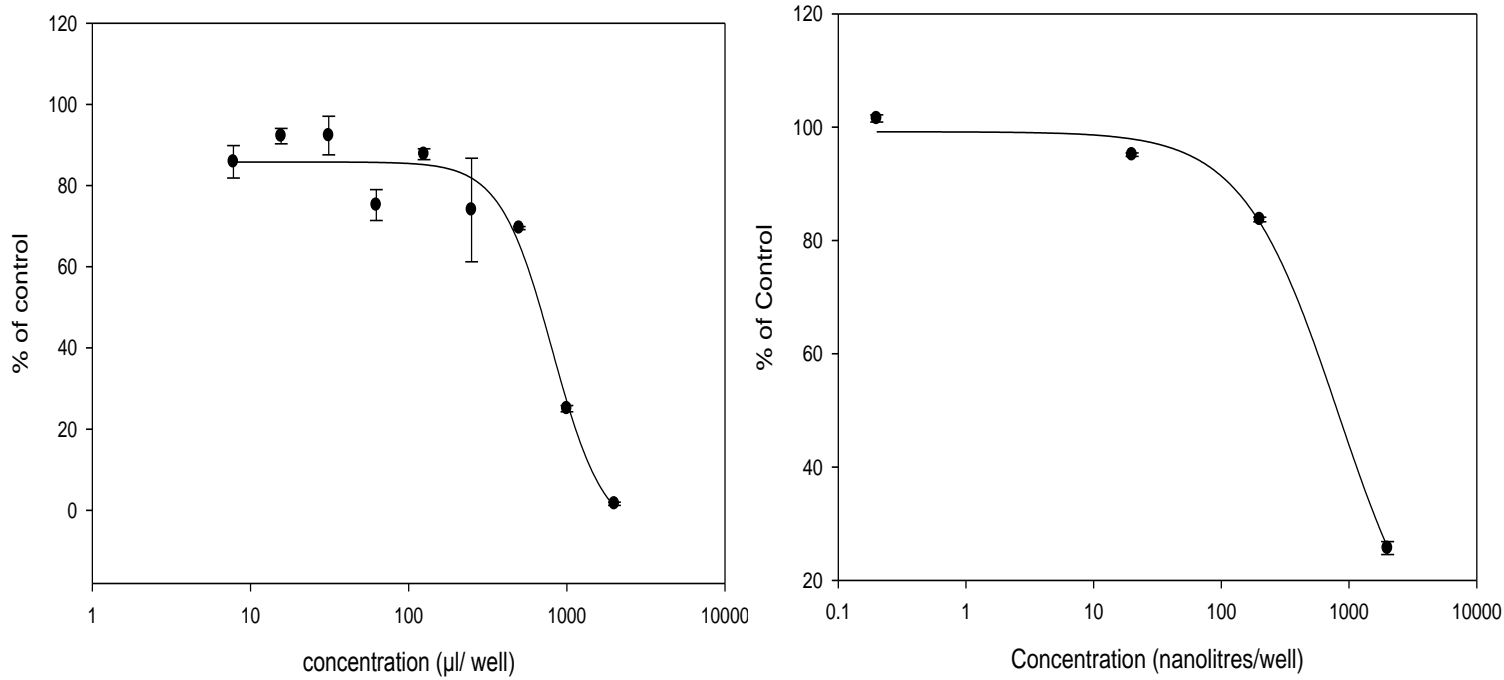

Ethanol (IC50 = $1.03+/-31.259 \mu$ l/well $)$

Methanol (IC50 $=0.73+/-9.586 \mu l /$ well)
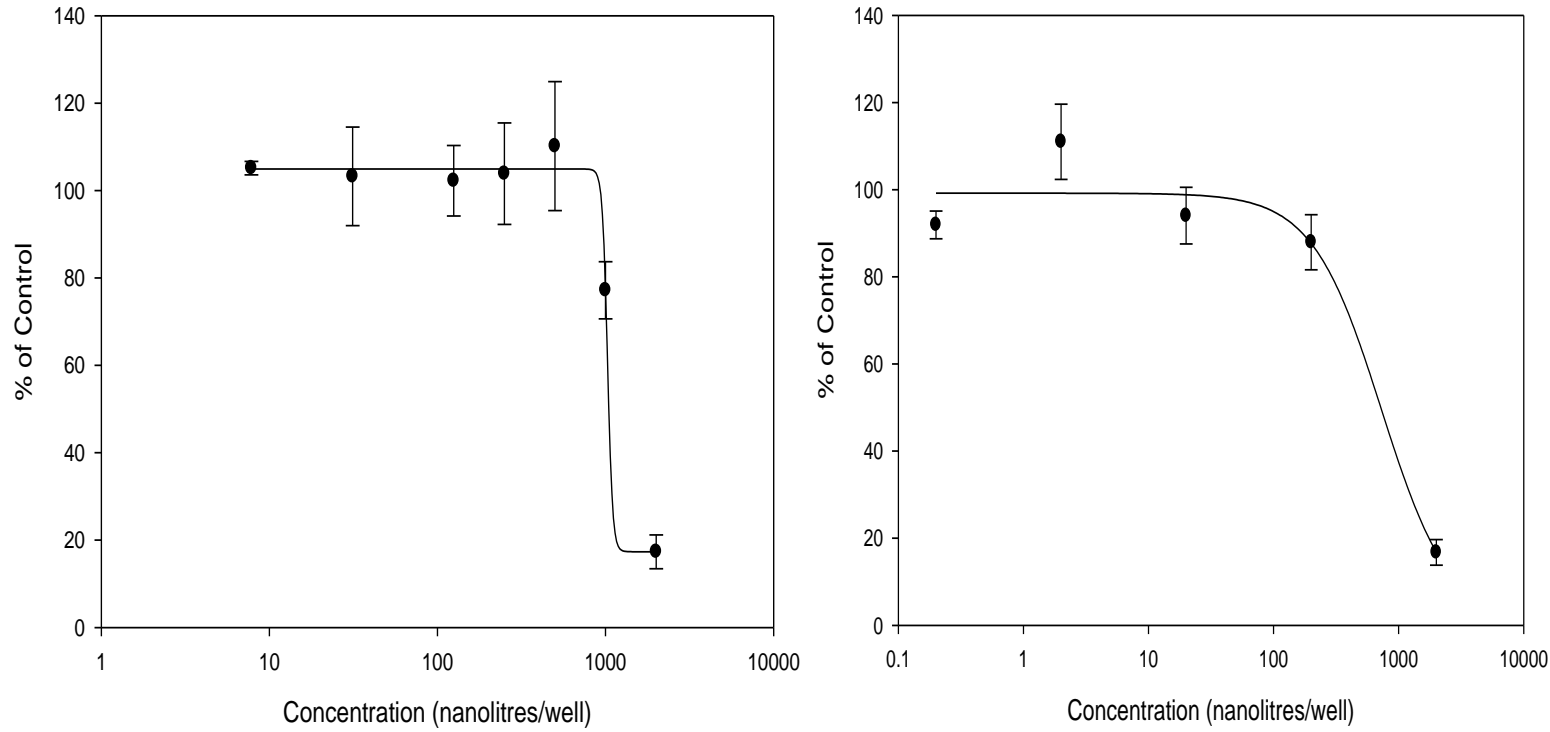


\section{(III) Cytotoxic compounds}

Epothilone A (IC50 - 6.74 +/- 2.85 nM)

Mycalamide (IC50 - $0.7287+/-0.0702$ nM)
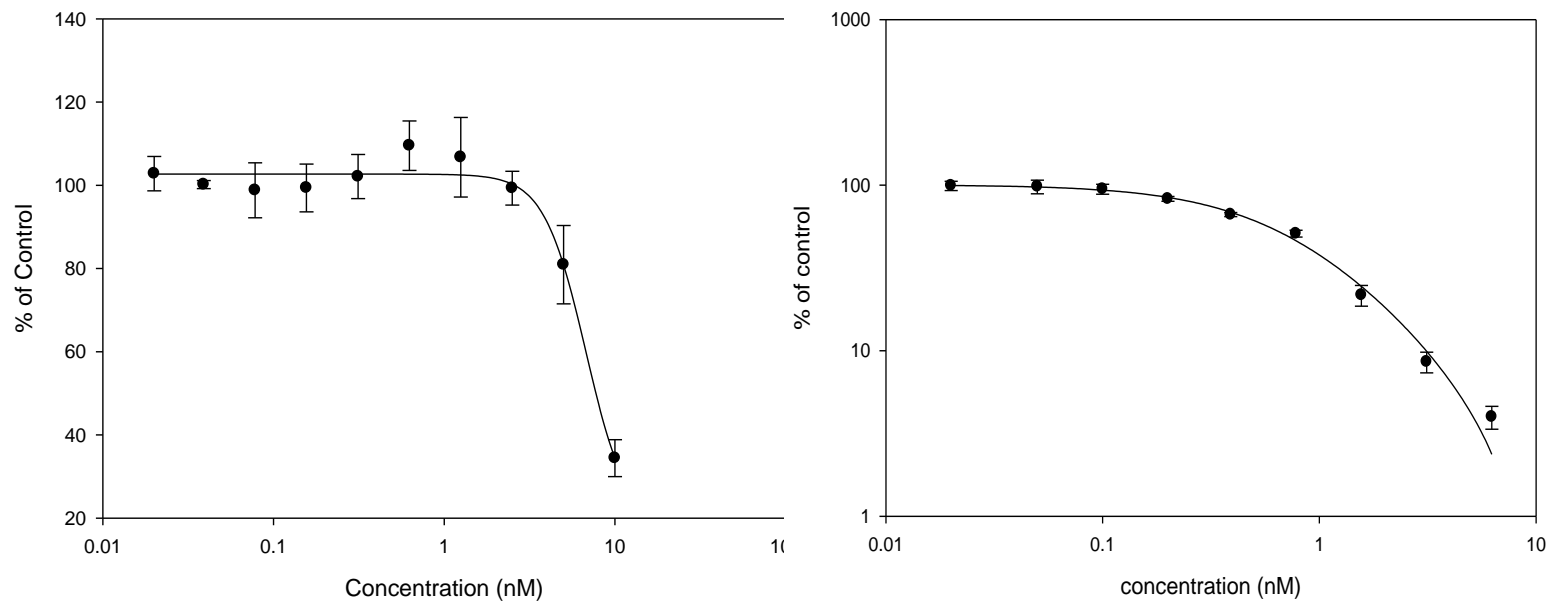

(IV) LOPAC compound series.

Zinocycline $($ IC50 = $13.41+/-1.61 \mu \mathrm{M})$

Diphenyleneiodonium chloride (IC50 - $3.6+/-0.73 \mu \mathrm{M}$ )

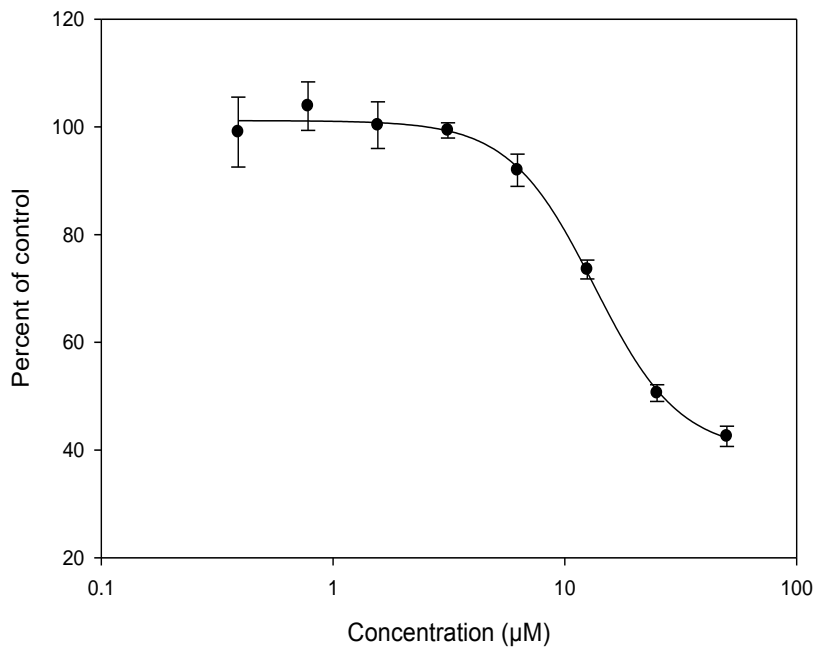

Rilmedine (IC50 - 63.01 +/- $28.24 \mu \mathrm{M})$

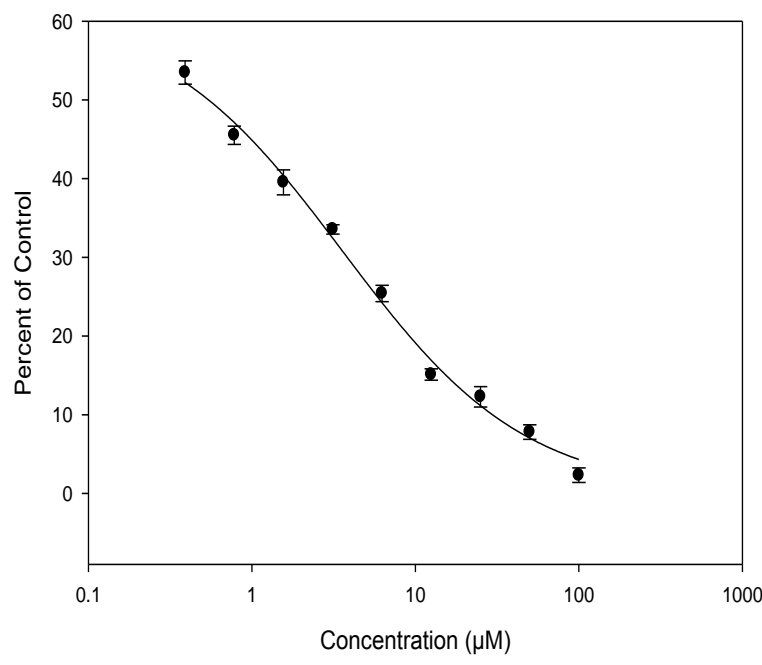

Sanguinarine (IC50 - $0.138+/-6.19 \mu \mathrm{M})$
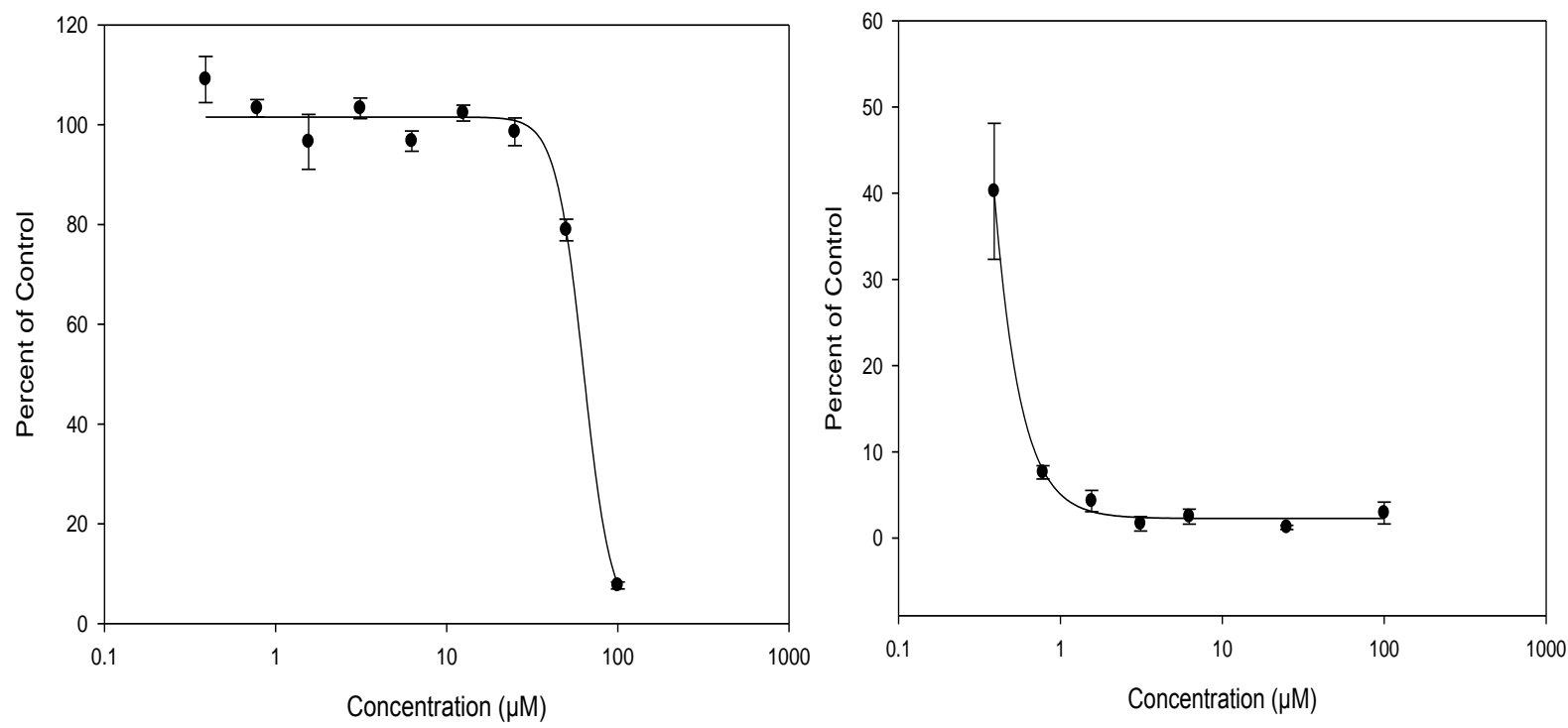
Idaubicin (IC50 - $8.27+/-1.69 \mu \mathrm{M})$

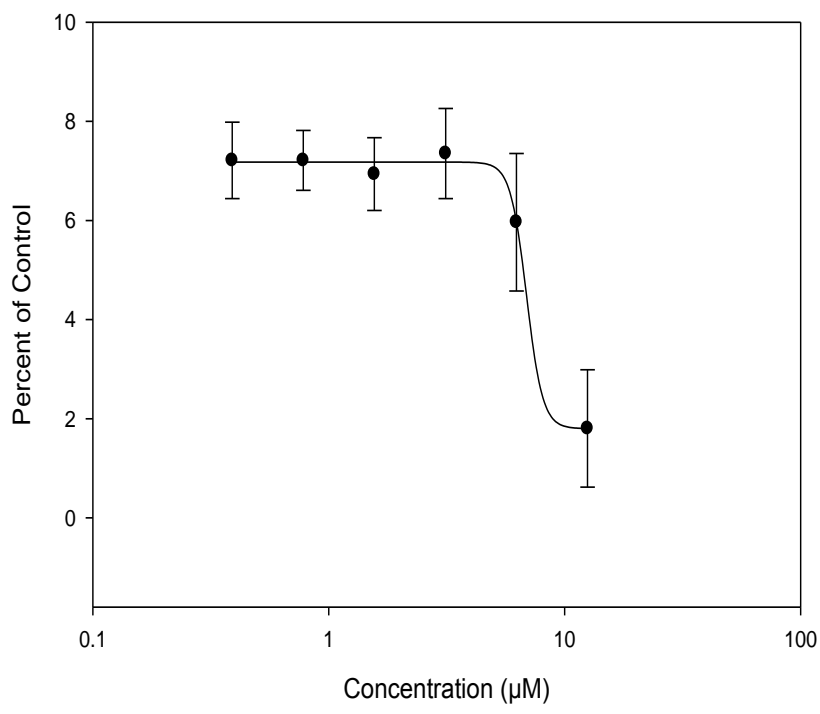

WB $64($ IC50 $=90.26+/-9.11 \mu \mathrm{M})$

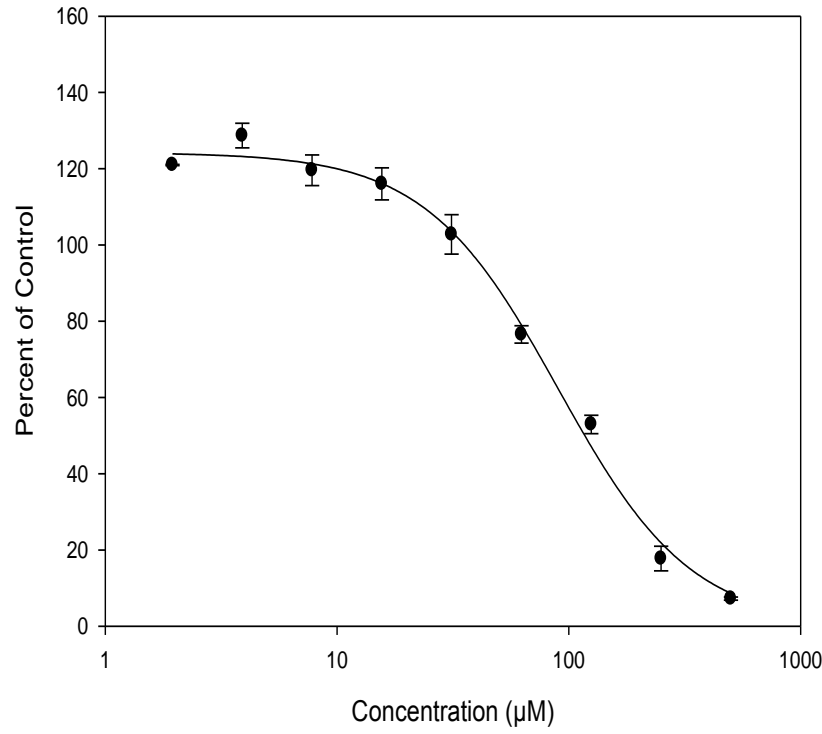

Dequalinium analog (IC50 - $1.26+/-0.11 \mu \mathrm{M})$

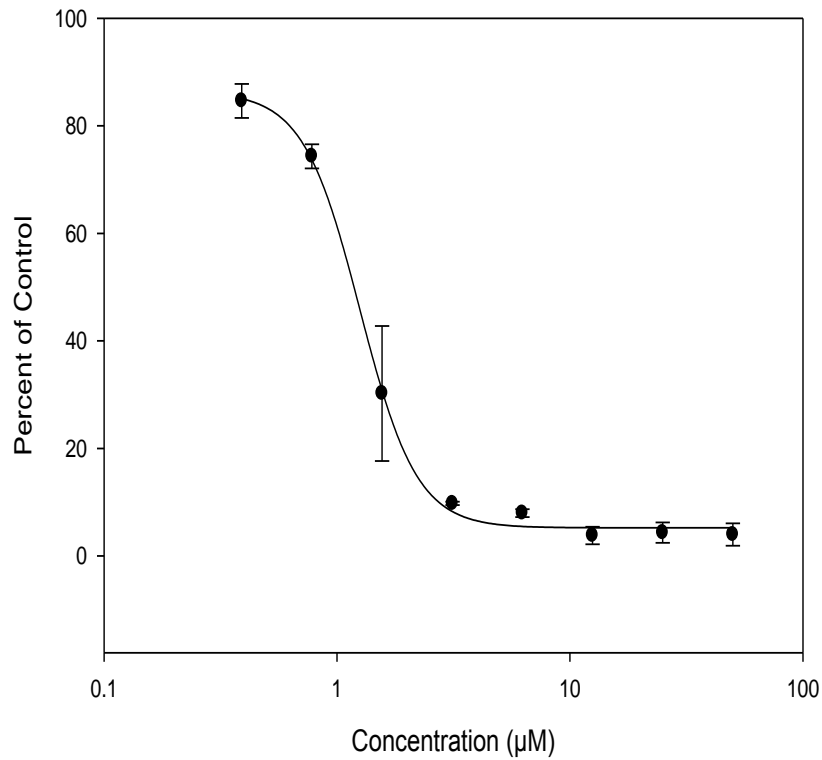

1,10 Phenanthroline $($ IC50 $=1.95+/-0.08 \mu \mathrm{M})$

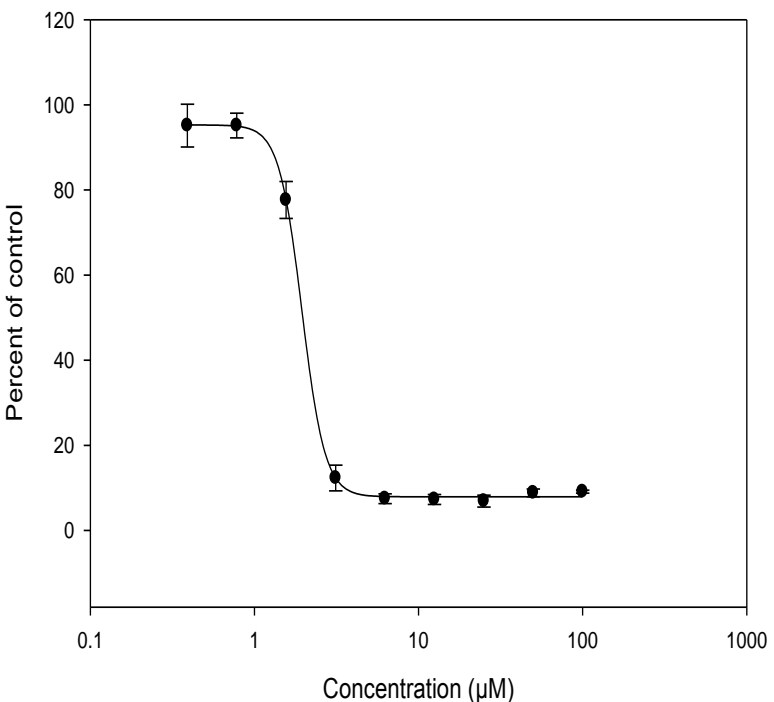

Trifluoperazine (IC50 - 8.71 +/- $0.81 \mu \mathrm{M}$ )

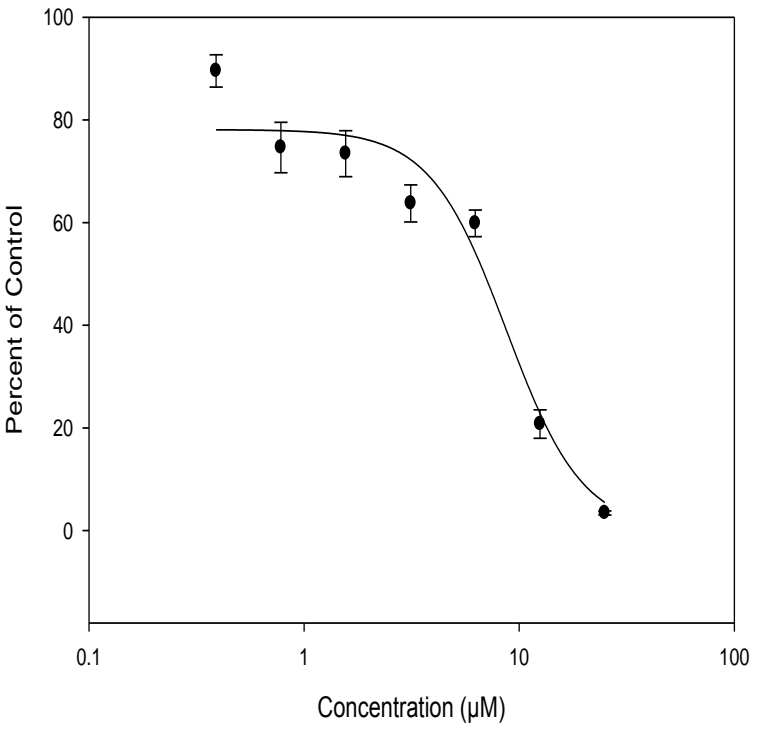

Lomefloxacin $\mathrm{HCl}(\mathrm{IC} 50=335.72+/-2750.48 \mu \mathrm{M})$

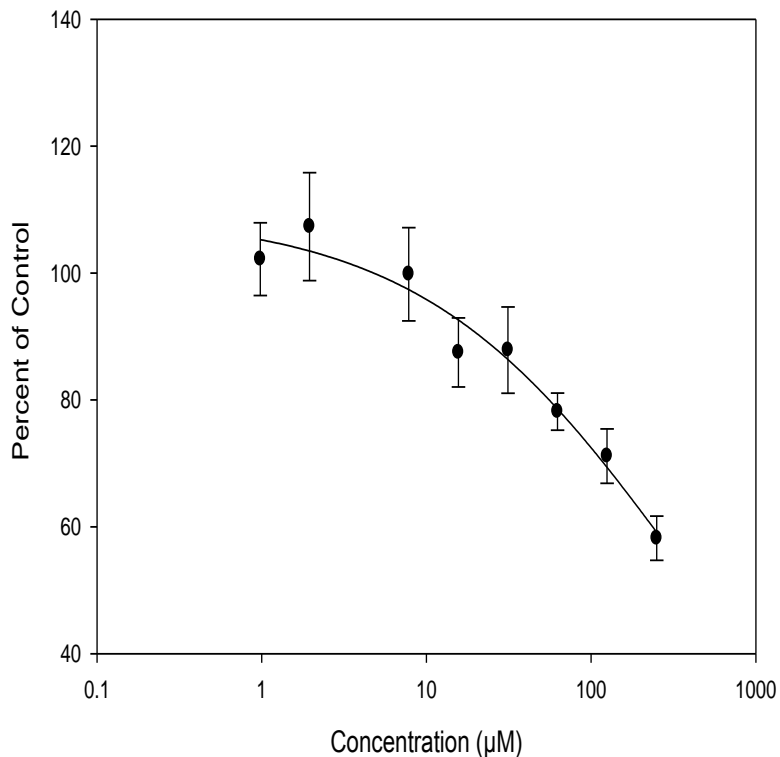


Minocycline $($ IC50 $=6.37+/-1.30 \mu \mathrm{M})$

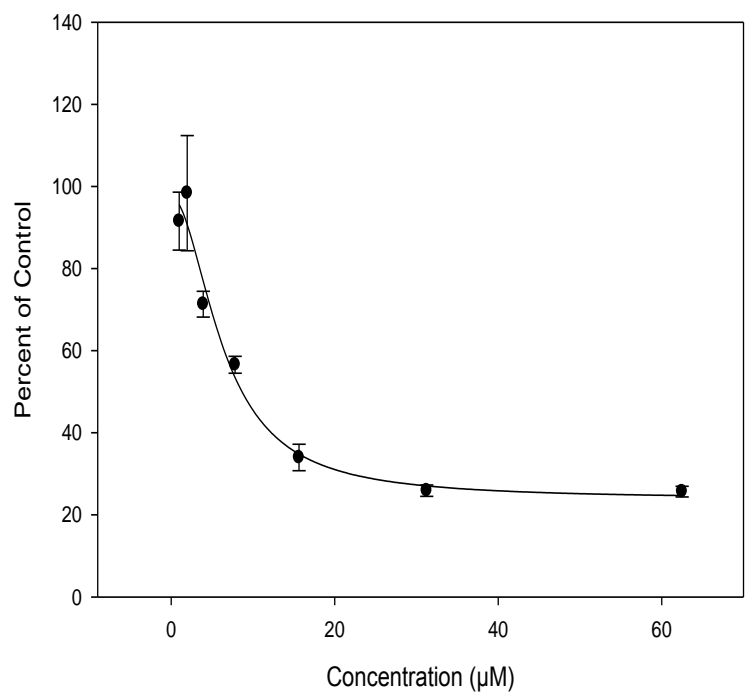

Droperidol (IC50 - $27.52+/-6.27 \mu \mathrm{M})$

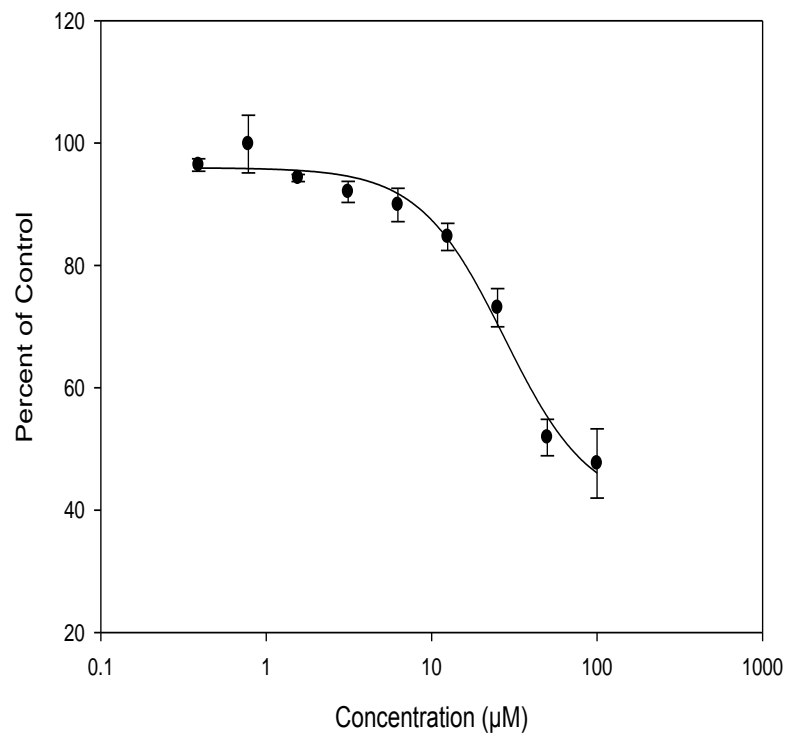

LY-367265 $($ IC50 $=25.21+/-5.07 \mu \mathrm{M})$

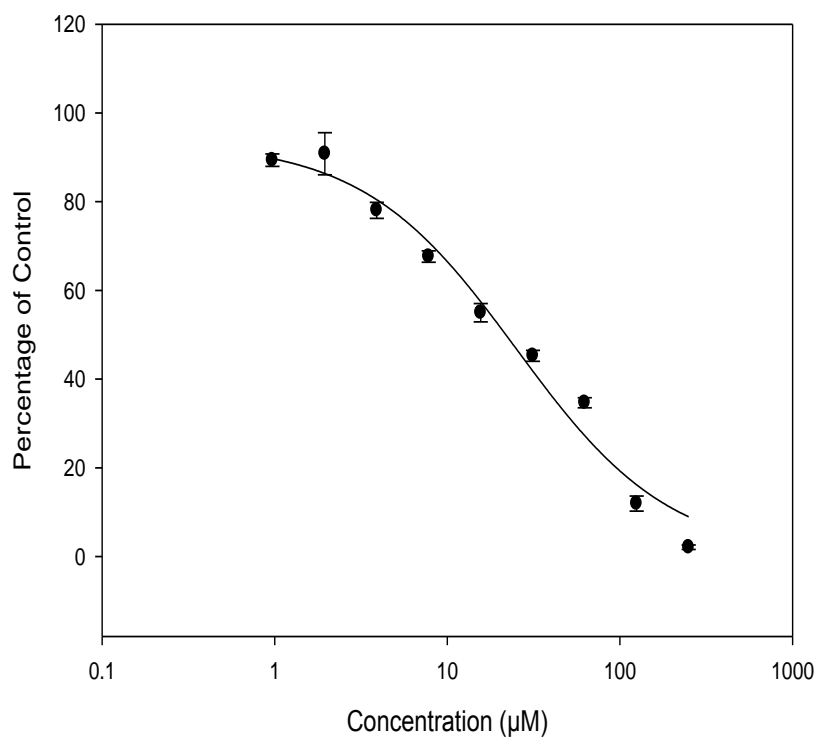

Ofloxacin (IC50 = $112.19+/-132.12 \mu \mathrm{M})$

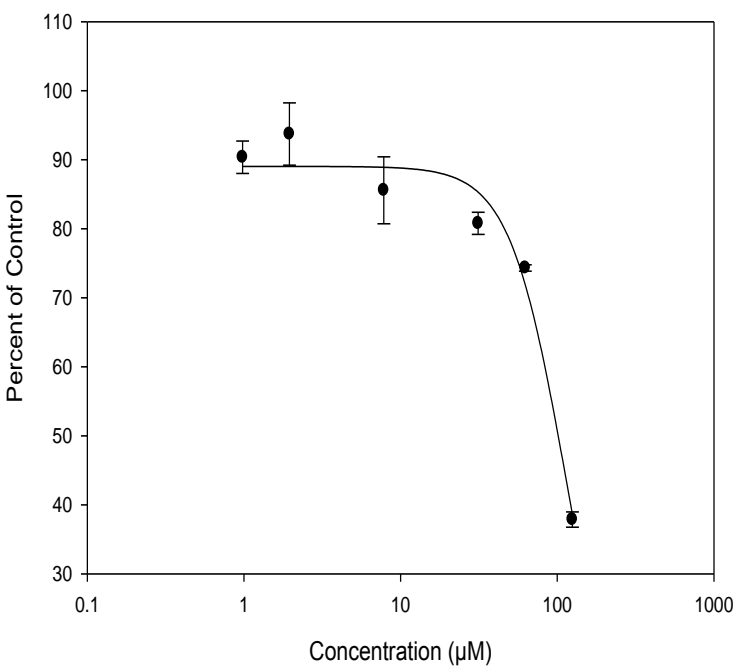

Clotrimazole $($ IC50 $=2.37+/-0.12 \mu \mathrm{M})$

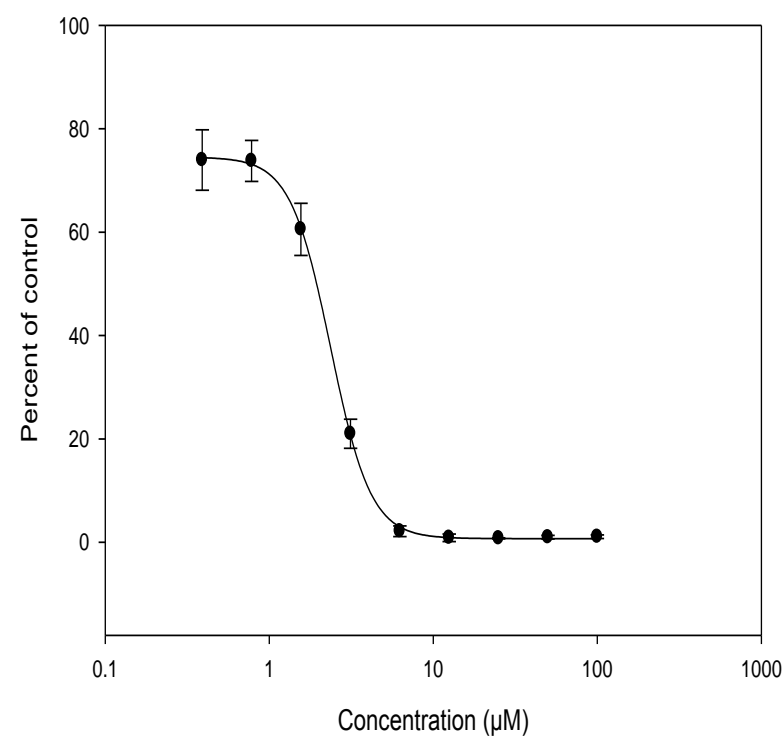

Resveratrol (IC50 - 16.11 +/- $1.82 \mu \mathrm{M})$

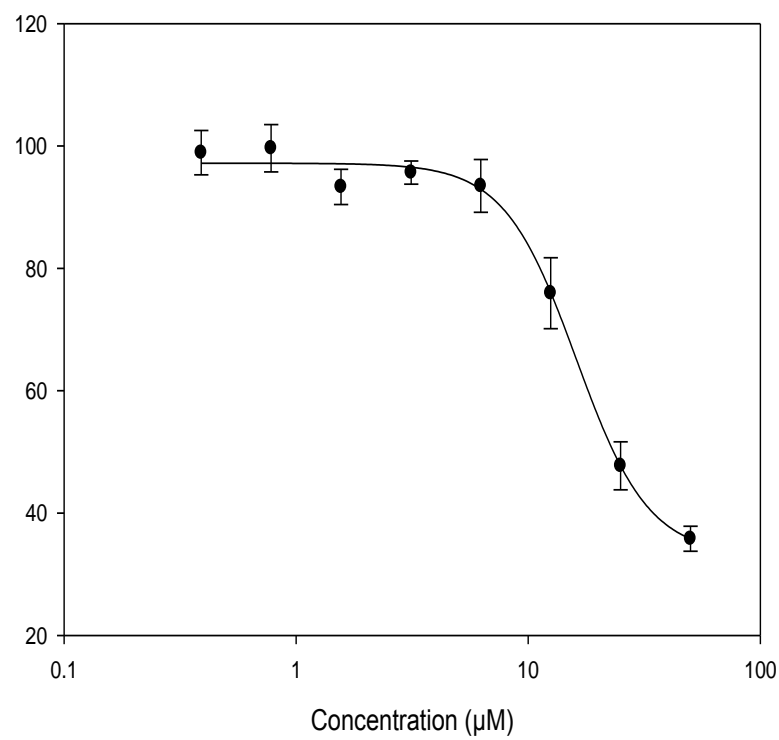


Methocramine $($ IC50 $=39.20+/-41.87 \mu \mathrm{M})$

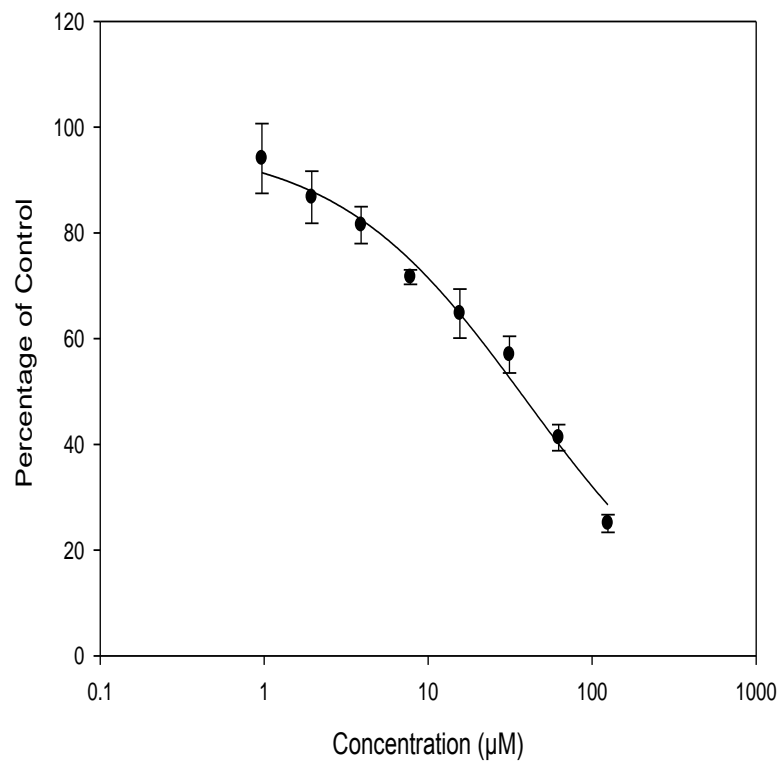

Se - methyl - selenocystiene $($ IC50 $=25.62+/-8.81 \mu \mathrm{M})$

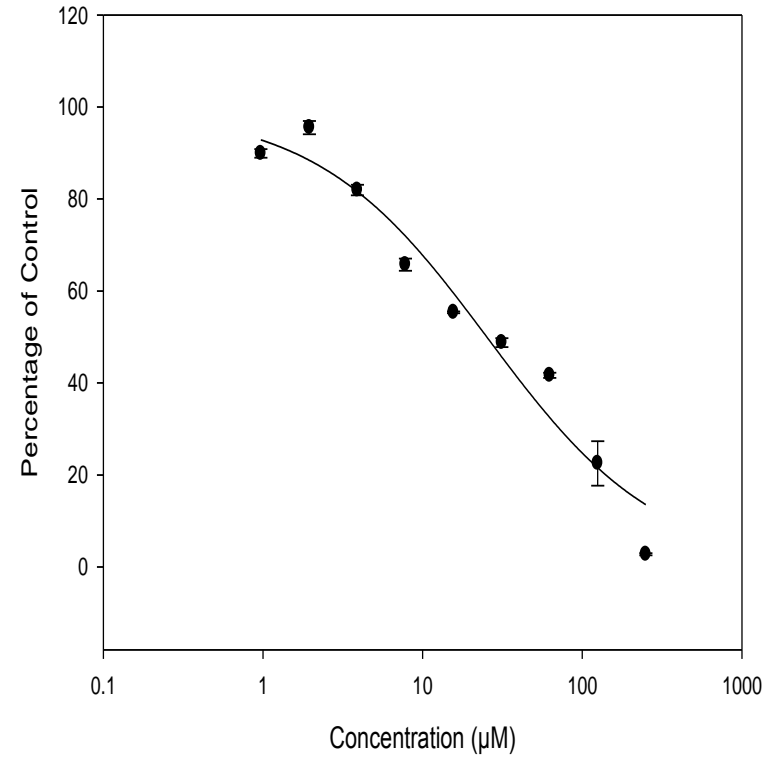

162 | P a g e 


\section{References}

Aderem, A., and Underhill, D. M., 1999, Mechanisms of phagocytosis in macrophages, Annual review immunology, v. 17, p. 593 - 623.

Al - Nasiry, S., Geusens, N., Hanssens, M., Luyten, C., and Pijnenborg, R., (2007), The use of Alamar blue assay for quantitative analysis of viability, migration and invasion of choriocarcinoma cells, Human Reproduction, v. 22, p. $1304-1309$.

Andreu, N., Zelmer, A., Fletcher, T., Elkington. P. T., and Wiles, S., 2010, Optimisation of bioluminescent reporters for use with mycobacteria, Public library of sciences, v. 5.

Anderson, M. I. and MacGrown, A. P., 2003, Development of the quinolones, Journal of antimicrobials and chemotherapy, v. 51, p. $1-11$.

Apt, A., and Kondratieva, T. K., 2008, Tuberculosis: Pathogenesis, immune response, and host genetics, Molecular biology, v. 42, p. $784-$ 793.

Armstrong, J. A., and Hart, P. D., 1975, Phagosome - lysosome interactions in cultured macrophages infected with virulent tubercle bacilli. Reversal of the usual nonfusion pattern and observations on bacterial survival, The Journal of Experimental Medicine, v. 142, p. 1-16.

Basel, H. H., (1998), History of tuberculosis, Respiration, v. 65, p. 5 - 15.

Bauvois, B. and Dauzonne, D., 2005, Aminopeptidase - N/ CD13 (EC 3. 4. 11. 2) Inhibitors: Chemistry, biological evaluations and therapeutic prospects, Medicinal research reviews, v. 26, p. $88-130$.

Bedard, K., and Krause, K. H., 2007, The NOX family of ROS - generating NADPH oxidases: physiology and pathophysiology, Physiological reviews, v. 87, p. $245-313$.

Beckman, J. S., Beckman, T. W., Chen, J., Marshall, P. A., and Freeman, B. A., 1990, Apparent hydroxyl radical production by peroxynitrite: implications for endothelial injury from nitric oxide and superoxide, Proceedings of the National Academy of Sciences, v. 87, p. 1620 - 1624.

Berridge, M. V., Tan, A. S., Mc Coy, K. D., and Wang, R., 1996, The Biochemical and Cellular Basis of Cell Proliferation Assays That Use Tetrazolium Salts, Biochemica, v. 4, p 14 - 19. 
Brennan, P. J., 2003, Structure function and biogenesis of the cell wall of Mycobacterium tuberculosis, Tuberculosis, v. 83, p. $91-97$.

Brennan, P. J., and Young, D. B., 2008, Tuberculosis, Mc. Grawhill Publication.

Brock., R., Vamosi, G., Vereb, G., and Jovin, T. M., 1999, Rapid characterization of green flourscent protein fusion proteins on the molecular and cellular level by flourscence correlation microscopy, Proceedings of the National Academy of Sciences, v. 96, p. 10123 10128.

Burman, W. J., 2010, Rip Van Winkle wakes up: Development of Tuberculosis treatment in the $21^{\text {st }}$ century, Clinical infectious diseases, v. 50 , p. $S 165$ - S171.

Boshoff, H. I., Reed, M. B., Barry, C. E., and Mizrahi, V., 2003, DnaE2 polymerase contributesto in vivo survival and the emergence of drug resistance in Mycobacterium tuberculosis, Cell, v. 113, p. $183-193$.

Bryant, H. E., and Helleday, T., 2006, Inhibition of poly (ADP- ribose) polymerase activates ATM which is required for subsequent homologous recombination repair, Nucleic acids research, v. 34, p. 1685 - 1691.

Cardona, P. J., 2006, New insights on the nature of latent tuberculosis infection and its treatment, Inflammation and allergy - drug targets, v. 6, p. $27-39$.

Cavalli, V., Vilbois, F., Corti, M., Marcote, M. J., and Tamura, K. et al., 2001, The stress induced MAP kinase p38 regulates endocytic trafficking via the GDI : Rab5 complex, Molecular cell biology, v. 7, p. $421-432$.

Christophe, T., Jackson, M., Jeon, H. K., Fenistein, D., Contrerasdominguez, and M., et al., 2009, High content screening identifies decaprenyl - phosphoribose 2' epimerase as a target for intracellular antimycobacterial inhibitors, Public library of sciences, v. 5.

Collins, D. M., 2000, New tuberculosis vaccines based on attenuated strains of the Mycobacterium tuberculosis complex, Immunology and Cell Biology, v. 78, p 342-348.

Collins, L. A., Torrero, M. N., and Franzblau, S. G., 1998, Green flourscent protein reporter microplate assay for high - throughput screening of compounds against Mycobacterium tuberculosis, Antimicrobial agents and chemotherapy, v. 42 , p. $344-347$. 
Cosma, C. L., Sherman, D. R., and Ramakrishnan, L., 2003, The secret lives of the pathogenic mycobacterium, Annual reviews of Microbiology, v. 57 , p. $641-676$.

Daniel, T. M., 2006, The history of tuberculosis, Respiratory medicine, v. 100 , p. $1862-1870$.

Darwin, K. H., and Nathan, C. F., 2005, Role for nucleotide excision repair in virulence of Mycobacterium tuberculosis, Infection and immunity, v. 73, p. $4581-4587$.

Darwin, K. H., Ehrt, S., Gutierrez - Ramoz, J. C., Weich, N., and Nathan, C. F., 2003, The proteasome of $M$. tuberculosis is required for resistance to nitric oxide, Science, v. 302, p. $1963-1966$.

Das, D., Baker, M., Calider, L., 2006, Tuberculosis epidemiology in New Zealand: 1995 - 2004, Journal of the New Zealand Medical Association, v. 119.

Deghmane, A. E., Soalhine, H., Bach, H., and Sendide, K., et al. 2007, Lipoamide dehydrogenase mediates retention of coronin 1 on BCG vacuoles, leading to arrest in phagosome maturation, Journal of cell science, v. 120, p. $2796-2806$.

de Hostos, E. L., Bradtke, B., Lottspeich, F., Guggenheim, R., and Gerisch, G., 1991, Coronin an actin binding protein of dictyostelium discoideum localized to cell surface projection has sequence similarities to $G$ protein $\beta$ subunits, European molecular biology organization, v. 10, p. 4097 - 4104.

Deretic, V., Singh, S., Master, S., Harris, J., and Roberts, E., et al., 2006, Mycobacterium tuberculosis inhibition of phagolysosome biogenesis and autophagy as a host defence mechanism, Cellular microbiology, v. 8, p. $719-727$.

Dunn, M. F., Ramirez - Trujillo, J. A. and Hernandez - Lucas, I., 2009, Major roles of isocitrate lyase and malate synthase in bacterial and fungal pathogenesis, Microbiology, v. 155, p. $3166-3175$.

Eklund, D., Welin, A., Schon, T., and Lerm, M., 2010, Validation of a medium - throughput method for evaluation of intracellular growth of Mycobacterium tuberculosis, Clinical vaccine immunology, v. 10, p. 1-15.

Ernst, J. D., 1998, Macrophage receptors for Mycobacterium tuberculosis, Infection and immunity, p. 1277 - 1281. 
Feng, Z., and Barletta, P. G., 2003, Role of Mycobacterium smegmatis Dalanine: $D$-alanine ligase and $D$ - alanine racemase in the mechanism of action of resistance to the peptidoglycan inhibitor $D$ - cycloserine, Antimicrobial agents and chemotherapy, v. 47, p. $283-291$.

Ferrari, G., Naito, M., Langen, H., and Pieters, J., 1999, A coat protein on phagosom involved in the intracellular survival of mycobacteria, Cell, v. 97, p. $435-447$.

Flynn, J. L., and Chan, J., 2001, Tuberculosis: latency and reactivation, Infection and immunity, v. 69, p. $4105-4201$.

Fontan, P. A., Walters, S., and Smith, I., 2004, Cellular signaling pathways and transcriptional regulation in Mycobacterium tuberculosis: Stress control and virulence, Current science, v. 86, p. 122 - 134.

Fratti, R. A., Chua, J., and Deretic, V., 2003, Induction of p38 mitogen activated protein kinase reduces early endosome autoantigen 1 (EEA1) recruitment to phagosomal membranes, The Journal of Biological Chemistry, v. 278, p. $46961-46967$.

Fratti, R. A., Chua, J., Vergne, I., and Deretic, V., 2003, Mycobacterium tuberculosis glycosylated phosphatidylinositol causes phagosome maturation arrest, Proceedings of the national academy of sciences, v. 100 , p. $5437-5442$.

Freimoser, F. M., Jakob, C. A., Aebi, M. and Tuor, U., 1999, The MTT [ 3 (4, 5 - dimethylthiazol - 2-yl) - 2, 5- diphenyl tetrazolium bromide] assay is a fast and reliable method for colorimetric determination of fungal cell densities, Applied and environmental microbiology, v. 65, . 3727 - 3729.

Fuente, R. De La., Sonawane, ND., Arumainayagam, D., and Verkman, AS., 2006, Small molecules with antimicrobial activity against E. coli and P. aeruginosa identified by high - throughput screening, British journal of pharmacology, v. 149 , p. $551-559$.

Gordon, S., Keshav, S., and Stein, M., 1994, BCG - induced granuloma formation in murine tissues, Immunobiology, v. 191, p. $369-377$.

Hamid, R., Rotshteyn, Y., Rabadi, L., Parikh, R., and Bullock, P., (2004), Comparison of alamar blue and MTT assays for high through-put screening, Toxicology in Vitro, v. 18, p. $703-710$.

Janin, Y. L., 2007, Antituberculosis drugs: Ten years of research, Bioorganic and medicinal chemistry, v. 15, p. $2479-2513$. 
Kain, S. R., 1999, Green fluorescent protein (GFP): applications in cell based assays for drug discovery, Research focus review, v. 4, p. $304-$ 312.

Kasugai, S., Hasegawa, N., and Ogura, H., 1990, A simple in vitro cytotoxicity test using the MTT $(3-(4,5)$-dimehylthiazol $-2-y l)-2,5-$ diphenyl tetrazolium bromide) colorimetric assay: Analysis of eugenol toxicity ondental pulp cells (RPC - C2A), Japan journal of pharmacology, v. 52 , p. $95-100$.

Kaufmann, S. H., 2001, How can immunology contribute to the control of tuberculosis?, Nature review of immunology, v. 1, p. $20-30$.

Kotra, L. P., Haddad, J., and Mobashery, S., 2000, Aminoglycosides: Perspectives on mechanism of action, resistance and strategies to counter resistance, Antimicrobial agents and chemotherapy, v. 44, p. $3249-3256$.

Kremer, L., Baulard, A., Estaquler, J., Godefroy, O. P., and Locht, C., 1995, Green flourscent protein as a new expression marker in mycobacteria, Molecular microbiology, v. 17, p. 913 - 922.

Kuhn, D. M., Balkis, M., Chandra, J., and Ghannoum, M. A., 2003, Use and limitations of the XTT assay in studies of Candida growth and metabolism, Journal of clinical microbiology, v. 41, p. $506-508$.

Kurz, C. L., and Ewbank, J. J., 2007, Infection in a dish: high throughput analyses of bacterial pathogenesis, Current opinion of Microbiology, v. 10, p. $10-16$.

Khodaei, Z. M., Mokhtari, J., and Nouri, M., 2009, Novel anti-bacterial acid dyes derived from naphthalamide: synthesis, characterisation and evaluation of their technical properties on nylon-6, Society of dyes and colourists, Color technology, v. 126,p. 81-85

Lay G., Poquet Y., and Salek - Peyron P., 2007, Langhans giant cells from $M$. tuberculosis induced human granulamatous cannot mediate mycobacterial uptake, Journal of Pathology, v. 211, p. 76-85.

Li, X., Zhao, X., Fang, Y., Jiang, X., Duong, T., and Fan, C., et al., 1998, Generation of destabilized green fluorescent protein as a transcription reporter, The journal of biological chemistry, v. 273, p. 34970 - 34975.

Lim, E., Tisch, C., Williman, J., and Heffernan, H., 2009, Annual report 2008, Tuberculosis in New Zealand. 
Liu, K. J., (2009), Lipase - catalyzed synthesis and antibacterial activity of $\mathrm{N}$ - vanillylnonanamide, Journal of Molecular Catalysis B: Enzymatic, v. 58, p. $181-186$.

Liu, P. T., and Modlin, R. L., 2008, Human macrophage host defence against Mycobacterium tuberculosis, Current opinion in immunology, v. 20, p. $371-376$.

Liu, Y., and Nair, M. G., (2010), An efficient and economical MTT assay for determining the antioxidant activity of plant natural product extracts and pure compounds, Journal of Natural Products, v. 73, p. $1193-1195$.

Long, R., 2000, Canadian Tuberculosis Standards ( $5^{\text {th }}$ edition), Canadian Lung Association/ Canadian Thoracic Society and Centra of infectious disease prevention and control.

Maioli, E., Torricelli, C., Fortino, V., Carlucci, F., and Pacini, A., 2009, Critical appraisal of the MTT assay in the presence of Rottlerin and Uncouplers, Biological procedures online, v. 11, p. $227-239$.

Maira, F. C., and Darwin, K. H., 2009, The Mycobacterium tuberculosis proteasome: more than just a barrel - shaped protease, Microbes and infection, v. 11, p. $1150-1155$.

Malik, Z. A., Thompson, C. R., Hashimi, S., Porter, B., Iyer, S. S., and Kusner, D. J., 2003, Cutting edge: Mycobacterium tuberculosis blocks $\mathrm{Ca}^{+2}$ signalling and phagosome maturation in human macrophage via specific inhibition of sphingosine kinase, The Journal of Immunology, v. 170 , p. $2811-2815$.

Masip, L., Veeravalli, K., and Georgiou, G., 2006, The many faces of glutathione in bateria, Antioxidants and redox signaling, v. 8, p. $753-762$.

Miller, C. H., Nisa, S., Dempsey, S., Jack, C., and O' Toole, R., 2009, Modifying culture conditions in chemical library screening identifies alternative inhibitors of mycobacteria, Antimicrobial agents and chemotherapy, v. 53 , p. $5279-5283$.

Mitchison, D. A., 1979, Basic mechanism of chemotherapy, Chest, v. 76, p. $771-781$.

Morrison, C., Sonoda, E., Takao, N., and Shinohara, A. et al., 2000, The controlling role of ATM in homologous recombinationional repair of DNA damage, European Molecular biology organization, v. 19, p.463-471. 
Moy, T. I., Conery, A. L, Ford, J. L., Wu, G., and Mazitschek, R., (2009), High throughput screen for novel antimicrobials using a whole animal infection model, American chemical society, v. 4, p. 527 - 533.

Moy, T. I., Ball, A. R., Anklesaria, Z., Casadei, G., Lewis, K., and Ausubel, F. M. (2006), Identification of novel antimicrobials using a live animal infection model, Proceedings of the National Academy of Siences, v. 103, p. $10414-10419$.

Morlock, G. P., Metchock, B., Sikes, D., and Crawford, J. T., et al., 2003, ethA, inhA, and katG loci of ethionamide resistant clinical Mycobacterium tuberculosis isolates, Antimicrobial agents and chemotherapy, v. 47, p. $3799-3805$.

Nakayama, G. R., Caton, M. C., Nova, M. P., and Parandoosh, Z., (1997), Assessment of the alamar blue assay for cellular growth and viability in vitro, Journal of Immunological Methods, v. 204, p. $205-208$.

Nathan, C., and Shiloh, M. U., 2000, Reactive oxygen and nitrogen intermediates in the relationship between mammalian hosts and microbial pathogens, Proceedings of the national academy of sciences, v. 97, p. $8841-8848$.

Ngamwongsatit, P., Banada, P. P., Panbangred, W., and Bhuria, A. K., 2008, WST - 1 based cell cytotoxicity assay as a substitute for MTT based assay for rapid detection of toxigenic Bacillus species using $\mathrm{CHO}$ cell line, Journal of microbiological methods, v. 73, p. $211-215$.

Nguyen, L., and Pieters, J., The Trojan horse: survival tactics of pathogenic mycobacteria I macrophages, Trends in cell biology, v. 15, p. $269-276$.

Prabhudesai, P. P., and Singh, R. V. P., 2009, Multidrug resistant Tuberculosis, Bombay hospital journal, v. 51, p. $63-67$.

Promega (2009), Cell titer blue/ Cell viability assay. www.promega.com.

Pieters, J., 2008, Mycobacterium tuberculosis and the macrophage: Maintaining the balance, Cell host and microbe review, v. 3, p. $399-407$.

Ramaswamy, S. V., Reich, R., Don, S. J., and Jasperse, L., 2003, Single nucleotide polymorphism in genes associated with isoniazid resistance in Mycobacterium tuberculosis, Antimicrobial agents and chemotherapy, v. 47 , p. $1241-1250$. 
Roberts, E. A., Chua, J., Kyei, G. B., and Deretic, V., 2006, Higher order Rab programming in phagolysosome biogenesis, The journal of cell biology, v. 174, p. $923-929$.

Saunders, B. M., and Britton, W. J., 2007, "Life and death in the granuloma: Immunopathology of tuberculosis, Immunobiology and Cell biology, v. 85, p. $103-111$.

Scanga, C. A., Mohan, V. P., Joseph, H., Yu, K., Chan, J., and Flynn, J. L., (1999), Reactivation of latent tuberculosis: Variations on the Cornell Murine Model, Infection and Immunity, v. 67, p. 4531 - 4538.

Schluger, N. W., 2005, The pathogenesis of tuberculosis (the first one hundred (and twenty three) years, American journal of cell and molecular biology, v. 32, p. $251-256$.

Seyler, R. W., Olson, J. W., and Maier, R. J., 2001, Superoxide dismutase - deficient mutants of Helicobacter pylori are hypersensitive to oxidative stress and defective in host colonization, Infection and immunity, v. 69 , p. $4034-4040$.

Shiloh, M. U., Ruan, J., and Nathan, C., 1997, Evaluaion of bacterial survival and phagocyte function with a flourescence based microplate assay, Infection and immunity, v. 65, p. $3193-3198$.

Singh, B., and Mitchinson, D. A., 1995, Bactericidal activity of streptomycin and isoniazid in combination with $\mathrm{p}$-aminosalicylic acid against Mycobacterium tuberculosis, Journal of general microbiology, v. 12, p. $76-84$.

Smith, I., 2003, Mycobacterium tuberculosis pathogenesis and molecular determinants of virulence, Clinical microbiology reviews, v. 16, p. $463-$ 496.

Somoskovi, A., Parsons, L. M., and Salfinger, M., 2001, The molecular basis of resistance to isoniazid, rifampicin and pyrazinamide in Mycobacterium tuberculosis, Respiratory research, v. 2, p. $164-168$.

Spotts, C. R., Stanier, R. Y., 1961, Mechanism of streptomycin action on bacteria: a unique hypothesis, Nature, v. 192, p. $633-637$.

Sreevatsan, S., Stockbauer, K. E., Pan, X., Kreiswirth, B. N., and Moghazeh, S. L., et al., 1997, Ethambutol resistance in Mycobacterium tuberculosis: critical role of embB mutations, Antimicrobial agents and chemotherapy, v. 41 , p. $1677-1681$. 
Srivastava, V., Rouanet, C., Srivastava, R., Ramalingam, B., and Srivastava, S., 2007, Macrophage - specific Mycobacterium tuberculosis genes: identification by green fluorescent protein and kanamycin resistance selection, Microbiology, v. 153, p. $659-666$.

Talat, N., Perry, S., Personnet, J., Dawood, G., and Thusalis, R., 2010, Vitamin $\mathrm{D}$ deficiency and tuberculosis progression, Emerging infectious diseases, v. 10, p. $1-7$.

Takii, T., Yamamoto, Y., Chiba, T., Abe, C., and Belisle, J. T., 2002, Simple fibroblast - based assay for screening of new antimicrobial drugs against Mycobacterium tuberculosis, Antimicrobial agents and chemotherapy, v. 46, p. $2533-2539$.

Teresa, M., Lugo, G., and Bewley, C. A., 2008, Natural products, small molecules and genetics in TB drug development, Journal of medicinal chemistry, v. 51, p. $2606-2612$.

Tian, Z. Y., Xie, S. Q., Du, Y. W., Ma, Y. F. and Wang, C. J., 2009, Synthesis cytotoxicity and apoptosis of naphthalamide polyamine conjugates as antitumor agents, European journal of medicinal chemistry, v. 44 , p. $393-399$.

Tiwari, D., Singh, R. K., Goswami, K., and Verma, S. K., et al., 2009, Key residues in Mycobacterium tuberculosis protein kinase $G$ play a role in regulating kinase activity and survival in the host, Journal of biological chemistry, v. 284, p. $27467-27479$.

Tsuchiya, H., 2001, Biphasic membrane effects of capsaicin, an active component in Capsicum species, Journal of Ethnopharmacology, v. 75, p. $295-299$.

Tueberiberger, A. M., Lupas, A. N., Henry, L., Ecke, M., Simmeth, E., and Gerrisch, G., 2001, Calreticulin and calnexin in the endoplasmic reticulam are important for phagocytosis, The European molecular biology organization, v. 20, p. $6772-6782$.

Vergne, I., Chua, J., and Deretic, V., 2003, Tuberculosis toxin blocking phagosome maturation inhibits a novel $\mathrm{Ca}^{+2 /} /$ calmodulin - PI3K hVPS34 cascade, Journal of experimental medicine, v. 198, p. $653-659$.

Vergne, I., Chua, J., Singh, S. B., and Deretic, V., 2004, Cell biology of Mycobacterium tuberculosis phagosome, Annual review of cell developmental biology, v. 20, p. $367-394$. 
Vohra, R., Gupta, M., Chaturvedi, R., and Singh. Y., 2006, Attack on the scourage of tubeculosis: Patented drug targets, Recent patents on antiinfective drug discovery, v. 1, p. $95-106$.

Voss, M., Fechner, L., Walz, B., and Baumann, O., 2010, Calcineurin activity augments CAMP/ PKA - dependent activation of V - ATPase in blowfly salivary glands, American journal physiology - cell physiology, v. 298, p. $1047-1056$.

Waksman, S. A., Reilly, H. C., and Johnstone, D. B., 1946, Isolation of streptomycin - producing strain of Streptomyces griseus, v. 52, p. $393-$ 397.

Weissbach, H., Etienne, F., Hoshi, T., Heinemann, S. H., Lowther, W. T., and Matthews, B., et al., 2002, Peptide methionine sulphoxide reductase: structure, mechanism of action and biological function, Archives of biochemistry and biophysics, v. 397, p. $172-178$.

Wright, E. L.,Quenelle, D. C., Suling, W.J., and Barrow, W. W., 1996, Use of mono Mac 6 human monocytic cell line and J774 murine macrophage cell line in parallel antimycobacterial drug studies, American Society of Microbiology, v. 40, p. 2206-2208.

WHO, 2006, Actions for life towards a world free of tuberculosis, The global plan to stop TB 2006 - 2015, WHO/ HTM/ TB/ 2006. 35.

WHO, 2006, The stop TB strategy, World health organization, WHO/ HTM/ TB/ 2006. 368.

WHO, 2009, Global tuberculosis control - a short update to the 2009 report, WHO/ HTM/ TB/ 2009. 426.

WHO, 2010, Multidrug and extensively drug resistant TB (M/ XDR - TB): 2010 global report on surveillance and response, WHO/ HTM/ TB/ 2010. 3.

Williams, DL., Spring, L., Collins, L., Miller, L. P., and Heifets, L. B., et al., 1998, Contribution of rpoB mutations to development of rifamycin cross resistance in Mycobacterium tuberulosis, Antimicrobial agents and chemotherapy, v. 42, p. $1853-1857$.

Zhang, Y., Wade, M. M., Scorpio, A., and Zhag, H., 2003, Mode of action of pyrazinamide: disruption of Mycobacterium tuberculosis membrane transport and energitics by pyrazinoic acid, Journal of antimicrobial chemotherapy, v. 52, p. $790-795$. 
Zhang, Y., Post - Martens, K., and Denkin, S., 2006, New drug candidates and therapeutic targets for tuberculosis therapy, Gene to Science, v. 11, p. $21-27$.

Zhang, J. H., Chang, T. D., and Oldenburg, K. R., 1999, A simple statistical parameter for use in evaluation and validation of high throughput screening assays, Journal of biomolecular screening, v. 4 .

Zhang, Y., and Yew, W. W., 2009, Mechanisms of drug resistance in Mycobacterium tuberculosis, The International Journal of Tuberculosis and lung disease, v. 13, p. $1320-1330$. 